\title{
INFORMATION AND INDUSTRY DYNAMICS
}

\author{
by \\ Emin M. Dinlersoz * \\ U.S. Bureau of the Census \\ and \\ Mehmet Yorukoglu * \\ Central Bank of the Republic of Turkey
}

CES 10-16 August, 2010

The research program of the Center for Economic Studies (CES) produces a wide range of economic analyses to improve the statistical programs of the U.S. Census Bureau. Many of these analyses take the form of CES research papers. The papers have not undergone the review accorded Census Bureau publications and no endorsement should be inferred. Any opinions and conclusions expressed herein are those of the author(s) and do not necessarily represent the views of the U.S. Census Bureau. All results have been reviewed to ensure that no confidential information is disclosed. Republication in whole or part must be cleared with the authors.

To obtain information about the series, see www.ces.census.gov or contact Cheryl Grim, Editor, Discussion Papers, U.S. Census Bureau, Center for Economic Studies 2K130B, 4600 Silver Hill Road, Washington, DC 20233, CES.Papers.List@census.gov. 


\begin{abstract}
This paper develops a dynamic industry model in which firms compete to acquire customers over time by disseminating information about themselves under the presence of random shocks to their efficiency. The properties of the model's stationary equilibrium are related to empirical regularities on firm and industry dynamics. As an application of the model, the effects of a decline in the cost of information dissemination on firm and industry dynamics are explored.
\end{abstract}

JEL Classification: D80, L11, L16, M37

Keywords: Information, industry dynamics, entry and exit, firm growth

* Any opinions and conclusions expressed herein are those of the author(s) and do not necessarily represent the views of the U.S. Census Bureau. All results have been reviewed to ensure that no confidential information is disclosed. 


\section{Introduction}

A fundamental task for any firm is to build and maintain a customer base. Many firms invest in attracting and retaining consumers to survive and grow. Technologies used by firms to reach and inform consumers are therefore essential in firm growth and consumer reallocation among firms. Improvements in these technologies have reduced firms' costs of reaching beyond their local boundaries. Transmission of commercial information to wider markets started with the first true mass medium: power-driven printing combined with mass mailing by rail. ${ }^{1}$ Later, commercial use of radio, then television, and most recently the Internet, increased the reach, scope, and effectiveness of information dissemination. As a result, successful firms could compete with rivals in distant markets and overtake them. The emergence of major corporations and national chains in the U.S. during the 20th century can in part be attributed to the rapid decline in the cost of information dissemination. ${ }^{2}$ Similarly, the escalation of international trade and the rise of multi-national corporations owe much to declining cost of penetration into foreign consumer masses. ${ }^{3}$

Effects of technological progress in information dissemination pervade the economy. Little is known, however, about the specific effects on firm and industry dynamics. When information about firms spreads more quickly at lower cost, a firm's good fortune can lead to more rapid expansion, whereas an unfavorable development may result in a faster downsizing and exit. Growth of Internet-based firms like Amazon.com exemplifies how reaching larger consumer populations at low cost using a new medium can speed up firm growth and dynamics. Amazon.com's employment at five years from its inception was achieved only gradually over several decades by major firms founded earlier in the 20 th century. ${ }^{4}$ To generate its high growth rate, Amazon.com spent heavily to inform consumers and expand its customer base, even though this strategy led to large initial losses. ${ }^{5}$ Enduring losses to ensure growth

\footnotetext{
${ }^{1}$ See, e.g., Fang (1997) for more on the historical perspective.

${ }^{2}$ Chandler and Cortada (2000) and Cortada (2002) provide excellent accounts of how new information technologies have been transforming the U.S. economy.

${ }^{3}$ See Arkolakis (2009) for the role of market penetration costs in international trade.

${ }^{4}$ For instance, it took HP and Allstate about 25 years, IBM and Lowes nearly 20 years, and Walmart about 15 years to reach a comparable size. See Figure 1 in Luttmer (2008).

${ }^{5}$ See, e.g., Frey and Cook (2004).
} 
and future profitability through an emphasis on information dissemination was in fact a common practice in the early days of Internet-based commerce. Internet-based firms used public awareness campaigns, including print and television ads, to enlarge their customer base. While the experience of Internet-based firms is an extreme case, the improvements in information dissemination technologies have influenced many industries, and in some cases, transformed their structure. ${ }^{6}$

To assess the role of information dissemination by firms in shaping firm and industry dynamics, we develop a dynamic industry model where firms spread information about themselves to consumers. We consider a market for a homogeneous good with a large number of firms and consumers. Firm entry and exit are allowed, and firms must thrive among many rivals, in contrast to markets with a small number of firms and low turnover. Firms differ in their efficiency reflected in marginal costs, which change randomly over time. To survive and grow, a firm must build a customer base in the presence of this randomness. Consumer awareness and information are key in this growth process.

Information dissemination by firms is akin to informative advertising. The main purpose is to let consumers know the price and other firm attributes relevant for consumer decisionmaking. There is no effort by firms to persuade consumers or induce loyalty, although such efforts can be accommodated. ${ }^{7}$ Information dissemination includes all efforts by firms to inform consumers, not just well-organized advertising campaigns. An informal phone call, an e-mail, a catalog, or a coupon aimed at informing or updating a consumer may qualify as information dissemination. The advertising technology, common to all firms, determines how easily a firm can penetrate consumer population. A high cost of advertising implies limited reach to consumers, whereas a low cost leads to overlapping reach by firms and more intense competition.

Heterogeneity in firm efficiency highlights a critical issue in the provision of information: the effect of the information released into the market by more efficient firms on less efficient ones. This negative pecuniary externality is important for understanding how markets func-

\footnotetext{
${ }^{6}$ Sutton (1991) discusses the role of advertising in shaping the structure of several major industries.

${ }^{7}$ Empirically, informative advertising seems to be equally important as other types of advertising. See Bagwell (2005) for a recent discussion.
} 
tion under competitive information dissemination. Low advertising costs tend to favor more efficient firms which are able to offer lower prices, while high advertising costs can shield inefficient firms from competition. Advertising and changes in firm efficiency jointly result in a gradual, stochastic firm growth. A favorable efficiency draw allows a firm to expand, and a bad draw causes a firm to shrink, and even exit. The larger a firm, the higher its value and the worse the efficiency level it can withstand without exit. Accumulated customer base is therefore a valuable asset for a firm.

Consumers are passive information filters who do not engage in search. They can live for several periods, and like firms, make forward-looking decisions. Because consumers are longlived, how they store and discard information about firms needs to be specified. Since there is a large number of infinitesimal consumers and ads reach consumers randomly, a consumer who purchased from a firm does not necessarily have updated information from that firm in the future. Consequently, if a firm's past customers do not recall the firm, or have no updated information from the firm, there is no persistence in firm size. Some consumer memory or information update is therefore needed to link a firm's clientele over time. To introduce this link, we consider a specific but intuitive process as a baseline: a consumer recalls only the most recent firm he purchased from, and he is updated of that firm's current payoff-relevant information through means other than just random ads. The baseline process implies that a consumer values long-term relationship with a firm. A consumer obtains more surplus from visiting a firm with a lower likelihood of exit, because the consumer is more likely to have information about that firm in the future. Since larger firms are less likely to exit, firm size affects a consumer's decision to visit a firm. The role of firm size in a consumer's decision process arises without any explicit reputation or brand-name effects that may be related to size. We also consider alternatives to the baseline process and discuss their implications.

The mechanism of building a clientele through information dissemination is at work in varying degrees in many industries. The model's framework can represent markets where a large number of firms offer substitutable products and information about firms and prices is disseminated into various media. In such markets consumers are unlikely to be aware of all firms and prices, and basic price information is valuable, as consumers are interested in prices and terms of sale more so than other product attributes. Furthermore, consumers 
in the model value the option of repeated purchases from a firm. The environment of certain traditional and Internet-based retail industries, wholesalers, mail-order companies, long-distance phone service and certain subscription-based service providers, credit card providers, stock brokers, insurance providers, and some manufacturing industries may be approximated by the model's framework. ${ }^{8}$

The model's stationary equilibrium admits a number of properties relevant for firm and industry level evidence. A distinguishing feature is a two-dimensional price distribution. More efficient firms charge lower prices, but size also matters. Larger firms command higher prices as they are able to appropriate some of the extra surplus their size confers its customers. A firm's pricing behavior changes along the firm's life-cycle. Younger and smaller firms charge low prices to secure a customer base, similar to penetration pricing. As a firm grows, its pricing becomes less aggressive. Small firms need to be more efficient on average to be viable in the industry and they exhibit high positive growth rates, but firm growth rate declines eventually as a firm grows. Older firms tend to be larger because firm size is persistent and it takes time to accumulate a large customer base. Firm size and age are negatively associated with the likelihood of exit. Age alone, however, does not contain sufficient information to assess firm value and dynamics. Conditional on age, a firm's value and growth rate depend on size. On the other hand, once size is known, knowledge of age does not matter for firm value and growth. If there is persistence in random process driving efficiency, one still needs to know efficiency to assess firm dynamics, given size. ${ }^{9}$ The model can also generate a positively-skewed firm size distribution observed in empirical studies without assuming a fundamental skewness in the distribution of firm efficiency. ${ }^{10}$ We discuss the model's properties in view of existing empirical evidence, and provide some new evidence

\footnotetext{
${ }^{8}$ Lambin (1976) argues that "...Almost all advertising by wholesalers, retailers (department stores, supermarket chains, mail order firms), and industrial and financial firms (savings banks, insurance) is informative in a narrow sense because of the prominent place given to prices and terms of sales...".

${ }^{9}$ Jovanovic (1982) and Hopenhayn (1992) represent, respectively, the two classes of industry dynamics models: one in which firm dynamics are characterized by the knowledge of firm age, and the other by the knowledge of firm size. See also Cooley and Quadrini (2001) for a model where conditional dependence of firm dynamics on firm size and age emerges under financial frictions.

${ }^{10}$ See, among others, Cabral and Mata (2003) for the shape of firm size distribution.
} 
on less explored predictions of the model.

As an application of the model, we investigate how lower cost of reaching consumers influences firm and industry dynamics. There are two main effects of a decline in the cost of information dissemination. The direct effect is a higher incentive for firms to advertise. However, there is also an indirect effect. Lower information cost allows more efficient firms to release more information containing low prices. Inefficient firms' ads are then less likely to turn into sales, and their return from sending ads can diminish. A decline in information cost has implications on both the mean and standard deviation of firm growth rates. Lower information costs can speed up the growth of a firm with a low marginal cost and hasten the demise of a firm with a high marginal cost, amplifying inherent firm volatility. Numerical analysis of the model demonstrates that lower information cost can lead to higher industry concentration, higher entry and exit rates, faster firm growth, higher volatility in firm size and value, and an increase in the relative importance of firm efficiency versus firm size in determining firm value. We present evidence on these effects for certain retail and service industries which experienced significant diffusion of Internet-based information dissemination and commerce.

This paper integrates two main strands of literature. Informative advertising has been analyzed in a static framework for identical firms, notably by Butters (1977) and Stegeman (1991). We add firm heterogeneity, as well as firm and consumer dynamics, to these models. The dynamic setup is related to models of industry dynamics, including Jovanovic (1982), Hopenhayn (1992), Ericson and Pakes (1995), and Fishman and Rob (2002). We introduce informative advertising to this class of models. In Hopenhayn (1992), firm dynamics and size are determined solely by an exogenous productivity process. Here, in addition to efficiency, the accumulated customer base of a firm influences the firm's survival and growth. However, persistent efficiency is not required to generate persistent firm size. Fishman and Rob (2002) consider industry dynamics with consumer search costs. While search and advertising both generate mechanisms of allocating consumers to firms, their implications on pricing and firm dynamics can differ. ${ }^{11}$ In a related paper, Asplund and Nocke (2006) an-

\footnotetext{
${ }^{11}$ For instance, in Fishman and Rob (2002) search costs lead to no price dispersion in equilibrium due to the Diamond Paradox. Consumers never switch firms after their initial purchase. Furthermore, new
} 
alyze the role of market size in the dynamics of imperfectly competitive industries. This paper investigates instead the role of firms' market reach, given market size. Doraszelski and Markovich (2007) study dynamics generated by informative and goodwill advertising in the context of a duopoly, whereas the focus here is on an industry with many firms and firm turnover. The model also has connection to models of firm dynamics with consumer switching costs, e.g. Klemperer and Beggs (1992) and Farrell and Shapiro (1988). While there is no explicit switching cost, the fact that a consumer can default to his most-recentlyvisited firm introduces some inertia. As consumers receive information and make purchases, they become heterogeneous with respect to their reservation surplus - the surplus provided by the most-recently visited firm. Customers of larger and more efficient firms have higher reservation surplus and are less likely to switch.

The rest of the paper is organized as follows. Section 2 introduces the model. Section 3 describes the stationary equilibrium. Section 4 discusses properties of the stationary equilibrium and compares them with empirical evidence. Section 5 studies some effects of improvements in information dissemination technology and presents evidence on these effects. Section 6 concludes. Proofs are collected in Appendix A.

\section{The model}

Consider an economy with a large number of firms offering a homogenous good to a large number of consumers. The population of firms and consumers are each represented by a continuum. A firm is by construction small with respect to the rest of the industry. It has no influence on industry aggregates by itself and takes them as given. Time is discrete, denoted by $t \geq 1$. Figure 1 gives the timing of events and decisions within a period. At the beginning of each period, a potential entrant decides whether to enter before learning its marginal cost during its first period in the industry. Incumbents then decide whether to stay or irreversibly exit after observing their marginal cost for the current period. ${ }^{12}$ In

consumers entering the market are allocated equally among existing firms - a process that does not assign an active role to firm-specific factors in luring new consumers.

${ }^{12}$ Alternatively, one can assume, without altering the results, that an incumbent decides whether to exit before learning its marginal cost. 
the meantime, some consumers exit the market, while new ones enter. ${ }^{13}$ Firms then send ads to consumers, who make their purchase decisions. Firms and consumers have the same discount rate $\beta \in(0,1)$.

Incumbent Firms: Learn the cost

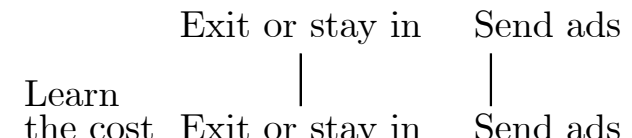

Potential Entrants: Enter or stay out the cost Exit or stay in Send ads

Old Consumers:

New Consumers:

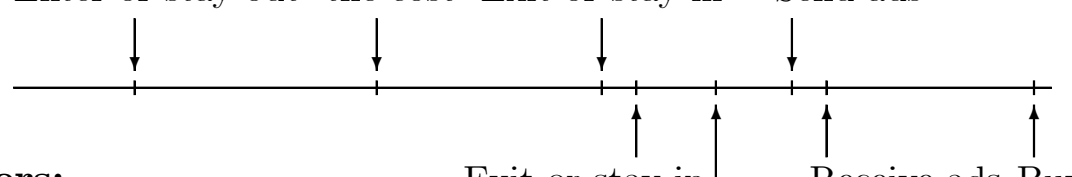

Exit or stay in Receive ads Buy or refuse Enter Receive ads Buy or refuse

Figure 1: The timing of events and decisions within a period

\subsection{Consumers}

There is a unit mass of ex-ante identical consumers who demand the good every period. Each period a fraction $\lambda \in(0,1)$ of the consumers is replaced by new ones, implying an expected consumer life of $1 / \lambda$ periods. In any period, a consumer can purchase either zero or one unit of the good, resulting in a net surplus of

$$
U(p)=\left\{\begin{array}{lc}
s-p, & \text { if the consumer buys at price } p \\
0, & \text { otherwise }
\end{array}\right.
$$

where $s>0$ is the gross consumer surplus for a period. A consumer is assumed to purchase when indifferent.

\footnotetext{
${ }^{13}$ Such exogenous turnover could occur, for example, if consumers enter and exit a market because of birth and death, or due to emergence of alternative products in other markets.
} 


\subsubsection{Consumer information and memory}

Consumers receive ads randomly and independently. Within a period, no consumer receives more than one ad from a firm, each ad is received by some consumer, and each consumer is equally likely to receive an ad. These assumptions are compatible with the fact that there is a very large number of small consumers. Denote by $\Psi_{t}(i)$ the probability that a consumer receives $i \geq 0$ integer ads in period $t$.

Let $I_{t}$ be the information flow to a consumer during period $t . I_{t}$ contains information for the firms from which the consumer received an ad in period $t$, and for those firms visited in the past that provide the consumer with period $t$ information about themselves. $I_{t}$ is either empty $(\varnothing)$, implying no new information, or consists of $K$ integer elements. Each element is a vector of variables that describe the corresponding firm's attributes that help a consumer identify a firm and evaluate the surplus from patronizing it.

Because consumers can survive multiple periods, how a consumer stores and discards past information needs to be specified. If consumers do not recall any firms visited in the past and have no current-period information from those firms, there is no persistence in firm size. This result follows because the probability that a consumer receives an ad from the same firm in any two consecutive periods is zero, as a firm's customers has measure zero with respect to the total mass of consumers.

There are several ways to specify consumer memory. At one extreme, a consumer recalls all past information (total recall). At the other extreme, a consumer forgets the past (no recall). Let $\mathbf{M}_{t}$ be a consumer's memory. No recall corresponds to $\mathbf{M}_{t}=\varnothing$, and total recall to $\mathbf{M}_{t}^{\bar{\tau}}=\bigcup_{j=t-\bar{\tau}}^{t-1} I_{j}$, where $\bar{\tau} \geq 1$ is consumer age. Any arbitrary memory process can be represented as a subset of $\mathbf{M}_{t}^{\bar{\tau}}$. For instance, one can define a $\tau$-period memory, $\mathbf{M}_{t}^{\tau}=\bigcup_{j=t-\tau}^{t-1} I_{j}$, as one that contains all the past information flow from period $t-\tau$ upto period $t-1$, where $\tau \in\{1, \ldots, \bar{\tau}\}$. Another example is a memory that contains only the firms from which a purchase was made, or the largest of such firms. A consumer's cumulative information in period $t, \mathbf{I}_{t}$, is the collection of his memory and current information flow, i.e. $\mathbf{I}_{t}=\mathbf{M}_{t} \cup I_{t}$ for $\tau \in\{0,1, \ldots, \bar{\tau}\}$. A consumer makes his purchase decision based on $\mathbf{I}_{t}$.

Our baseline assumption about consumer information is a specific, but intuitive one: 
consumers do not recall any past ads or firms, except that if a consumer purchased from a firm in the previous period and that firm did not exit, the consumer possesses the current period payoff-relevant information about that firm. The baseline corresponds to a no recall memory $\left(\mathbf{M}_{t}=\varnothing\right)$ and to an information flow $I_{t}$ that contains the information in the new ads received plus the period- $t$ information about the most-recently-visited firm (if any). The baseline cumulative information process is therefore $\mathbf{I}_{t}=\varnothing \cup I_{t}=I_{t}$.

To motivate the baseline, one might argue that a consumer becomes more familiar with the firm he purchased from in the previous period, compared to the firms he received an ad from, but chose not to visit. The most-recently-visited firm is also likely the freshest firm in consumer memory. The consumer may receive the current payoff-relevant information about this firm through means other than just random ads. Lists of previous customers are frequently used by firms to update their former customers directly. Current catalogs or coupons may be sent directly to previous customers' addresses. The cost of advertising defined below can include the cost of sending such updates to consumers who purchased from the firm in the previous period. The assumed information structure generates some persistence in a firm's customer base. We discuss alternative information structures in Section 4.6.

Next, consider the contents of $I_{t}$. As in the static models of informative advertising, a firm's current price matters for consumer surplus and is a part of each element in $I_{t}$. In a dynamic environment where consumers can purchase from a firm for consecutive periods, other firm attributes that matter for firm survival are also pay-off relevant. Assumptions on consumer memory and information imply that the firm visited by a consumer in period $t$ will be in $I_{t+1}$, unless that firm exits. Consumers therefore attach value on firm attributes that matter for survival, such as size. To simplify, we assume that a firm's size is revealed in an ad. In practice, a firm may include proxies for its size in an ad. ${ }^{14}$ Firm size may also become common knowledge over time, especially for firms that grow beyond a certain size. We assume that a consumer does not know a firm's efficiency.

\footnotetext{
${ }^{14}$ Because firm size is positively associated with firm age in equilibrium, firm age can proxy for firm size.
} 


\subsubsection{A consumer's dynamic problem}

If $\mathbf{I}_{t}=\varnothing$, the consumer does not purchase in period $t$. Otherwise, the consumer purchases from the firm in $I_{t}$ that provides the highest net surplus. Because a consumer can purchase from the most-recently-visited firm, consumers are heterogeneous with respect to their reservation values, which change over time randomly as new information is received. Let $W_{t}\left(p, m^{o}\right)$ be the discounted expected surplus from a firm that charges price $p$ during period $t$ and that had $m^{o} \geq 0$ customers at the end of the period $t-1$. We refer to $m^{o}$ as the "size" of the firm at the beginning of period $t .{ }^{15}$ Let $X_{t}\left(p, m^{o}\right)$ be the probability exit at the beginning of period $t$. Also, let $W_{t}^{\varnothing}$ be the discounted expected surplus of a consumer with $\mathbf{I}_{t}=\varnothing$. Note that $W_{t}\left(p, m^{o}\right) \geq W_{t}^{\varnothing}>0$, i.e. being informed of some firm brings at least as much surplus as having no information. We can write

$$
\begin{aligned}
W_{t}\left(p, m^{o}\right)= & U(p) \\
& +\beta(1-\lambda)\left\{\Psi_{t+1}(0)\left[\left(1-X_{t+1}\left(p, m^{o}\right)\right) E\left[W_{t+1}\left(p^{\prime}, m^{\prime}\right)\right]+X_{t+1}\left(p, m^{o}\right) W_{t+1}^{\varnothing}\right]\right. \\
& +\sum_{i=1}^{\infty} \Psi_{t+1}(i)\left[\left(1-X_{t+1}\left(p, m^{o}\right)\right) E\left[\int \max \left\{W, W_{t+1}\left(p^{\prime}, m^{\prime}\right)\right\} d G_{t+1}^{i}(W)\right]\right. \\
& \left.\left.+X_{t+1}\left(p, m^{o}\right) \int W d G_{t+1}^{i}(W)\right]\right\} .
\end{aligned}
$$

In (1), $G_{t}^{i}$ is the period- $t$ c.d.f. of the first-order statistic of net consumer surplus among $i>0$ ads received by the consumer. Because ads from different firms arrive independently, one can write $G_{t}^{i}(W)=\left[G_{t}(W)\right]^{i}$, where $G_{t}(W)$ is the probability that an ad is from a firm that offers a surplus of at most $W$. The expectations in (1) are taken with respect to all feasible next period pairs $\left(p^{\prime}, m^{\prime}\right)$ for the firm conditional on survival in period $t+1$.

The first term on the right hand side of (1) is the current net surplus. The second term is the expected discounted future surplus if no ad is received. The second term has two components: the future surplus if the consumer's current firm stays in the market, and the future surplus if that firm exits, leaving the consumer with a surplus of

$$
W_{t+1}^{\varnothing}=\beta(1-\lambda)\left\{\Psi_{t+2}(0) W_{t+2}^{\varnothing}+\sum_{i=1}^{\infty} \Psi_{t+2}(i) \int W d G_{t+2}^{i}(W)\right\} .
$$

\footnotetext{
${ }^{15}$ Sales, which is a strictly increasing function of the number of customers in equilibrium, can also be used to measure size.
} 
In this case, the utility in the period $t+1$ is zero, and the following period's surplus depends on the number of ads received. If no ad is received, the surplus is $W_{t+2}^{\varnothing}$, otherwise the consumer chooses the firm that yields the highest surplus. The third and fourth terms in (1) together give the expected future surplus from receiving one or more ads. The third term applies when the consumer's current firm stays in the market. In this case, $\mathbf{I}_{t+1}$ has $i+1$ elements corresponding to $i$ new ads and the new information about the most recently visited firm. The consumer chooses the firm that offers the highest surplus. Similarly, the fourth term represents the case where the current firm exits and the consumer has $i$ new ads. A consumer chooses the firm in $\mathbf{I}_{t}$ that yields the highest expected surplus

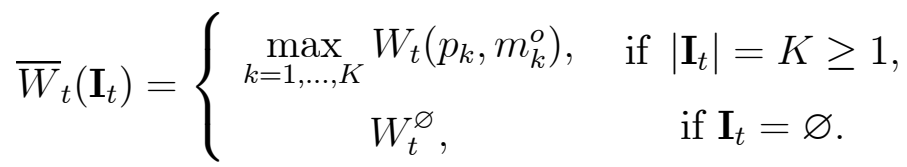

It is important to emphasize that firm size matters for consumer surplus only through exit probability, which affects a consumer's continuation surplus in (1). Firm size confers no other advantage to a consumer, unlike in cases where firm size is associated with brand-name or prestige effects, which may directly enhance utility.

Consider now the probability that a consumer purchases from firm $\left(p, m^{o}\right)$, conditional on having information about the firm. This probability is also the demand the firm faces from a consumer informed of the firm. Each such consumer can be of two types: one who patronized the firm in the previous period, and the other who did not. Let the demand functions for these two types of consumers be $z_{t}\left(p, m^{o}\right)$ and $\omega_{t}\left(p, m^{o}\right)$, respectively. Because the latter type may have purchased from a firm that provides higher surplus than firm $\left(p, m^{o}\right)$, $z_{t}\left(p, m^{o}\right)$ weakly exceeds $\omega_{t}\left(p, m^{o}\right)$. In other words, firm $\left(p, m^{o}\right)$ faces more demand from a previous-period customer than a consumer it reaches through current period advertising.

Lemma $1 z_{t}\left(p, m^{o}\right) \geq \omega_{t}\left(p, m^{o}\right)$. Furthermore, price-elasticities satisfy $\varepsilon_{w_{t}}\left(p, m^{o}\right) \geq \varepsilon_{z_{t}}\left(p, m^{o}\right)$.

The function $z_{t}\left(p, m^{o}\right)$ can be more explicitly written as

$$
z_{t}\left(p, m^{o}\right)=\sum_{i=0}^{\infty} \Psi_{t}(i) G_{t}^{i}\left(W_{t}\left(p, m^{o}\right)\right)
$$


where the $i$ th term is the probability of sale to a consumer who has received $i$ ads from firms other than firm $\left(p, m^{o}\right)$. Furthermore, using the proof of Lemma 1,

$$
\omega_{t}\left(p, m^{o}\right)=\left[\theta_{t}+\left(1-\theta_{t}\right) \alpha_{t}\left(p, m^{o}\right)\right] z_{t}\left(p, m^{o}\right) .
$$

where $\theta_{t}$ is the measure of consumers with no information from any other firms, and $\alpha_{t}\left(p, m^{o}\right)$ is the probability that the firm a consumer purchased from in period $t-1$ provides more surplus than firm $\left(p, m^{o}\right)$. Lemma 1 suggests that a price-discriminating firm would like to charge higher prices to its previous-period customers compared to the new ones. However, we assume that firms cannot engage in such discrimination. As shown below, this assumption implies that a firm's price reflects the composition of its existing and new customers.

\section{$2.2 \quad$ Firms}

Firms pay a one-time sunk cost of $\kappa>0$ upon entry. A firm's marginal cost, $c$, is a realization of a continuous random variable with a c.d.f. $H(c)$ and a differentiable density $h(c)$ over $[\underline{c}, \infty)$ with $s>\underline{c}>0$, such that $H(c)<1$ for all $c \in[\underline{c}, \infty)$ and $\lim _{c \rightarrow \infty} H(c)=1$. Marginal costs are generated from $H$ independently (over time) and identically. ${ }^{16}$ An i.i.d. distribution isolates the role of advertising in generating persistence in firm size. If marginal cost exhibits persistence, then both the marginal cost persistence and the advertising effort lead to persistence in firm size. Because $H(c)<1$ for all $c \in[\underline{c}, \infty)$, there is a positive probability that a firm's marginal cost is larger than the highest sustainable marginal cost without exit. As a result, there is always some exit, consistent with continuing exit even in mature industries. An incumbent firm incurs a fixed cost of $f>0$ per period, which can be avoided only if the firm exits. Since all firms have the same fixed cost, a firm with a lower marginal cost than another is "more efficient".

\footnotetext{
${ }^{16}$ We assume that the realized frequency distribution of marginal cost in a period coincides with the actual distribution $H$. Certain conditions are needed for the applicability of this law of large numbers with a continuum of agents (see, e.g., Judd (1985), Feldman and Gilles (1985)). Following Feldman and Gilles (1985, p. 28), one solution is to assume that firms that are closely located in the marginal cost space have correlated cost shocks within a period.
} 


\subsubsection{Information technology}

Firms disseminate information using a common advertising technology, $\Phi .{ }^{17} \Phi(a)$ is the total cost of sending $a \in[0, \infty)$ ads.

Assumption 1 (i) $\Phi$ is twice differentiable and $\Phi^{\prime}>0$ and $\Phi^{\prime \prime}>0$ on $(0, \infty),(i i) \Phi(0)=0$, and $($ iii $) \lim _{a \rightarrow 0} \Phi^{\prime}(a)=0$.

Assumption 1(i) captures the basic empirical regularity of diminishing returns to advertising, as documented in Sutton (1991). From an individual firm's perspective, there is a very large pool of consumers and each ad reaches a distinct consumer. If the advertising technology exhibits constant or increasing returns to scale, some firms can reach an arbitrarily large number of consumers and grow without bound. Convexity in advertising cost prevents such an outcome. As Grossman and Shapiro (1984) point out, increasing marginal cost of advertising can stem from media saturation, overlapping media, or the existence of different predispositions to view ads in the consumer population. As the amount of ads sent increases, it becomes increasingly costly for the firm to find an additional consumer who has not yet received an ad. In other words, deeper penetration to consumer population requires increasingly higher marginal cost of marketing.

Assumptions 1(ii) and 1(iii) are made for simplicity and ensure that all surviving firms advertise, preventing the possibility that a firm coasts for a while without advertising. ${ }^{18}$ Any unavoidable fixed cost of advertising can be included in the fixed cost, $f$. A positive fixed cost of advertising or a positive marginal cost around zero can lead to no advertising for some firms in a period. ${ }^{19}$

\footnotetext{
${ }^{17}$ Differences in the advertising technology across firms can also be introduced.

${ }^{18}$ Some empirical evidence points to 'pulse' advertising strategies in certain cases, i.e. a firm advertises and then coasts for some time without advertising (see Dube, Hitsch, and Manchanda (2005)). Such behavior can emerge in the model when there is a fixed cost of advertising or when the marginal cost of advertising is steep around zero. In that case, firms do not to advertise in periods when they get sufficiently bad cost shocks and wait until they have a better shock to resume advertising.

${ }^{19}$ One class of advertising technologies which satisfy Assumption 1 is $\Phi(a)=\chi a^{\varphi}, \varphi>1, \chi>0$. One class which violates Assumption 1(iii), but satisfies Assumptions 1(i)-(ii), is $\Phi(a)=\chi\left(e^{\varphi a}-1\right), \varphi, \chi>0$.
} 


\subsubsection{A firm's dynamic problem}

The period profit of a firm with size $m^{o}$ and marginal cost $c$, when it charges price $p$ and sends $a$ ads, is

$$
\Pi_{t}\left(p, a ; m^{o}, c\right)=m_{t}\left(p, a ; m^{o}\right)(p-c)-\Phi(a)-f
$$

where $m_{t}$ is the firm's residual demand, or the end-of-period number of customers given by

$$
m_{t}\left(p, a ; m^{o}\right)=m^{o}(1-\lambda) z_{t}\left(p, m^{o}\right)+a \omega_{t}\left(p, m^{o}\right) .
$$

It can be verified that $\Pi_{t}$ is strictly increasing in $m_{t}$, strictly concave in $a$, and strictly decreasing in $c$ and $f$. The law of motion (7) can also be viewed as capital accumulation subject to stochastic depreciation and investment. In this interpretation, $m^{o}$ is the firm's capital stock at the beginning of period $t$. During period $t$, a fraction $\lambda+(1-\lambda)\left(1-z_{t}\left(p, m^{o}\right)\right)$ of this stock depreciates, where $\lambda$ is the industry-wide depreciation rate common to all firms and $\left(1-z_{t}\left(p, m^{o}\right)\right)$ is the firm-specific depreciation rate. A fraction $\omega_{t}\left(p, m^{o}\right)$ of investment $a$ turns into new capital, where $\omega_{t}\left(p, m^{o}\right)$ is the firm-specific investment success rate. The total cost of investment is $\Phi(a)$.

Let the pair $\left(m^{o}, c\right)$ be a firm's type. A type $\left(m^{o}, c\right)$ firm has the value

$$
V_{t}\left(m^{o}, c\right)=\max \left\{0, \max _{p, a}\left[\Pi_{t}\left(p, a ; m^{o}, c\right)+\beta \int V_{t+1}\left(m_{t}, c^{\prime}\right) h\left(c^{\prime}\right) d c^{\prime}\right]\right\} .
$$

The first term inside the curly brackets is the value of exit normalized to zero, and the second term is the maximized sum of the current and expected discounted future profit. A firm is assumed to stay when indifferent.

Entry is unrestricted. Each period a mass of $M_{t} \geq 0$ of new firms enter the industry. An entrant starts off with zero customers. Free entry implies

$$
\int_{\underline{c}}^{\infty} V_{t}(0, c) h(c) d c \leq \kappa,
$$

which holds with equality when $M_{t}>0$.

The state of the industry in period $t$ can be described by a measure $\mu_{t}$ over the set of firm types $\left(m^{o}, c\right)$. For any Borel set $S \subset \mathbb{R}^{+} \times[\underline{c}, \infty), \mu_{t}(S)$ gives the mass of firms with 
types in $S$. Given an initial measure of firms $\mu_{o}, \mu_{t}$ results from entry, exit and changes in incumbents' sizes and efficiencies up to time $t$.

A consumer's demand function can now be related to the measure of firms. Let $B_{t}\left(p, m^{o}\right)$ denote the set of firm types that provide a consumer a surplus of at most $W_{t}\left(p, m^{o}\right)$. The probability that an ad comes from some firm with type in $B_{t}\left(p, m^{o}\right)$ is

$$
Q_{t}\left(p, m^{o} ; \mu_{t}\right)=\frac{1}{A_{t}}\left(\int_{B_{t}\left(p, m^{o}\right)} a_{t}(m, c) d \mu_{t}(m, c)\right),
$$

where $a_{t}(m, c)$ is the number of ads sent by a type $(m, c)$ firm, and $A_{t}=\int_{(m, c)} a_{t}(m, c) d \mu_{t}(m, c)$ is the total number of ads in the economy. By noting that $Q_{t}\left(p, m^{o} ; \mu_{t}\right) \equiv G_{t}\left(W_{t}\left(p, m^{o} ; \mu_{t}\right)\right)$, the individual demand function in (4) can be expressed in terms of the measure of firms $\mu_{t}$ as $z_{t}\left(p, m^{o} ; \mu_{t}\right)=\sum_{i=0}^{\infty} \Psi_{t}(i) Q_{t}^{i}\left(p, m^{o} ; \mu_{t}\right)$. Similarly, $\omega_{t}\left(p, m^{o}\right)$ can also be related to $\mu_{t}$ using (5).

\section{Stationary equilibrium}

Let $(*)$ identify variables and functions in equilibrium.

Definition 1 (Stationary equilibrium) A stationary equilibrium consists of pricing and advertising policies $p^{*}\left(m^{o}, c\right)$ and $a^{*}\left(m^{o}, c\right)$, a cumulative distribution of consumer surplus across ads $G^{*}(W)$, a measure $\mu^{*}$ over firm types, an entry mass $M^{*} \geq 0$, and an exit rule $x^{*}(c) \geq 0$, such that, in any given period of time,

(i) Firms maximize their profits by adopting policies $p^{*}\left(m^{o}, c\right)$ and $a^{*}\left(m^{o}, c\right)$,

(ii) Consumers maximize their surplus,

(iii) Firms types $\left(m^{o}, c\right)$ with $m^{o}<x^{*}(c)$ exit,

(iv) $M^{*}$ satisfies the free entry condition (9),

(v) $G^{*}$ is consistent with pricing and advertising policies,

(vi) $\mu^{*}$ is consistent with conditions (i) through $(v){ }^{20}$

\footnotetext{
${ }^{20}$ In other words, starting with the measure $\mu^{*}$ at the beginning of a period, firms' pricing and advertising policies, consumers' purchase decisions, entry, exit and changes in surviving firms' types together result in the same measure $\mu^{*}$ at the end of the period.
} 
In the case of free advertising, i.e. $\Phi(a)=0$ for $a \geq 0$, every consumer has information about all firms. If there is a positive measure of firms, price competition implies that firms offering the highest surplus charge a price that leaves them with zero profit gross of the fixed cost, while all other firms make no sales. A firm's value gross of fixed cost is therefore zero. This polar case is ruled out by Assumption 1. The rest of the analysis focuses on equilibria with non-zero advertising cost where a positive mass of firms in the industry compete with each other. ${ }^{21}$

Assuming for now that a stationary equilibrium with positive advertising, entry, and exit exists, we characterize the equilibrium. Let $z^{*}\left(p, m^{o}\right)$ and $\omega^{*}\left(p, m^{o}\right)$ be the individual demand functions in equilibrium, and $\widetilde{z}^{*}\left(m^{o}, c\right)$ and $\widetilde{\omega}^{*}\left(m^{o}, c\right)$ be the demand functions evaluated at the optimal price. The evolution rule for a firm's customer base is given by

$$
m^{*}\left(m^{o}, c\right)=m^{o}(1-\lambda) \widetilde{z}^{*}\left(m^{o}, c\right)+a^{*}\left(m^{o}, c\right) \widetilde{\omega}^{*}\left(m^{o}, c\right) .
$$

A firm's value $V^{*}\left(m^{o}, c\right)$ is

$$
V^{*}\left(m^{o}, c\right)=\max \left\{0, \Pi^{*}\left(m^{o}, c\right)+\beta \int V^{*}\left(m^{*}, c^{\prime}\right) h\left(c^{\prime}\right) d c^{\prime}\right\} .
$$

Following the theory of stochastic dynamic programming in Stokey and Lucas (1993), it can be shown that there exists a unique continuous and bounded function $V^{*}\left(m^{o}, c\right)$ that satisfies (12).

Let $W^{*}\left(p, m^{o}\right)$ be the surplus from visiting firm $\left(m^{o}, c\right)$, and let $W^{\varnothing *}$ be the surplus of an uninformed consumer. $W^{*}$ and $W^{\varnothing *}$ are the fixed-points of equations (1) and (2), respectively. Once again, the dynamic programming techniques in Stokey and Lucas (1993) ensure the existence and uniqueness of continuous and bounded functions $W^{*}$ and $W^{\varnothing *}$. There exists then a unique bounded function $\bar{W}^{*}(\mathbf{I})$ that gives the maximum surplus associated with any cumulative information, I. The individual demand function, firm value, and consumer surplus satisfy the following properties.

\footnotetext{
${ }^{21}$ In the other polar case of very high advertising costs, no firm advertises. Given other parameters of the model one can find an advertising cost such that $\lim _{a \rightarrow 0} \Phi^{\prime}(a)>M$ for any $M>0$. Thus, the marginal cost of advertising around zero can be made high enough to exceed the marginal benefit from advertising even for the most efficient firm type.
} 
Proposition 1 (i) $z^{*}\left(p, m^{o}\right)$ and $\omega^{*}\left(p, m^{o}\right)$ are strictly decreasing in $p$, (ii) $z^{*}\left(p, m^{o}\right)$ and $\omega^{*}\left(p, m^{o}\right)$ are strictly increasing in $m^{o}$, and (iii) $V^{*}\left(m^{o}, c\right)$ is strictly decreasing in $c$, and strictly increasing in $m^{o}$, and (iv) $W^{*}\left(p, m^{o}\right)$ is strictly decreasing in $p$, and strictly increasing in $m^{o}$.

Proposition 1(iii) implies exit probability strictly increases as the marginal cost increases, and the minimum size, $x^{*}(c)$, a firm with marginal cost $c$ can sustain without exit is a strictly increasing function of $c$. A firm exits the industry the first time its beginning-of-period size, $m^{o}$, is below $x^{*}(c) .^{22}$

Consider next the pricing and advertising policies. Because the equilibrium price distribution across ads is atomless by Proposition 1, the demand functions $z^{*}\left(p, m^{o}\right)$ and $\omega^{*}\left(p, m^{o}\right)$, and hence period profit and firm value, are all continuous in $p$. Given the price distribution, the firm type that provides the lowest surplus to a consumer makes a sale when it is the only firm a consumer is informed of. Hence, that firm type must charge its monopoly price to consumers. ${ }^{23}$ For all other firms, the optimal price, $p^{*}\left(m^{o}, c\right)$, is an interior solution that satisfies the first order condition (see also Proposition 2$)^{24}$

$$
m^{*}\left(p, a ; m^{o}\right)+\frac{\partial m^{*}\left(p, a ; m^{o}\right)}{\partial p}\left[(p-c)+\beta \frac{\partial}{\partial m^{*}} \int V^{*}\left(m^{*}, c^{\prime}\right) h\left(c^{\prime}\right) d c^{\prime}\right]=0 .
$$

A firm chooses its price considering the dynamic effect of this choice. This effect is represented by the second term inside the brackets in (13), which is the change in the firm's continuation value due to a small change in its customer base $m^{*}$ at the beginning of the next period. The relative markup can be defined as

$$
\frac{p^{*}-c+R^{*}}{p^{*}}=\frac{1}{\varepsilon^{*}\left(p^{*}, m^{o}\right)},
$$

where $R^{*}$ is the contribution to the firm's continuation value from marginal customer (represented by the second term in brackets in (13)), and $\varepsilon^{*}$ is the weighted average of the elasticities of demand by the firm's previous-period customers and the new consumers

$$
\varepsilon^{*}\left(p^{*}, m^{o}\right)=\frac{m^{o}(1-\lambda) z^{*}\left(p^{*}, m^{o}\right)}{m^{*}\left(p^{*}, a ; m^{o}\right)} \varepsilon_{z^{*}}\left(p^{*}, m^{o}\right)+\frac{a \omega^{*}\left(p^{*}, m^{o}\right)}{m^{*}\left(p^{*}, a ; m^{o}\right)} \varepsilon_{\omega^{*}}\left(p^{*}, m^{o}\right) .
$$

\footnotetext{
${ }^{22}$ Alternatively, a firm exits if it observes a marginal cost draw $c$ greater than some threshold $c^{*}\left(m^{o}\right)$.

${ }^{23}$ Monopoly price can exceed a consumer's period gross surplus $s$. Because a consumer's expected net present surplus $W^{*}$ increases as the probability of exit decreases, $W^{*}>s$ is possible.

${ }^{24}$ Note that the value function $V^{*}\left(m^{o}, c\right)$ is differentiable in $m^{o}$ except at point $m^{o}=x^{*}(c)$.
} 
In other words, under the assumption of no price discrimination, a firm's price reflects the composition of its customers.

High efficiency firms charge lower prices compared to less efficient ones of the same size. Given efficiency, a larger firm offers more surplus because of its lower probability of exit. This additional surplus gives larger firms a price premium. Therefore, size and efficiency have opposite effects on price. Consumers also derive higher net surplus from visiting larger and more efficient firms. Competition among firms prevents firms from appropriating the largest possible surplus. The firm type that offers the lowest surplus leaves a consumer a surplus of $W^{\varnothing *}$, making the consumer indifferent between buying versus refusing. Other firm types leave a surplus strictly higher than $W^{\varnothing *}$ to their customers. However, if the firm sizeconsumer surplus connection is broken, for instance, by removing exit from the model (e.g. setting fixed cost to zero), by making exit independent of firm size (e.g. random exit with an exogenously fixed probability), or by allowing consumers to forget all past information, then a firm's price does not depend on size.

Proposition 2 (i) There exists a unique pricing policy, $p^{*}\left(m^{o}, c\right)$, which is a strictly increasing function of size, $m^{o}$, and a strictly decreasing function of marginal cost, $c$, (ii) If consumer surplus does not depend on firm size through the exit probability, pricing policy is independent of firm size, $m^{o}$.

In equilibrium, some firms can set a price below marginal cost, sacrificing current profits for future profitability. Below-cost-pricing can be observed especially for young and small firms with high marginal cost.

Assumption 1 ensures that firms advertise every period. The advertising policy, $a^{*}\left(m^{o}, c\right)$, is thus an interior maximizer defined implicitly by the first order condition

$$
\frac{\partial m^{*}\left(p, a ; m^{o}\right)}{\partial a}\left[(p-c)+\beta \frac{\partial}{\partial m^{*}} \int V^{*}\left(m^{*}, c^{\prime}\right) h\left(c^{\prime}\right) d c^{\prime}\right]-\Phi^{\prime}(a)=0 .
$$

As in the choice of price, a change in current period's advertising level affects the firm's continuation value. The second term in brackets in (15) pertains to the dynamic effects of the marginal ad. The advertising policy is an increasing function of a firm's efficiency and size, because the expected profit per consumer is higher for firms with larger clientele and higher efficiency. 
Proposition 3 There exists a unique advertising policy, $a^{*}\left(m^{o}, c\right)$, which is a strictly increasing function of size, $m^{o}$, and a strictly decreasing function of marginal cost, $c$.

Let the sales of a firm in any period be $r^{*}\left(m^{o}, c\right)=m^{*}\left(m^{o}, c\right) p^{*}\left(m^{o}, c\right)$.

Proposition 4 A firm's demand, $m^{*}\left(m^{o}, c\right)$, and sales, $r^{*}\left(m^{o}, c\right)$, are strictly increasing functions of size, $m^{\circ}$, and strictly decreasing functions of marginal cost, $c$.

Because a firm's end-of-period number of customers, $m^{*}\left(m^{o}, c\right)$ is strictly increasing in previous-period size $m^{o}$, there is persistence in firm size. This persistence drives some properties of equilibrium.

The results so far were obtained by assuming that there exists a stationary equilibrium with positive advertising, entry, and exit. Under certain conditions a unique such equilibrium exists. Theorem 1 in Appendix A provides a formal treatment.

\section{Properties of the stationary equilibrium}

\subsection{Firm size, efficiency, and advertising}

In the model current advertising expenditures are positively associated with both current efficiency and previous-period firm size (Proposition 3). A positive relation between firm size and advertising expenditures is empirically well-established..$^{25}$ Little evidence exists, however, on efficiency-advertising relationship. We present evidence on both relationships using US Census Bureau's Census of Manufactures (CM) for 4-digit SIC level industries. ${ }^{26}$ Following the model, we relate a firm's advertising expenditures to its previous size and current efficiency. Advertising expenditures is the sum of advertising expenditures reported by all establishments of a firm operating in a given industry in $1997 \mathrm{CM}$. In the expenditures, we include the cost of advertising by a firm's auxiliary and administrative establishments, which can be important when advertising campaigns are run centrally by an administrative

\footnotetext{
${ }^{25}$ See, e.g., Sutton (1991) and Bagwell (2007).

${ }^{26}$ Advertising expenditures in non-manufacturing industries are available only in select survey data and cannot be traced straightforwardly to establishments of a firm within narrowly defined industries.
} 
office. We allocate such advertising expenditures to an industry based on firm's share of value of shipments classified in that industry.

Previous firm size is measured in alternative ways: total value of shipments in $1992 \mathrm{CM}$, total employment in $1992 \mathrm{CM}$, and the corresponding measures in 1996 Annual Survey of Manufactures (ASM), all aggregated to firm level from establishment level. For firms that entered between 1992 and 1997 CM, 1992 firm size measures are set to zero. Firms that exited between the two censuses were excluded, as they do not have 1997 advertising expenditures. 1992 CM gives a previous size measure five years prior to 1997 CM. Five years may be too long depending on persistence in firm size. ASM is updated annually, providing a previous size measure equal to previous year's size, but only for a sample of large establishments and firms. The measure of efficiency in the model is marginal cost, which cannot be calculated or estimated easily and accurately using CM for a large number of firms. ${ }^{27}$ Instead, we use a firm's 1997 revenue-based total factor productivity (TFP) as a proxy for current efficiency. Appendix $\mathrm{C}$ gives the details on the calculation of revenue-based TFP.

We first use OLS estimation to explore the relationship between advertising expenditures, size, and efficiency. Because some firms report zero advertising in CM, we also use a Tobit model. As discussed earlier, zero advertising by a firm in a given period can be easily obtained in the model by introducing a fixed cost of advertising (modifying Assumption 1(ii)), or by modifying Assumption 1(iii), either of which leads to a corner solution, and therefore, censoring at zero. Estimation results are in Table 1. Specifications I and II indicate a significant positive association between advertising expenditures and size measures. Specification III also suggests a positive association between advertising expenditures and TFP. ${ }^{28}$ In specifications IV and V, size measures are used jointly with the TFP measure. The positive relationships remain significant and support Proposition 3. Table 2 repeats the analysis for the ASM sample. The pattern is similar to Table 1. We repeated our analysis by excluding establishments, usually small ones, that rely on administrative records for variables used in TFP calculations. We also repeated the analysis using 1987, 1992, or 2002 CM instead. The

\footnotetext{
${ }^{27}$ For a small subset of establishments in CM, physical output measures are reported, along with cost measures. We utilize this information later in our investigation of prices.

${ }^{28}$ For a number of firms TFP measure cannot be reliably calculated due to issues with reporting of inputs. These firms are excluded from specifications III, IV, and V.
} 
main findings in Tables 1 and 2 were robust.

\subsection{Firm size, age, and survival}

Evans (1987) and Dunne, Roberts, and Samuelson (1989) found a higher probability of survival for larger firms. ${ }^{29}$ In the model, this is a consequence of the fact that firm value is increasing in size. Older firms are larger on average (see Evans (1987) and Dunne, Roberts, and Samuelson (1989)), and size increases with age in a first order stochastic sense (see Dunne, Roberts, and Samuelson (1989)). Stationary equilibrium is also consistent with these findings.

Proposition 5 (i) Firm size increases with firm age in a first order stochastic sense, (ii) average firm size increases with firm age, and (iii) older firms have lower exit rates on average.

Note that Proposition 5 is obtained under i.i.d. shocks to firms' marginal costs - no persistence in efficiency. Instead, the persistence in a firm's clientele causes the positive association between firm age and size, and the negative association between firm age and exit probability, consistent with the empirical findings that indicate higher hazard rates for younger firms (see, e.g., Dunne, Roberts, and Samuelson (1989)).

\subsection{Firm size, efficiency, and price}

The model has implications on a firm's pricing along its life-cycle. Smaller firms have lower prices, conditional on efficiency, and more efficient firms also have lower prices, conditional on size (Proposition 2). Because each entrant starts off with zero customers, the most efficient entrant type has the lowest price. Young and small firms tend to charge lower prices to build a customer base. As a firm grows, its pricing becomes less aggressive on average.

In the model, firm efficiency decreases in a first order stochastic sense as size increases. Consequently, smaller firms are on average more efficient than larger firms, in contrast to Hopenhayn (1992) and Jovanovic (1982), where efficiency dictates size and small firms are

\footnotetext{
${ }^{29}$ The latter study actually focuses on establishments rather than firms.
} 
necessarily less efficient. This result follows directly because the highest marginal cost a firm can withstand without exit increases with size. A similar result is obtained by Fishman and Rob (2002) in a dynamic industry model with consumer search.

Some recent evidence supports certain predictions of the model on prices. Foster, Haltiwanger, and Syverson (2008) find that new entrants and young businesses tend to have higher productivity and lower prices compared to older incumbents in manufacturing industries with highly homogeneous products. Large firms in Internet retailing, such as Amazon.com and Barnes and Noble.com, also do not charge the lowest prices (see, e.g., Brynjolfsson and Smith (2000) and Smith and Brynjolfsson (2001)). We next provide more systematic evidence on the relationship between a firm's price, size, and efficiency.

For a subset of establishments in CM, measures for physical quantities shipped are collected for their products at the 7 -digit SIC level. ${ }^{30}$ From this subset, we use a plantlevel dataset for 11 manufacturing industries consisting of highly homogenous products constructed by Foster, Haltiwanger, and Syverson (2008) using several years of CM. ${ }^{31}$ Because the model focuses on homogenous goods, its implications on price can be more cleanly tested using this set of products. Price is defined as the value of shipments divided by the quantity shipped by all establishments of the firm that report a positive quantity for that product. The availability of quantity information in well-defined and consistent units across firms also allows us to use physical quantity as an alternative measure of firm size. The quantity information is also used to compute a firm-level quantity-based (physical) TFP, instead of a revenue-based TFP, following Foster, Haltiwanger, and Syverson (2008). Quantity-based TFP is preferred in the analysis of prices because part of revenue-based TFP incorporates price and therefore already exhibits some positive correlation with price when used as a regressor to measure efficiency. As another measure of efficiency, we also calculate an average variable cost measure (AVC) as the total cost of materials and labor divided by the total quantity shipped by a firm.

In the model, current price is a function of previous period size and current efficiency.

\footnotetext{
${ }^{30}$ No quantity information is available in non-manufacturing censuses, so the analysis is limited to CM.

31 The products are boxes, bread, carbon black, coffee, concrete, flooring, gasoline, block ice, processed ice, plywood, and sugar. The details on the construction of this dataset can be found in the Appendix of Foster, Haltiwanger, and Syverson (2008). We thank the authors for generously providing their dataset.
} 
We relate a firm's price in 1992 CM to its previous size, measured by its value of shipments, employment, or physical quantity shipped in $1987 \mathrm{CM}$, and to its efficiency, as measured by its quantity-based TFP or AVC in $1992 \mathrm{CM}^{32}$ We focus only on the set of firms that appear in both censuses. Our results were similar when we used 1982-1987 or 1977-1982 CM samples instead. ${ }^{33}$ Table 3 presents the OLS estimation with various specifications. All specifications indicate a significant positive association between price and firm size, and a significant negative association between price and efficiency. The estimated elasticities for size measures vary across specifications somewhat, with the quantity measure having the lowest elasticity. Size elasticities are much higher when the average cost measure is used as an efficiency measure. The estimated elasticities for efficiency measures are also higher in absolute value than those for size measures. Overall, the estimated coefficients in Table 3 lend support to Proposition 2. However, the samples used represent only a very small fraction of all products and firms in U.S. and the generality of the results remains to be seen.

\subsection{Firm size distribution}

Empirical studies indicate a positively skewed firm size distribution (see, e.g., Cabral and Mata (2003)) with a decreasing firm size density at least towards its right tail. Pareto distribution appears to provide a good fit for firm size greater than some threshold (see, e.g., Axtell (2000, 2006) and Palestrini (2007)). The model can generate a decreasing firm size density and a skewed firm size distribution. A firm needs a sufficiently long streak of favorable cost shocks to achieve a large size. Such streaks become increasingly rare as the ultimate size to be achieved increases, implying a decreasing firm size density for sufficiently large firm size levels and a positively skewed firm size distribution.

Formally, let $f^{*}(m)$ be the stationary firm size density over the support $\left[\underline{m}^{*}, \bar{m}^{*}\right]$, where $\underline{m}^{*}>0$ and $\bar{m}^{*}<\infty .{ }^{34}$ Let $c^{*}\left(m, m^{o}\right) \in[\underline{c}, \infty)$ be the largest cost shock a firm can withstand

\footnotetext{
${ }^{32}$ Unlike in the case of samples used in analyzing advertising expenditures in Section 4.1., the ASM samples are small for the products considered in price analysis, so we do not use 1991 ASM size measures.

${ }^{33}$ The dataset contains a much smaller number of observations for 1997, because no quantity information was collected by the Census Bureau for concrete in 1997. Therefore, we did not use the 1992-1997 CM sample.

${ }^{34}$ With positive exit in equilibrium, the minimum firm size exceeds zero. The maximum size $\bar{m}_{t}^{*}$ at age $t$
} 
to achieve a size of at least $m$ at the end of the period, starting from a previous period size of $m^{o} \geq 0$. The function $c^{*}\left(m, m^{o}\right)$ is strictly decreasing in its first argument, as a higher size next period requires a lower current cost draw. The conditional probability that next period size is at most $m$ given $m^{o} \geq 0$ can then be written as

$$
P^{*}\left(m \mid m^{o}\right)=\left\{\begin{array}{cc}
0 & \text { if } c^{*}\left(m, m^{o}\right)<\underline{c}, \\
1-H\left(c^{*}\left(m, m^{o}\right)\right) & \text { if } c^{*}\left(m, m^{o}\right) \in\left[\underline{c}, c^{*}\left(m^{o}\right)\right) .
\end{array}\right.
$$

The firm size density can then be expressed as a fixed point of the operator that relates current firm size density to that of the next-period

$$
f^{*}(m)=\int_{\underline{m}^{*}}^{\bar{m}^{*}} f^{*}\left(m \mid m^{o}\right) f^{*}\left(m^{o}\right) d m^{o}+f^{*}(m \mid 0) P^{*}(0)
$$

where $f^{*}\left(m \mid m^{o}\right)=\frac{d P^{*}\left(m \mid m^{o}\right)}{d m}$ is the firm size density conditional on previous period size and $P^{*}(0)$ is the fraction of firms that are new entrants. For firm size to exhibit a non-increasing density throughout its entire support, a sufficient condition is $f^{* \prime}\left(m \mid m^{o}\right) \leq 0$ for $m, m^{o} \geq 0$, or equivalently, using (16),

$$
\frac{h^{\prime}\left(c^{*}\left(m, m^{o}\right)\right)}{h\left(c^{*}\left(m, m^{o}\right)\right)} \leq-\frac{\frac{\partial^{2} c^{*}\left(m, m^{o}\right)}{\partial m^{2}}}{\frac{\partial c^{*}\left(m, m^{o}\right)}{\partial m}} .
$$

When the right hand side of (17) is positive, (17) holds for all non-increasing density functions $\left(h^{\prime} \leq 0\right)$, such as uniform, exponential, and Pareto, and can hold for some increasing density functions. For a given marginal cost distribution, the right hand side of (17) is positive when the advertising cost increases steeply enough so that $\frac{\partial^{2} c^{*}\left(m, m^{o}\right)}{\partial m^{2}}>0$.

is attained by an entrant which receives the minimum marginal cost draw $\underline{c}$ every period,

$$
\bar{m}_{t}^{*}=a^{*}\left(\bar{m}_{t-1}^{*}, \underline{c}\right) \widetilde{z}^{*}\left(\bar{m}_{t-1}^{*}, \underline{c}\right)+(1-\lambda) a^{*}\left(\bar{m}_{t-2}^{*}, \underline{c}\right) \widetilde{z}^{*}\left(\bar{m}_{t-2}^{*}, \underline{c}\right)+\ldots+(1-\lambda)^{t-1} a^{*}(0, \underline{c}) \widetilde{z}^{*}(0, \underline{c}) .
$$

Note that $a^{*}\left(\bar{m}_{t}^{*}, \underline{c}\right) \widetilde{z}^{*}\left(\bar{m}_{t}^{*}, \underline{c}\right)$ is a strictly increasing function of $t$ (by Propositions 1 and 3). Furthermore, $a^{*}\left(\bar{m}_{t}^{*}, \underline{c}\right) \widetilde{z}^{*}\left(\bar{m}_{t}^{*}, \underline{c}\right) \leq a^{*}\left(\bar{m}_{t}^{*}, \underline{c}\right)<\infty$, where the first inequality follows from $\widetilde{z}^{*}\left(\bar{m}_{t}^{*}, \underline{c}\right) \leq 1$. Therefore, $\bar{m}_{t}^{*} \leq a^{*}\left(\bar{m}_{t-1}^{*}, \underline{c}\right) \frac{\left[1-(1-\lambda)^{t}\right]}{\lambda}$. As a result, $\bar{m}^{*}=\lim _{t \rightarrow \infty} \bar{m}_{t}^{*} \leq \lim _{t \rightarrow \infty} a^{*}\left(\bar{m}_{t-1}^{*}, \underline{c}\right) \frac{\left[1-(1-\lambda)^{t}\right]}{\lambda}=\frac{a^{*}\left(\bar{m}^{*}, \underline{c}\right)}{\lambda}<\infty$ for $\lambda \in(0,1)$, by continuity of $a^{*}\left(m^{o}, c\right)$ in $m^{o}$. Thus, a limit $\bar{m}^{*}<\infty$ exists, and the maximum firm size in equilibrium is the solution to $\lambda \bar{m}^{*}=a^{*}\left(\bar{m}^{*}, \underline{c}\right)$. 


\subsection{Firm size, growth, and Gibrat's Law}

Growth rate for a surviving type $\left(m^{o}, c\right)$ firm is

$$
g^{*}\left(m^{o}, c\right)=\frac{m^{*}\left(m^{o}, c\right)-m^{o}}{m^{o}}=(1-\lambda) \widetilde{z}^{*}\left(m^{o}, c\right)+\frac{a^{*}\left(m^{o}, c\right) \widetilde{\omega}^{*}\left(m^{o}, c\right)}{m^{o}}-1,
$$

and the expected growth rate conditional on size and survival is $\bar{g}^{*}\left(m^{o}\right)=E_{c}\left[g^{*}\left(m^{o}, c\right) \mid m^{o}, c \leq\right.$ $\left.c^{*}\left(m^{o}\right)\right]$. The first term on the right hand side of $(18)$ is the fraction of the firm's customers from the previous period that continue to purchase from the firm, and the second term is the ratio of the number of new customers acquired in the current period to the beginning-ofperiod size. Because the first term is less than one, a negative growth rate can occur when a bad cost shock induces sufficient loss of customers.

Conditional on size, more efficient firms have higher growth rates, because $g^{*}\left(m^{o}, c\right)$ is strictly decreasing in $c$. Because $g^{*}(0, c)=+\infty$ for $c \leq c^{*}(0)$, it holds that $\bar{g}^{*}(0)=$ $+\infty$, implying that new entrants have the highest expected growth rates. ${ }^{35}$ As firm size increases, the expected growth rate must eventually become negative. To see this claim, note that from (18) and the facts that $\widetilde{z}^{*}\left(\bar{m}^{*}, c\right) \leq 1$ and $\widetilde{\omega}^{*}\left(\bar{m}^{*}, c\right) \leq 1$, one can write $\bar{g}^{*}\left(\bar{m}^{*}\right) \leq-\lambda+E_{c}\left[\frac{a^{*}\left(\bar{m}^{*}, c\right)}{\bar{m}^{*}}\right] \leq \lambda\left(E_{c}\left[\frac{a^{*}\left(\bar{m}^{*}, c\right)}{a^{*}\left(\bar{m}^{*}, \underline{c}\right)}\right]-1\right)<0$, where we used $\bar{m}^{*}=\frac{a^{*}\left(\bar{m}^{*}, \underline{c}\right)}{\lambda}$ and $a^{*}\left(\bar{m}^{*}, c\right)<a^{*}\left(\bar{m}^{*}, \underline{c}\right)$. A sufficient condition for the expected growth rate to be declining over the entire support of firm size is that the number of new customers acquired, $a^{*} \widetilde{\omega}^{*}$, is a sufficiently concave function of size. In the special case of full consumer turnover $(\lambda=1)$, current size is independent of previous-period size. Both $g^{*}\left(m^{o}, c\right)$ and $\bar{g}^{*}\left(m^{o}\right)$ are then strictly decreasing in $m^{o}$. In general, values of $\lambda$ close to 1 imply a weak dependence of current firm size on previous period firm size.

In summary, Gibrat's Law of independence of firm growth and size, as incorporated in some models of firm growth (e.g. in Ijiri and Simon (1977)), does not necessarily emerge. Recent evidence suggests that Gibrat's Law does not hold for entrants and established firms tracked for a five-year or longer time period (Mata (1994), Geroski (1995), Audretsch et al. (2002), and Lotti, Santarelli, and Vivarelli (2003)). Empirical work by Evans (1987) and

\footnotetext{
${ }^{35}$ This result follows because $\widetilde{z}^{*}(0, c), \widetilde{\omega}^{*}\left(m^{o}, c\right)$, and $a^{*}(0, c)$ are strictly positive, as there is always a positive mass of uninformed consumers when advertising is not free.
} 
Dunne, Roberts, and Samuelson (1989) also points to a general failure of Gibrat's Law in US manufacturing. Large firms in services and retail also tend to have lower growth rates than small firms (e.g. Acs and Armington (2001), Estevez (2007)).

\subsection{Robustness}

We now discuss robustness to main assumptions. First, consider a longer consumer memory. Suppose a consumer recalls all the firms he was informed of upto current period $t$ starting from his entry to the market (total recall, $\mathbf{M}_{t}^{\bar{\tau}}$ ). We maintain the assumption that the consumer is updated of the current-period information about the most-recentlyvisited firm. The consumer needs to assess expected period- $t$ surplus from each firm in $I_{t-\tau}, \tau=1, \ldots, \bar{\tau}$. The consumer can actually infer the size of each firm in period $t-\tau+1$ from period $t-\tau$ size and price information. Among the firms in $I_{t-\tau}$, the largest firm at the beginning of period $t-\tau+1$ provides the highest expected surplus at time $t$ because cost shocks are i.i.d.. Consequently, remembering only the largest firm at the beginning of period $t-\tau+1$ is sufficient for assessing the highest possible surplus associated with $I_{t-\tau}$. The consumer can then compare the expected period- $t$ surplus from these largest firms using each firm's size and the length of time, $\tau$, the consumer has known about the firm. The main properties of the stationary equilibrium do not change. However, because consumers now have more information each period compared to the baseline memory process, firms face more competition. Pricing is more aggressive especially among larger and more efficient firms which are more likely to be recalled by consumers. Other memory processes, all subsets of $\mathbf{M}_{t}^{\bar{\tau}}$, can also be considered. For instance, a consumer can recall randomly one of the firms visited in the past, or the largest firm ever visited. The model's general properties are robust to a variety of such specifications.

The assumption that a consumer is updated of the current-period payoff-relevant information about the most-recently-visited firm can also be relaxed. Suppose that consumer recalls only the period $t-1$ size of the most-recently-visited firm, but has no update about its period $t$ price. The consumer can then assess the expected surplus from the firm based on period $t-1$ information. This modification preserves persistence in firm size; however, a consumer's problem becomes more complicated, as discussed in the preceding paragraph. 
The assumption that firm size is revealed in an ad can also be modified. If firm size is not revealed, consumers must take into account possible future firm sizes in forming expectations about the surplus offered by a firm. An alternative is to assume that firm size is common knowledge, or becomes so after a firm grows to a certain size. Another alternative is to assume that firm age, which is positively correlated with size, is revealed in an ad, or that age is common knowledge. Both alternatives preserve the main properties of the model.

It is also possible to break the firm size-consumer surplus link that works through repeat purchase probability. Suppose that the discount factor $\beta$ is set to zero for consumers, but kept positive for firms. ${ }^{36}$ A consumer's problem then becomes static. If consumers are allowed to recall the most-recently-visited firm (or other firms in the past), firm size still exhibits persistence, but consumers do not place any value on repeat purchase probability and firm size, as they do not care about the future. In this case, price is the only payoff-relevant variable for consumers.

Consider next the nature of the advertising technology. Assumption 1 places little restriction on the technology other than convexity. Advertising cost can be non-convex over some range, implying that the cost of reaching an additional consumer is non-increasing. Such cases can arise, for instance, if an ad is shared, e.g. through word-of-mouth, by several consumers at no additional cost to the firm. If the advertising cost is not strictly convex, advertising policy may not be bounded, unique, and monotonic in firm's size and marginal cost. As mentioned earlier, a fixed cost of advertising can be introduced, or the slope of the advertising technology around zero can be made positive, without changing the main results.

Finally, suppose that marginal cost is not i.i.d. over time, but rather follows a persistent stochastic process. The possibility of efficiency signalling now arises. Suppose there is an equilibrium where firms signal efficiency through prices. If the equilibrium is separating, consumers are able to infer a firm's type correctly. On the other hand, a pooling equilibrium where some positive mass of firms with different types charge the same price cannot exist. If there was pooling at some price, any of the firms charging the common price can charge a slightly lower price and steal a positive mass of consumers from others with the same price, ending up with a discrete increase in its profit. A persistent marginal cost reinforces many

\footnotetext{
${ }^{36}$ We thank an anonymous referee for suggesting this alternative.
} 
features of the equilibrium. For instance, a firm's size, advertising outlays, and price would be more persistent over time, and inequality in firm value and size across different levels of efficiency would increase.

\section{The role of information cost}

In this section, we analyze some effects of a decline in the information cost. Analytical solution of equilibrium even with simple specifications of the fundamentals is difficult. We therefore examine numerically how the equilibrium responds to changes in the information dissemination cost. The goal is to demonstrate some effects using different parameterizations. Appendix B details the algorithm used for computing the stationary equilibrium.

Consider two otherwise identical economies where it is cheaper to spread information on the margin in the second economy: $\Phi_{1}^{\prime}(a)>\Phi_{2}^{\prime}(a)$ for all $a>0$, implying $\Phi_{1}(a)>\Phi_{2}(a)$ for all $a>0$ by Assumption 1. There are two main effects of a decline in the cost of information dissemination. The direct effect is an incentive to advertise more. This effect alone works to increase value for all firms. However, there is also an indirect effect, which changes the expected return to an ad. This effect is represented by the first term on the left hand side of (15). The indirect effect depends not only on a firm's efficiency but also on the collective advertising made by all firms that offer more surplus than the firm. If advertising outlays of larger and more efficient firms increases sufficiently, the mass of consumers who receive ads offering high surplus becomes large. Less efficient and smaller firms' ads are then less likely to turn into a sale. The value of such firms can decrease, leading to a higher exit probability. A small yet efficient firm can have a higher value in the low-information-cost economy, because it can build a large clientele more easily and grow faster. On the other hand, a firm can also fail more easily in response to an unfavorable cost shock in such an environment. Therefore, a decline in information cost has implications on both the mean and standard deviation of firm growth rates. Because the decline affects firms with different efficiencies disparately, inequality in firm values and sizes as measured by industry concentration can also increase. The exact nature and magnitude of these effects depend on the distribution of marginal cost and advertising technology. 


\subsection{Baseline specification}

The distribution of marginal cost $H(\cdot)$ is uniform over $[1,5] .{ }^{37}$ Uniform distribution is chosen to demonstrate that the model can deliver skewed empirical firm size and value distributions without any fundamental skewness in marginal cost. The advertising cost is a strictly convex function in accordance with Assumption 1: $\Phi(a)=\chi a^{\varphi}, \chi>0$ and $\varphi>1 .^{38}$ Our baseline specification is $\chi=1$ and $\varphi=2$. Appendix B shows that this advertising technology generates positive advertising under both the baseline and other specifications used below. The discount factor $\beta$ is 0.95 . The entry cost and the fixed cost are $\kappa=1$ and $f=0.2$, respectively. Finally, consumer gross period surplus is $s=4$ and the probability of consumer exit is $\lambda=0.02$, implying an expected consumer life-time of 50 periods. We study two types of change in the advertising technology.

\subsection{Scale of information cost}

We first change the value of the scaling parameter to $\chi=2$, corresponding to the highinformation-cost economy. Re-scaling increases the marginal and total cost of advertising by a constant factor at all levels of advertising. The firm types that exit lie below the exit schedules in Figure 2. The exit region is larger in the low information cost economy. Figure 3 presents the average market value of firms as a function of marginal cost. Lower information cost leads to an increase in efficient firms' values, and at the same time, make inefficient firms worse off. Moreover, firm size becomes less critical for firm value, as shown in Figure 4, where, for each size percentile, the market values of firms are averaged over cost levels. Larger firms have higher value in the high-information-cost economy where it is more difficult to grow, but easier to remain large. In contrast, in the low-information-cost economy, a small, yet efficient, firm can more easily attract consumers, and at the same time, a large but an inefficient firm loses its customers more easily. Note that firm size-value profile is steeper in the high-information-cost economy, implying that value effect of an increase in

\footnotetext{
${ }^{37}$ While it was assumed that the upper bound of the support of $H(\cdot)$ is arbitrarily large, in practice what is needed is that the upper bound be large enough (given the values of the other parameters), so that any firm with a cost draw close to that upper bound exits with certainty.

${ }^{38}$ See also Tirole (1988), p. 292 for this type of specification.
} 
size is higher at all size levels. Figure 5 shows a positive association between firm age and size, as implied by Proposition 5. In the model, firm growth is a gradual process. When the information cost is lower, it takes less time on average for firms to grow to a given size.

Figure 6 plots volatility, as measured by the standard deviation of the next-period-size conditional on current size and survival, i.e. $\operatorname{Vol}\left(m^{o}\right)=\left[V\left(m^{*}\left(m^{o}, c\right) \mid m^{o}, m^{o} \geq x^{*}(c)\right)\right]^{1 / 2}$. In both economies, larger firms exhibit lower volatility. In the low-information-cost economy volatility is higher for all size levels. Figure 7 shows industry concentration, defined as the fraction of sales accounted by firms larger than a given size percentile. Sales are much more concentrated in the low-information-cost economy. For instance, in the high-informationcost economy firms in the top decile account for $\sim 40 \%$ of sales, compared to $\sim 60 \%$ in the low-information-cost economy. The density of firm size is plotted in Figure 8. The size distribution is positively skewed and downward sloping, in line with available empirical evidence. In the high-information-cost economy the size distribution is more skewed, with a skewness measure of 0.89 versus 0.83 in the low-information-cost economy. ${ }^{39}$

\subsection{Convexity of information cost}

In this exercise, the value of the convexity parameter in the information cost is changed from its baseline value of $\phi=2$ to $\phi=3$. Compared to the re-scaling exercise, this modification implies a much steeper rise in marginal and total advertising cost for $a>2$. As shown in Figure 9, in the less convex cost case the exit region is larger, similar to Figure 2. The relationship between firm value and firm size is shown in Figure 10. Firms have higher average market value at all size percentiles in the economy with more convex advertising cost, as it is more difficult to achieve a given size in that economy. Average market value of firms also increases faster as firm size increases in the more convex case, indicating that the return to an increment in firm size is higher.

The firm size-age relationship is shown in Figure 11. As in Figure 5, average firm size increases with age. In the more convex advertising cost economy, however, it takes more time on average for firms to grow to a given size, as a firm has to experience on average a

\footnotetext{
${ }^{39}$ Skewness is measured by the empirical counterpart of $\gamma=\frac{E\left(\left(m-\mu_{m}\right)^{3}\right)}{\sigma_{m}^{3}}$, where $m$ is firm size and $\mu_{m}$ and $\sigma_{m}$ are its mean and standard deviation.
} 
longer streak of good shocks to achieve a given size. The volatility of firm size is plotted in Figure 12. Similar to Figure 6, less convex advertising cost generates higher volatility for all firm size percentiles. Firm size distributions in Figure 13 exhibit positive skewness as in the case of the re-scaling exercise, and the skewness measure increases (from 0.48 to 0.82 ) as the advertising cost becomes more convex. In figures omitted, we found that industry concentration and average market value-efficiency relationship also changed in a way similar to the re-scaling exercise. In addition, we found that profit volatility is a decreasing function of firm size, and it increases for all firm sizes as the information cost declines. The volatility of advertising to sales ratio for a firm across time also increases as the information cost declines. We also experimented with a wider range of values for $\chi$ and $\phi$, and found the results to be qualitatively similar.

\subsection{Some empirical evidence}

The numerical analysis suggests that a lower cost of information dissemination can lead to higher entry and exit, a higher industry concentration, and higher firm growth volatility. Campbell, Lettau, Malkiel and Xu (2001) find an increase in firm stock return volatility for

publicly-traded firms in U.S. between 1962 and 1997. Employment and sales growth volatility of publicly held firms also increased, as documented by Comin and Philippon (2005), using only the publicly traded firms in the Compustat database. However, Davis, Haltiwanger, Jarmin and Miranda (2006) find, using comprehensive data, that while employment growth volatility increased among publicly traded firms, it declined among privately held firms between 1976 and 2002. The model does not have a mechanism for employment volatility. The volatility of sales is the appropriate measure from the model's perspective. Sales can be more volatile than employment in response to changes in the competitive environment. We present evidence on sales volatility below.

There is also some evidence regarding the effects of information technologies on the evolution of industry aggregates. In an earlier study, Eckard (1988) found that between 1963 and 1977, a period during which TV advertising diffused substantially, prices fell and both output and concentration increased in a sample of 4-digit manufacturing industries where TV advertising is used by firms. Higher TV advertising was associated with a higher decline 
in average price. Similarly, Mueller and Rogers' (1980, 1984) analysis indicated that TV advertising is positively related to sales concentration in a sample of 4-digit manufacturing industries. More recently, Baye and Morgan (2003) found that average industry concentration across nearly 5,000 online product-markets increased between 2000 and 2002, as Internet-based commerce diffused.

To provide more evidence on the effects of lower information cost, we identified certain narrowly-defined retail and service industries for which the mechanics of the model is likely relevant. The industries in Table 4 experienced significant diffusion of Internet-based information dissemination and commerce since early 1990's. A constraint on the selection of the industries was the switch from SIC codes to NAICS codes in 1997, and a further revision in 2002. These changes coincide with a period during which Internet-based commerce diffused rapidly, rendering construction of consistent time series of industry aggregates difficult for other candidate industries. Except for life insurance, all industries in Table 4 have comparable industry codes and aggregates over the sample period. For life insurance, the discrepancy due to code revisions is small. See Appendix D for details.

The industries in Table 4 share a number of common features relevant for the model's environment. Many firms in these industries release information about their prices and attributes on the Internet through their websites, banner ads, pop-up ads, listings in search engines, ads tied to search results, and e-mails to existing and new customers. These industries have also experienced significant diffusion of Internet-based information dissemination and commerce starting in mid-1990's. While reliable e-commerce penetration rates (e-commerce sales as a percent of total sales) are not available at the 4-digit level, the penetration rates for certain product categories sold by electronic shopping and mail-order houses are provided by US Census Bureau. ${ }^{40}$ Some of these products are offered by the industries in Table 4. To give an idea, in 1999, the first year the statistics were released, penetration rates were as follows: Books and Magazines (45.2\%), Electronics and Appliances (17.7\%), and Music and Videos (18.0\%). In 2007, the corresponding rates rose to $61 \%, 74.1 \%$, and $74.0 \%$. Because of high e-commerce activity, the industries in Table 4 have also been the focus of recent research regarding the effect of easier information exchange between firms and consumers

\footnotetext{
${ }^{40}$ See US Census Bureau's E-stats Main Page at http://www. census.gov/econ/estats/index.html.
} 
made possible by the Internet. ${ }^{41}$

Our strategy is to document the evolution of each industry from 1992 onwards. In 1992, Internet-based information dissemination and commerce was negligible, and by 2006, the last year we calculate a statistic for, it was wide-spread. For each industry, we assess the evolution of the number of firms, and the concentration of sales using three measures: HirschmanHerfindahl index (HHI), 4-firm concentration ratio (CR4), and 8-firm concentration ratio (CR8). The numerical analysis suggests that an increase in the sales of larger firms is accompanied by a decline in those of smaller firms. We therefore expect both the inequality in sales share across firms, and the share of large firms to increase. HHI captures the former effect, whereas CR4 and CR8 capture the latter. We also calculate an estimate of skewness in firm size, using the same measure as in the numerical analysis. Concentration and skewness measures, and the number of firms are based on the 1992, 1997, and 2002 economic censuses, which provide the most comprehensive coverage of active firms. ${ }^{42}$ Because the market definition for the industries considered is not necessarily nationwide, we report both the nationwide concentration and the average concentration across Metropolitan Statistical Areas (MSA), which are proxies for local markets. ${ }^{43}$

Finally, we calculate the sales volatility estimates as follows. Suppose that, as in the model, a surviving firm's sales $r_{t}^{*}$ follows the process ${ }^{44}$

$$
r_{t}^{*}=\gamma_{t}\left(r_{t-1}^{*}\right)+\sigma_{t}\left(r_{t-1}^{*}\right) \varepsilon_{t}
$$

where $\gamma_{t}\left(r_{t-1}^{*}\right)=E\left[r_{t}^{*} \mid r_{t-1}^{*}\right]$ and $\sigma_{t}\left(r_{t-1}^{*}\right)=V\left(r_{t}^{*} \mid r_{t-1}^{*}\right)$. The error term is assumed to satisfy

\footnotetext{
${ }^{41}$ See, e.g., Brynjolfsson and Smith (2000) for books and CD's, Brown and Goolsbee (2001) for life insurance, and Baye, Morgan, and Scholten (2004) for electronic equipment. In particular, for the case of Life Insurance, Brown and Goolsbee (2001) found significant reduction in prices due to the increasing availability of price information disseminated to the Internet.

${ }^{42}$ At the time of this study, the final versions of the 2007 economic censuses were not available. However, our calculations based on preliminary versions of the 2007 economic censuses were consistent with the patterns found using these three censuses. We are unable to reveal our 2007 calculations because official concentration ratios and the number of firms will be published by the US Census Bureau.

${ }^{43}$ We use MSA definitions as of June 30, 1999.

${ }^{44}$ The equilibrium law of motion for sales is $r_{t}^{*}=p_{t}^{*} m_{t}^{*}=p_{t}^{*}\left(m^{o}(1-\lambda) z_{t}^{*}+a_{t}^{*} \omega_{t}^{*}\right)$. Noting that $m^{o}=\frac{r_{t-1}^{*}}{p_{t-1}^{*}}$, the expected sales $E\left[r_{t}^{*}\right]$ is a non-linear function of $r_{t-1}^{*}$ given by $\gamma^{*}\left(r_{t-1}^{*}\right)=$ $E_{c}\left[p_{t}^{*}\left(\frac{r_{t-1}^{*}}{p_{t-1}^{*}}, c\right)\left(\frac{r_{t-1}^{*}}{p_{t-1}^{*}}(1-\lambda) z_{t}^{*}\left(\frac{r_{t-1}^{*}}{p_{t-1}^{*}}, c\right)+a_{t}^{*}\left(\frac{r_{t-1}^{*}}{p_{t-1}^{*}}, c\right) \omega_{t}^{*}\left(\frac{r_{t-1}^{*}}{p_{t-1}^{*}}, c\right)\right)\right]$.
} 
$E\left[\varepsilon_{t} \mid r_{t-1}^{*}\right]=0$ and $V\left(\varepsilon_{t} \mid r_{t-1}^{*}\right)=1$. The specification in (19) is an ARCH process, and $\sigma_{t}(\cdot)$ is called the volatility function (see Engle (1982)). The volatility measure, $\operatorname{Vol}\left(m_{o}\right)$, reported in the numerical analysis is monotonically related to this function. Given an estimator $\widehat{\sigma}_{t}(\cdot)$ of $\sigma_{t}(\cdot)$, average volatility across firms in industry $i$ at time $t$ can be estimated as $\widehat{\sigma}_{i t}=\frac{1}{N_{i t}} \sum_{j=1}^{N_{t}} \widehat{\sigma}_{t}\left(r_{i t-1}\right)$, where $j=1, \ldots, N_{i t}$ indices surviving firms. ${ }^{45}$ The estimator $\widehat{\sigma}_{t}(\cdot)$ we use is a non-parametric one due to Fan and Yao (1998). First, the function $\gamma_{t}(\cdot)$ in (19) is estimated using a local linear estimator $\widehat{\gamma}_{t}(\cdot)$. The squared residuals from this estimation are then used to obtain a local linear estimator $\widehat{\sigma}_{t}^{2}(\cdot)$, whose square root yields $\widehat{\sigma}_{t}(\cdot){ }^{46}$ This approach is attractive because it assumes no strong functional forms for $\gamma_{t}(\cdot)$ or $\sigma_{t}(\cdot){ }^{47}$

For volatility estimates, we use higher frequency data than the economic census to analyze sales. The annual volatility estimates $\widehat{\sigma}_{i t}$ are calculated based on Business Register (BR), which provides annual coverage of establishments and firms. BR is US Census Bureau's annual source of basic employment and payroll measures, also summarized in the County Business Patterns. ${ }^{48}$ Reliable sales measures in the BR start in 1994, so we use 1995 as the first year of volatility estimates, because we require lagged sales. Some firms are late in reporting their receipts for a calendar year for a variety of reasons. Some of these late reports are recorded in a separate variable in the following two calendar years' data. Following Spletzer (1998), we made necessary adjustments to sales data to ensure as much coverage of firms in a year as possible. ${ }^{49}$ For an overall volatility estimate, we report the time-averages

\footnotetext{
${ }^{45}$ As an alternative, we also worked with a sales-weighted average volatility estimate and obtained similar results.

${ }^{46}$ Specifically, let $\widehat{\gamma}\left(r_{t-1}^{*}\right)=\widehat{a}$ where $(\widehat{a}, \widehat{b})=\arg \min _{a, b} \sum_{j=1}^{N_{i t}}\left[r_{j t}^{*}-a-b\left(r_{j t-1}^{*}-r_{t-1}^{*}\right)\right]^{2} K\left(\frac{r_{j t-1}^{*}-r_{t-1}^{*}}{h_{1}}\right)$. Also let $\widehat{\varepsilon}_{t}^{2}=\left(r_{t}^{*}-\widehat{\gamma}\left(r_{t-1}^{*}\right)\right)^{2}$. The estimator is then $\widehat{\sigma}_{t}^{2}\left(r_{t-1}^{*}\right)=\widehat{\alpha}$, where $(\widehat{\alpha}, \widehat{\beta})=\arg \min _{\alpha, \beta} \sum_{j=1}^{N_{i t}}\left[\widehat{\varepsilon}_{j t}^{2}-\alpha-\right.$ $\left.\beta\left(r_{j t-1}^{*}-r_{t-1}^{*}\right)\right]^{2} W\left(\frac{r_{j t-1}^{*}-r_{t-1}^{*}}{h_{2}}\right)$. The functions $K(\cdot)$ and $W(\cdot)$ are kernels and $h_{1}$ and $h_{2}$ are the bandwidths. See Fan and Yao (1998) for further details.

${ }^{47}$ In practice, exceptionally small or large residuals from the local linear estimation of (19) can unduly influence $\widehat{\sigma}_{t}(\cdot)$. To reduce the influence of potential outliers, we also used only those observations that fell within the 1st and 99th percentiles of the distribution of residuals. The results were qualitatively similar.

${ }^{48} \mathrm{BR}$ integrates information from several sources. Administrative records, supplied primarily by IRS, are the primary sources for BR. BR is updated continuously with the latest and best information available from Census Bureau and other Federal statistical and administrative records programs. For more information on BR, see http://www.census.gov/econ/overview/mu0600.html.

${ }^{49}$ The coverage changes between $72 \%$ and $85 \%$ percent of all firms in an industry for a non-census year.
} 
$\overline{\widehat{\sigma}}_{i}$ for two different time periods, $1995-2000$ and 2001-2006. We view the former period as the initial stage of the diffusion of Internet-based commerce, and the latter as a more progressed stage.

The first notable result in Table 4 is a net exit between 1992 and 2002 in all industries except for New Car Dealers, which experienced net entry. For Prerecorded Tapes and Travel Agencies, the number of firms increased between 1992 and 1997, before declining. Overall, the changes in the number of firms across the industries are consistent with escalated exit emerging in the numerical analysis, especially considering the fact that the market size for these industries grew during 1992-2002 as U.S. population increased. All concentration measures, both at the nationwide and MSA level, also increased for all industries between 1997 and 2002 during which Internet-based commerce diffused at a higher pace. There was also a general increase in concentration between 1992 and 1997 with exceptions for New Car Dealers, Travel Agencies and Life Insurance, but for many cases the increase was less than that during the 1997-2002 period. Skewness of firm size also increased between 1992 and 2002 for all industries. However, the increase was much more pronounced during 19972002, and skewness actually declined between 1992 and 1997 for New Car Dealers and Life Insurance. For all industries, average firm-level sales volatility was higher for the 2001-2006 period, compared to the 1995-2000 period. Overall, the findings give support to the patterns suggested by the numerical analysis. A more comprehensive analysis relating the observed patterns to growing intensity of Internet usage by firms can be made as accurate measures of firm's reliance on Internet-based information dissemination becomes available.

\section{Conclusion}

Among many factors that have influenced firm and industry dynamics over time, this paper focused on one: the cost of information dissemination. Information dissemination tech-

In a small number of cases, a firm in a given industry was part of a larger enterprise, and it did not have separately reported firm-level sales. We imputed firm-level sales in such cases by allocating the enterpriselevel total sales to the firm based on the firm's share of total payroll or employment within the enterprise, whichever measure was available. 
nologies matter for firm and industry dynamics because a firm's growth and survival depend on how easily it can inform, acquire, and keep customers. Introduction of an information dissemination technology to a dynamic framework has implications for price dynamics over a firm's life-cycle, the distribution of prices across firm size and efficiency, firm size distribution, and firm turnover and growth patterns. The model's main implications are generally consistent with existing empirical evidence and additional evidence this paper provided.

The model was used to analyze the effects of a decline in information costs. In an environment where consumers are not easily informed about the existence of better firms, inefficient firms can prevail. Easier spread of information, however, can speed up the demise of inefficient firms, enhance the dominance of more efficient ones, and lead to higher industry concentration. Numerical analysis of the model suggests that lower cost of information dissemination amplifies the effects of random shocks to firms' efficiency, leading to changes in firms' market value and size, and the mean and variance of firm growth rates. The experience of some retail and service industries that were heavily influenced by the recent diffusion of Internet-based information dissemination and commerce is consistent with some of these predictions.

The framework can accommodate several extensions. Broader marketing activities by firms can be introduced, such as investments that increase the probability that an ad turns into sale. Both the reach and effectiveness of information dissemination on industry dynamics can then be studied. The implications of limited consumer memory and bounded information processing capability on competition and firm dynamics can also be investigated in more detail. A limited consumer memory can encourage a firm to invest in helping consumers recall the firm, justifying expensive and repetitive ads by firms to become one of the few firms in consumer memory. The model can also be used at a broader level to the role of information costs in determining the responsiveness of prices and markups during expansions and recessions. 


\section{References}

[1] Acs, Zoltan, and Catherine Armington. 2001. "Gibrat's Law Reconsidered: The Relationship between Firm Growth, Establishment Age, Establishment Size and Firm Size", George Mason University Working Paper.

[2] Arkolakis, Konstantinos. 2008. "Market Penetration Costs and the New Consumers Margin in International Trade" NBER Working Paper No. 14214.

[3] Asplund, Marcus, and Volker Nocke. 2006. "Firm Turnover in Imperfectly Competitive Markets", Review of Economic Studies, 73(2): 295-327.

[4] Audretsch, David B., Luuk Klomp, Enrico Santarelli, and A. Roy Thurik. 2002. "Gibrat's Law: Are the services different?", EIM Policy and Business Research Report No. H200201. Zoetermeer, The Netherlands: EIM.

[5] Axtell, Robert. 2001. "Zipf Distribution of U.S. Firm Sizes", Science, 293(5536): 18181820.

[6] Axtell, Robert. 2006. "Firm Sizes: Facts, Formulae, Fables and Fantasies", Center on Social and Economic Dynamics Working Paper No.44.

[7] Bagwell, Kyle. 2007. "The Economic Analysis of Advertising", Chapter 28 in Handbook of Industrial Organization, Volume III, eds. Mark Armstrong and Robert Porter, Elsevier.

[8] Baye, Michael, Morgan, John and Patrick Scholten. 2004. "Price Dispersion in the Large and in the Small: Evidence from an Internet Price Comparison Site", Journal of Industrial Economics, 52(4), pp. 463-496.

[9] Baye, Michael and John Morgan. 2003. "Competition in Internet Industries: Evidence from E-retailing", Oxford Internet Institute Issue Brief, No 1.2, November 2003.

[10] Brown, Jeffrey R., and Austan Goolsbee. 2001. "Does the Internet Make Markets More Competitive? Evidence from the Life Insurance Industry", Journal of Political Economy, 110(3): 481-507. 
[11] Brynjolfsson, Erik, and Michael Smith. 2000. "Frictionless Commerce? A Comparison of Internet and Conventional Retailers", Management Science, 46(4): 563-585.

[12] Butters, Gerard. 1977. "Equilibrium Distributions of Sales and Advertising Prices", Review of Economic Studies, 44(3): 465-492.

[13] Cabral, Luis, and Jose Mata. 2003. "On the Evolution of Firm Size Distribution: Facts and Theory", American Economic Review, 93(4): 1075-1090.

[14] Campbell, John, Martin Lettau, Burton Malkiel and Yexiao Xu. 2001. "Have Individual Stocks Become More Volatile? An Empirical Exploration of Idiosyncratic Risk", Journal of Finance, 56(1): 1-43.

[15] Chandler, Alfred, and James Cortada. 2000. A Nation Transformed by Information: How Information has Shaped the United States from Colonial Times to the Present. Cambridge: Oxford University Press.

[16] Comin, Diego, and Thomas Philippon. 2005. "The Rise in Firm-Level Volatility: Causes and Consequences", NBER Macroeconomics Annual, Volume 20, eds M. Gertler and K. Rogoff.

[17] Cooley, Thomas F., and Vincenzo Quadrini. 2001. "Financial Markets and Firm Dynamics", American Economic Review, 91(5): 1286-1310.

[18] Cortada, James. 2002. Making the Information Society: Experiences, Consequences, and Possibilities. Prentice Hall.

[19] Davis, Steven, Haltiwanger, John, Jarmin, Ron and Javier Miranda. 2006. "Volatility and Dispersion in Business Growth Rates: Publicly Traded versus Privately Held Firms", NBER Macroeconomics Annual 2006, 2:107-156.

[20] Demsetz, Harold. 1973. "Industry Structure, Market Rivalry, and Public Policy", Journal of Law and Economics, 16(1): 1-9.

[21] Doraszelski, Ulrich, and Sarit Markovich. 2007. "Advertising Dynamics and Competitive Advantage", Rand Journal of Economics. 38(3): 557-592. 
[22] Dunne, Timothy, Mark Roberts, and Larry Samuelson. 1989. "The Growth and Failure of US Manufacturing Plants", Quarterly Journal of Economics, 104(4): 671-698.

[23] Eckard, Woodrow. 1988. "Advertising, Concentration Changes, and Consumer Welfare", Review of Economics and Statistics, 70(2): 340-343.

[24] Engle, Robert F. 1982. "Autoregressive Conditional Heteroskedasticity with Estimates of Variance of U.K. Inflation", Econometrica, 50: 987-1008.

[25] Ericson, Richard, and Ariel Pakes. 1995 "Markov-Perfect Industry Dynamics: A Framework for Empirical Work", Review of Economic Studies, 62(1): 53-82.

[26] Estevez, Luiz. 2007. "A Note on Gibrat's Law, Gibrat's Legacy and Firm Growth: Evidence from Brazilian Companies", Economics Bulletin, 12(9): 1-7.

[27] Evans, David S. 1987. "The Relationship between Firm Growth, Size, and Age: Estimates for 100 Manufacturing Industries", Journal of Industrial Economics, 35(4): $567-581$.

[28] Fan, Jianqing and Qiwei Yao. 1998. "Efficient Estimation of Conditional Variance Functions in Stochastic Regression", Biometrika, 85: 645-660.

[29] Fang, Irving. 1997. A History of Mass Communication, Newton: Focal Press.

[30] Farrell, Joseph and Carl Shapiro. 1988. "Dynamic Competition with Switching Costs", Rand Journal of Economics. 19(3): 123-137.

[31] Feldman, Mark, and Christian Gilles. 1985. "An Expository Note on Individual Risk without Aggregate Uncertainty", Journal of Economic Theory, 35(1): 26-32.

[32] Fishman, Arthur, and Rafael Rob. 2002. "Consumer Inertia, Firm Growth and Industry Dynamics", Journal of Economic Theory, 109(1): 24-38.

[33] Foster, Lucia, John, Haltiwanger, and Chad Syverson. 2008. "Reallocation, Firm Turnover, and Efficiency: Selection on Productivity or Profitability?", American Economic Review, 98(1): 394-425. 
[34] Frey, Christine, and John Cook. 2004. "How Amazon.com Survived, Thrived and Turned a Profit", Seattle Post-Intelligencer, January, 28.

[35] Hacia, Lechoslaw. 1995. "On Some Integral Inequalities and Their Applications", Journal of Mathematical Analysis and Applications, 206: 611-622.

[36] Hopenhayn, Hugo. 1992. "Entry, Exit, and Firm Dynamics in Long Run Equilibrium", Econometrica, 60(5): 1127-1150.

[37] Jovanovic, Boyan. 1982. "Selection and the Evolution of the Industry", Econometrica, 50(3): 649-670.

[38] Judd, Kenneth L. 1985. "The Law of Large Numbers with a Continuum of i.i.d. Random Variables", Journal of Economic Theory, 35(1): 19-25.

[39] Klemperer, Paul, and Alan Beggs. 1992. "Multi-period Competition with Switching Costs", 60(3): 651-666.

[40] Kolmogorov, A. N., and S. V. Fomin. 1970. Introductory Real Analysis. New York: Dover Publications.

[41] Lambin, J. J. 1976. Advertising, Competition, and Market Conduct in Oligopoly over Time. Amsterdam: North Holland.

[42] Lotti, Francesca, Enrico Santarelli and Marco Vivarelli. 2003. "Does Gibrat's Law hold in the case of young, small firms?", Journal of Evolutionary Economics, 13(3): 213-235.

[43] Luttmer, Erzo G. J. 2008. "On the Mechanics of Firm Growth", Working Paper, University of Minnesota, Department of Economics.

[44] Mueller, Willard and Richard Rogers. 1984. "Changing in Market Concentration of Manufacturing Industries", Review of Industrial Organization, 1: 1-14.

[45] Mueller, Willard and Richard Rogers. 1980. "The Role of Advertising in Changing Concentration of Manufacturing Industries", Review of Economic Studies, 62: 89-96. 
[46] Mata, Jose. 1994. "Firm Growth during Infancy", Small Business Economies, 6(1): $27-40$.

[47] Munkres, James. 1975. Topology: a first course. Prentice Hall.

[48] Palestrini, Antonio. 2007. "Analysis of Industrial Dynamics: A Note on the Relationship between Firms' Size and Growth Rate", Economics Letters, 94(3): 367-371.

[49] Smith, Michael and Erik Brynjolfsson. 2001. "Consumer Decision-Making at an Internet Shopbot: Brand Still Matters", Journal of Industrial Economics, 49(4): 541-558.

[50] Spletzer, James. 1998. Technical Report: Sales Data in the SSEL and the Economic Census. Bureau of Labor Statistics.

[51] Stegeman, Mark. 1991. "Advertising in Competitive Markets", American Economic Review, 81(1): 210-223.

[52] Stokey, Nancy and Robert E. Lucas. 1993. Recursive Methods in Economic Dynamics, Cambridge: Harvard University Press.

[53] Sutton, John. 1991. Sunk Costs and Market Structure. Cambridge: The MIT Press.

[54] Tirole, Jean. 1988. The Theory of Industrial Organization. Cambridge: MIT Press.

\section{A Proofs (Not for publication)}

For notational convenience, define $R^{*}=R^{*}(m) \equiv \beta \frac{\partial}{\partial m} \int V^{*}(m, c) h(c) d c$ as the derivative of the continuation value of a firm with respect to its size $m$ at the beginning of the next period. Given $A \subseteq \mathbb{R}^{n}(n \geq 1), B \subseteq \mathbb{R}$, and any two functions $f, g: A \rightarrow B, f \preceq g$ means $f(\mathbf{x}) \leq g(\mathbf{x})$ for all $\mathbf{x} \in A$. Similarly, $f \prec g$ means $f(\mathbf{x}) \leq g(\mathbf{x})$ for all $\mathbf{x} \in A$ and $f(\mathbf{x})<g(\mathbf{x})$ for some $\mathbf{x} \in A$. Whenever there is no ambiguity, the arguments of a function are suppressed.

Proof of Lemma 1. The demand $z_{t}$ is defined by (4), and the demand of a consumer who did not purchase from firm $\left(p, m^{o}\right)$ in period $t-1$ is

$$
\omega_{t}\left(p, m^{o}\right)=\sum_{i=0}^{\infty} \Omega_{t}(i) \widetilde{G}_{t}^{i}\left(W_{t}\left(p, m^{o}\right)\right)
$$


where $\Omega_{t}(i)$ is the measure of consumers informed of $i \geq 0$ firms in addition to firm $\left(p, m^{o}\right)$, and $\widetilde{G}_{t}^{i}$ is the probability that the consumer chooses firm $\left(p, m^{o}\right)$. Let $\delta_{t}<1$ denote the measure of consumers who purchased in period $t-1$ from a firm that exited at the beginning of period $t$. Let $\theta_{t}=\lambda+(1-\lambda) \delta_{t}<1$ be the sum of the mass of new consumers and the mass of surviving consumers whose firms exited at the beginning of period $t$. Label all of these consumers as 'unattached', since they have no information before they receive any ads. Label the rest of the consumers as 'attached', as they are informed of their most-recently-visited firms before they receive any ads. Then,

$$
\Omega_{t}(i)=\left\{\begin{array}{cc}
\theta_{t} \Psi_{t}(0) & \text { for } i=0 \\
\theta_{t} \Psi_{t}(i)+\left(1-\theta_{t}\right) \Psi_{t}(i-1) & \text { for } i>0
\end{array}\right.
$$

In (21), the term $\theta_{t} \Psi_{t}(0)$ gives the mass of unattached consumers who receive zero ads. The term for $i>0$ is the mass of unattached consumers who receive $i$ ads, plus the mass of attached consumers who receive $(i-1)$ ads. Next, let $\alpha_{t} \equiv \alpha_{t}\left(p, m^{o}\right)$ be the probability that a consumer prefers firm $\left(p, m^{o}\right)$ to the firm he purchased from in period $t-1$. Note that $G_{t}^{0}=\widetilde{G}_{t}^{0}=1$. For $i \geq 1,(21)$ implies

$$
\widetilde{G}_{t}^{i}=\left(\frac{\theta_{t} \Psi_{t}(i)}{\Omega_{t}(i)}\right) G_{t}^{i}+\left(\frac{\left(1-\theta_{t}\right) \Psi_{t}(i-1)}{\Omega_{t}(i)}\right) G_{t}^{i-1} \alpha_{t}
$$

where the first term in parentheses is the probability that a consumer is unattached and has $i$ new ads conditional on having information about $i$ other firms, and the second term in parentheses is the probability that a consumer is attached and has $i-1$ new ads conditional on having information about $i$ other firms. Using (20) and (22), one can then write

$$
\omega_{t}\left(p, m^{o}\right)=\theta_{t} \sum_{i=0}^{\infty} \Psi_{t}(i) G_{t}^{i}+\left(1-\theta_{t}\right) \sum_{i=1}^{\infty} \Psi_{t}(i-1) G_{t}^{i-1} \alpha_{t}=\left[\theta_{t}+\left(1-\theta_{t}\right) \alpha_{t}\right] z_{t}\left(p, m^{o}\right) .
$$

Because $\alpha_{t} \leq 1$ and $\theta_{t}<1$, it follows that $\omega_{t}\left(p, m^{o}\right) \leq z_{t}\left(p, m^{o}\right)$. Next, for $\alpha_{t}\left(p, m^{o}\right)<1$, using (23) and differentiating with respect to price and rearranging yields

$$
\varepsilon_{\omega_{t}}\left(p, m^{o}\right)=\frac{\left(1-\theta_{t}\right) \alpha_{t}\left(p, m^{o}\right)}{\left[\theta_{t}+\left(1-\theta_{t}\right) \alpha_{t}\left(p, m^{o}\right)\right]} \varepsilon_{\alpha_{t}}\left(p, m^{o}\right)+\varepsilon_{z_{t}}\left(p, m^{o}\right),
$$

which implies $\varepsilon_{\omega_{t}}\left(p, m^{o}\right)>\varepsilon_{z_{t}}\left(p, m^{o}\right)$ because $\varepsilon_{\alpha_{t}}\left(p, m^{o}\right)>0$ and $\left(1-\theta_{t}\right) \alpha_{t}\left(p, m^{o}\right)>0$. For $\alpha_{t}\left(p, m^{o}\right)=1, \varepsilon_{\omega_{t}}\left(p, m^{o}\right)=\varepsilon_{z_{t}}\left(p, m^{o}\right)$. Consequently, $\varepsilon_{\omega_{t}}\left(p, m^{o}\right) \geq \varepsilon_{z_{t}}\left(p, m^{o}\right)$.

Proof of Proposition 1. Part $(i)$. Using the definition (10), let $Q^{*}\left(p \mid m^{o}\right)$ denote the equilibrium probability that an ad contains a price of at least $p$, conditional on $m^{o}$. The 
cumulative distribution function, $1-Q^{*}\left(p \mid m^{o}\right)$, cannot have a mass point at any $p$ in its support, otherwise any firm charging $p$ could reduce its price slightly and steal a positive mass of consumers from other firms charging $p$, leading to a discrete increase in profit. Also, $1-Q^{*}\left(p \mid m^{o}\right)$ cannot be flat over some interval $\left[p_{1}, p_{2}\right]$, otherwise any firm charging $p_{1}$ could increase its price to $p_{2}$ without a reduction in its probability of sale. Thus, $1-Q^{*}\left(p \mid m^{o}\right)$ is differentiable and strictly increasing in $p$ over the interior of its support $\left[\underline{p}^{*}\left(m^{o}\right), \bar{p}^{*}\left(m^{o}\right)\right]$, where $\underline{p}^{*}\left(m^{o}\right)$ and $\bar{p}^{*}\left(m^{o}\right)$ are the minimum and maximum prices observed for firms with size $m^{o}$. Therefore, $\frac{\partial Q^{*}\left(p \mid m^{o}\right)}{\partial p}<0$. Let $z^{*}\left(p \mid m^{o}\right)=\sum_{i=0}^{\infty} \Psi^{*}(i)\left[Q^{*}\left(p \mid m^{o}\right)\right]^{i}$ be the demand function for a consumer conditional on $m^{o}$. It follows that $\frac{\partial z^{*}\left(p \mid m^{o}\right)}{\partial p}=\sum_{i=0}^{\infty} \Psi^{*}(i) i Q^{* i-1} \frac{\partial Q^{*}}{\partial p}<0$, which also implies $\frac{\partial z^{*}\left(p, m^{o}\right)}{\partial p}<0$. Similar arguments apply to $\omega^{*}\left(p, m^{o}\right)$.

Parts $(i i),(i i i)$ and $(i v)$. Note that $\frac{d V^{*}}{d c}=\frac{\partial V^{*}}{\partial c}=-m^{*}<0$, by the envelope theorem. Next, observe that

$$
\frac{\partial z^{*}}{\partial p}=\left(\sum_{i=0}^{\infty} \Psi^{*}(i) i G^{* i-1}\right) G^{* \prime} \frac{\partial W^{*}}{\partial p} .
$$

Because $\frac{\partial z^{*}}{\partial p}<0$ by Part (i) and $\left(\sum_{i=0}^{\infty} \Psi^{*}(i) i G^{* i-1}\right) G^{* \prime}>0$, it follows that $\frac{\partial W^{*}}{\partial p}<0$. Similar $\operatorname{arguments}$ establish $\frac{\partial \omega^{*}}{\partial p}<0$. Next, we argue that $z^{*}, V^{*}$, and $W^{*}$ must be strictly increasing in $m^{o}$. Differentiation of $z^{*}$ yields

$$
\frac{\partial z^{*}}{\partial m^{o}}=\left(\sum_{i=0}^{\infty} \Psi^{*}(i) i G^{* i-1}\right) G^{* \prime} \frac{\partial W^{*}}{\partial m^{o}} .
$$

Thus, $\frac{\partial z^{*}}{\partial m^{o}}$ and $\frac{\partial W^{*}}{\partial m^{o}}$ have the same sign. Similarly, $\frac{\partial \omega^{*}}{\partial m^{o}}$ and $\frac{\partial W^{*}}{\partial m^{o}}$ have the same sign, and therefore so do $\frac{\partial \omega^{*}}{\partial m^{o}}$ and $\frac{\partial z^{*}}{\partial m^{o}}$. Furthermore, by the envelope theorem,

$$
\frac{d V^{*}}{d m^{o}}=\frac{\partial V^{*}}{\partial m^{o}}=\frac{\partial m^{*}}{\partial m^{o}}\left(p^{*}-c+R^{*}\right)
$$

For (13) to hold, the term in parentheses in (26) must be positive. Consequently, $\frac{d V^{*}}{d m^{o}}$ and $\frac{\partial m^{*}}{\partial m^{o}}$ have the same sign. Next, note that

$$
\frac{\partial m^{*}}{\partial m^{o}}=(1-\lambda) z^{*}+\left(m^{o}(1-\lambda) \frac{\partial z^{*}}{\partial m^{o}}+a^{*} \frac{\partial \omega^{*}}{\partial m^{o}}\right) .
$$

To obtain a contradiction, suppose that $\frac{\partial z^{*}}{\partial m^{o}} \leq 0$ and $\frac{\partial \omega^{*}}{\partial m^{o}} \leq 0$. There are then two possibilities: $\frac{\partial m^{*}}{\partial m^{o}} \leq 0$ or $\frac{\partial m^{*}}{\partial m^{o}}>0$. If $\frac{\partial m^{*}}{\partial m^{o}} \leq 0,(26)$ implies $\frac{d V^{*}}{d m^{o}} \leq 0$. But then firm value is non-increasing in firm size, and a firm has no incentive to increase its size, because exit probability increases as firm 
size increases. Because the only way a firm can grow is to send ads, there is then no advertising. Therefore, $\frac{\partial z^{*}}{\partial m^{o}} \leq 0, \frac{\partial \omega^{*}}{\partial m^{o}} \leq 0$, and $\frac{\partial m^{*}}{\partial m^{o}} \leq 0$ cannot hold in an equilibrium with positive advertising.

If, on the other hand, $\frac{\partial m^{*}}{\partial m^{o}}>0$, then, by $(26), \frac{d V^{*}}{d m^{o}}>0$. Now, rewrite the consumer surplus in (1) in stationary equilibrium as

$$
\left.W^{*}\left(p, m^{o}\right)=U(p)+\beta(1-\lambda) \sum_{i=0}^{\infty} \Psi^{*}(i)\left\{\left(1-X^{*}\left(p, m^{o}\right)\right) W_{1}^{*}\left(p^{1}, m^{1}\right)+X^{*}\left(p, m^{o}\right) W_{2}^{*}\right]\right\},
$$

where $X^{*}$ is the probability of exit, $\left(p^{1}, m^{1}\right)$ denotes the next period price and size, and

$$
\begin{aligned}
W_{1}^{*}\left(p^{1}, m^{1}\right) & =\left\{\begin{array}{cc}
E\left[\int \max \left\{W, W^{*}\left(p^{1}, m^{1}\right)\right\} d G^{* i}(W)\right] & \text { if } i>0 \\
E\left[W\left(p^{\prime}, m^{\prime}\right)\right] & \text { if } i=0
\end{array},\right. \\
W_{2}^{*} & =\left\{\begin{array}{cc}
E\left[\int W d G^{* i}(W)\right] & \text { if } i>0 \\
W^{* \varnothing} & \text { if } i=0
\end{array} .\right.
\end{aligned}
$$

Then

$$
\frac{\partial W^{*}}{\partial m^{o}}=\beta(1-\lambda) \sum_{i=0}^{\infty} \Psi^{*}(i)\left(\frac{\partial X^{*}}{\partial m^{o}}\left(W_{2}^{*}-W_{1}^{*}\left(p^{1}, m^{1}\right)\right)+\left(1-X^{*}\right) \frac{\partial W_{1}^{*}}{\partial m^{1}}\right)
$$

and

$$
\frac{\partial W_{1}^{*}}{\partial m^{1}}=\beta(1-\lambda) \sum_{i=0}^{\infty} \Psi^{*}(i)\left(\frac{\partial X^{*}}{\partial m^{1}}\left(W_{2}^{*}-W_{1}^{*}\left(p^{2}, m^{2}\right)\right)+\left(1-X^{*}\right) \frac{\partial W_{1}^{*}}{\partial m^{2}}\right) \frac{\partial m^{1}}{\partial m^{o}}
$$

where $\left(p^{2}, m^{2}\right)$ is the two-period ahead price and size, and $m^{1}$ is the next period's demand. One can thus substitute $\frac{\partial W_{1}^{*}}{\partial m^{1}}$ in (27) using (28). Continuing with similar substitution for all future periods, one obtains

$$
\frac{\partial W^{*}}{\partial m^{o}}=\sum_{t=1}^{\infty} \beta^{t}(1-\lambda)^{t}\left(\prod_{j=1}^{t-1}\left(1-X^{*}\left(p^{t}, m^{t}\right)\right)\right) \frac{\partial X^{*}}{\partial m^{t}} \sum_{i=0}^{\infty} \Psi^{*}(i)\left(W_{2}^{*}-W_{1}^{*}\left(p^{t}, m^{t}\right)\right)\left(\prod_{j=1}^{t-1} \frac{\partial m^{j}}{\partial m^{j-1}}\right),
$$

where $\left(p^{t}, m^{t}\right)$ is the $t$ - period ahead price and size, and $m^{j}$ is the demand in period $j$. Because $\frac{d V^{*}}{d m^{\circ}}>0$ and exit probability declines with firm value, exit probability also declines with firm size, i.e. $\frac{\partial X^{*}}{\partial m^{t}}<0$ for all $t$. In addition, it was assumed that $\frac{\partial m^{j}}{\partial m^{j-1}}>0$. Furthermore, $W_{2}^{*}-$ $W_{1}^{*}\left(p^{1}, m^{1}\right)<0$, by the definitions of $W_{1}^{*}$ and $W_{2}^{*}$. Consequently, using (29), $\frac{\partial W^{*}}{\partial m^{o}}>0$. But since $\frac{\partial z^{*}}{\partial m^{o}} \leq 0,(25)$ implies $\frac{\partial W^{*}}{\partial m^{o}} \leq 0$, a contradiction. Therefore, $\frac{\partial z^{*}}{\partial m^{o}} \leq 0$ and $\frac{\partial \omega^{*}}{\partial m^{o}} \leq 0$ cannot hold. Thus, the only configuration consistent with positive advertising in equilibrium is $\frac{\partial z^{*}}{\partial m^{o}}>0$, $\frac{\partial \omega^{*}}{\partial m^{o}}>0, \frac{\partial V^{*}}{\partial m^{o}}>0$ and $\frac{\partial W^{*}}{\partial m^{o}}>0$. 
Proof of Proposition 2. Part $(i)$. Proposition 1(i) established that equilibrium entails a continuous (atomless) price distribution. The firm type that offers the least surplus to consumers cannot steal any consumers from other firms and thus must charge its monopoly price - a corner solution. For other firm types, optimal price must be an interior solution that satisfies (13). To see this claim, note that, by Proposition 1, the individual demand functions, $z^{*}\left(p, m^{o}\right)$ and $\omega^{*}\left(p, m^{o}\right)$, and hence a firm's residual demand $m^{*}\left(p, a ; m^{o}\right)$, are continuous in $p$, implying the continuity of the profit function and the value function in $p$. Furthermore, feasible prices for a firm type can be restricted to a compact set $\left[\underline{p}, p^{m}\right]$, where $p^{m} \geq s$ is the monopoly price for the corresponding firm type, and the lower bound $\underline{p}$ exists because as price declines $p-c+R^{*}$ becomes negative eventually by the fact that $R^{*}$ is bounded from above. Therefore, for firms that offer more than the lowest possible surplus, a value maximizing price lies in the set $\left(\underline{p}, p^{m}\right)$. Given the continuity of $m^{*}$ in $p$, lowering price entails a trade-off: a decline in profit per consumer (including captive consumers) versus an increase in profits due to a higher probability of sale to consumers who have ads from other firms. The first order condition (13) balances these two trade-offs. To see uniqueness, suppose that the value function for firm $\left(m^{o}, c\right)$ admits two or more countable interior global maximizers. Take any two such maximizers, $\left(p_{1}, a_{1}\right)$ and $\left(p_{2}, a_{2}\right)$, such that $p_{1} \neq p_{2}$. Since (13) holds at both $\left(p_{1}, a_{1}\right)$ and $\left(p_{2}, a_{2}\right)$, by the generalized intermediate value theorem (see, e.g. Munkres (1975) p. 154) there must exist a pair $\left(p^{\prime}, a^{\prime}\right)$ such that

$\left[m^{o}(1-\lambda) z^{*}\left(p^{\prime}, m^{o}\right)+a^{\prime} \omega^{*}\left(p^{\prime}, m^{o}\right)\right]+\left[m^{o}(1-\lambda) \frac{\partial z^{*}\left(p^{\prime}, m^{o}\right)}{\partial p}+a^{\prime} \frac{\partial \omega^{*}\left(p^{\prime}, m^{o}\right)}{\partial p}\right]\left(p^{\prime}-c+R^{*}\right)=0$.

Because the distribution of price and advertising pairs is continuous conditional on $m^{o}$, there must exist some firm $\left(m^{o}, c^{\prime}\right)$ with $c^{\prime} \neq c$ for which $\left(p^{\prime}, a^{\prime}\right)$ is optimal. For this firm, $\left(p^{\prime}, a^{\prime}\right)$ satisfies

$\left[m^{o}(1-\lambda) z^{*}\left(p^{\prime}, m^{o}\right)+a^{\prime} \omega^{*}\left(p^{\prime}, m^{o}\right)\right]+\left[m^{o}(1-\lambda) \frac{\partial z^{*}\left(p^{\prime}, m^{o}\right)}{\partial p}+a^{\prime} \frac{\partial \omega^{*}\left(p^{\prime}, m^{o}\right)}{\partial p}\right]\left(p^{\prime}-c^{\prime}+R^{*}\right)=0$.

But because $c \neq c^{\prime}$ and all other terms are identical in (30) and (31), the two equalities cannot hold simultaneously. Thus, there cannot be more than one discrete global interior maximizer. The remaining possibility is that there exists a continuum of maximizers for firm $\left(m^{o}, c\right)$ that form a connected set of $(p, a)$ pairs, and no other firm type has a value-maximizing pair within this set. Now consider the smallest and largest value-maximizing prices $p_{\min }$ and $p_{\max }$ charged by firm 
$\left(m^{o}, c\right)$. Because there is no other firm for which a price $p^{\prime} \in\left[p_{\min }, p_{\max }\right]$ is a value maximizer, firm $\left(m^{o}, c\right)$ can raise its price from $p_{\min }$ to $p_{\max }$ without a reduction in its residual demand, and thereby increase its value. This contradicts with $p_{\min }$ being part of the set of maximizers for firm $\left(m^{o}, c\right)$.

Taking the total derivative of (13) and (15) with respect to $c$, solving for $\frac{\partial p^{*}}{\partial c}$, and simplifying leads to

$$
\frac{\partial p^{*}}{\partial c}=-\frac{1}{\Delta}\left[\Phi^{\prime \prime}\left(m^{o}(1-\lambda) \frac{\partial z^{*}}{\partial p}+a^{*} \frac{\partial \omega^{*}}{\partial p}\right)+\left(\omega^{*}+\frac{\partial \omega^{*}}{\partial p}\left(p^{*}-c+R^{*}\right)\right)\right],
$$

where

$$
\begin{aligned}
\Delta= & \left(\omega^{*} \frac{d R^{*}}{d a}-\Phi^{\prime \prime}\right)\left[\left(m^{o}(1-\lambda) \frac{\partial z^{*}}{\partial p}+a^{*} \frac{\partial \omega^{*}}{\partial p}\right)\left(2+\frac{\partial R^{*}}{\partial p}\right)+\left(m^{o}(1-\lambda) \frac{\partial^{2} z^{*}}{\partial p^{2}}+a \frac{\partial^{2} \omega^{*}}{\partial p^{2}}\right)\left(p^{*}-c+R^{*}\right)\right] \\
& -\left(\frac{\partial \omega^{*}}{\partial p}\left(p^{*}-c+R^{*}\right)+\omega^{*}\left(1+\frac{\partial R^{*}}{\partial p}\right)\right)^{2}
\end{aligned}
$$

is the determinant of the Hessian of $V^{*}$. Note that $\Delta>0$ given the fact that the Hessian of $V^{*}$ is negative definite at the global maximizer $\left(p^{*}, a^{*}\right)$. Inside the square brackets in $(32)$, the first term is negative because $\Phi^{\prime \prime}>0$ (Assumption 1), $\frac{\partial z^{*}}{\partial p}<0$ and $\frac{\partial \omega^{*}}{\partial p}<0$ (Proposition 1). To sign the second term inside the square brackets, note that (5) and (13) together yield

$$
\omega^{*}+\frac{\partial \omega^{*}}{\partial p}\left(p^{*}-c+R^{*}\right)=\frac{\left(1-\theta^{*}\right) \frac{\partial \alpha^{*}}{\partial p} z^{*}\left(p^{*}-c+R^{*}\right)}{1+\left[\theta^{*}+\left(1-\theta^{*}\right) \alpha^{*}\right] \frac{a^{*}}{m^{o}(1-\lambda)}}<0,
$$

because $\frac{\partial \alpha^{*}}{\partial p}<0$ and all other terms in the ratio of the r.h.s. of (33) are positive. Consequently, the expression in square brackets in (32) is negative, implying $\frac{\partial p^{*}}{\partial c}>0$.

To sign $\frac{\partial p^{*}}{\partial m^{o}}$, suppose, to obtain a contradiction, that for two firm types with marginal cost $c$ and size $m_{2}^{o}>m_{1}^{o}$, it holds that $p^{*}\left(m_{2}^{o}, c\right) \leq p^{*}\left(m_{1}^{o}, c\right)$. Given the continuity of the pricing policy, one can find a firm type $\left(m_{3}^{o}, c\right)$ where $m_{3}^{o} \in\left[m_{1}^{o}, m_{2}^{o}\right]$ such that $p^{*}\left(m_{3}^{o}, c\right)=p^{*}\left(m_{2}^{o}, c\right)$ and $p^{*}\left(m^{o}, c\right)$ is non-increasing over the interval $\left(m_{3}^{o}-\varepsilon, m_{3}^{o}\right)$ for some $\varepsilon>0$. By Proposition 1(iv), $W^{*}\left(p^{*}\left(m_{3}^{o}, c\right), m_{3}^{o}\right)>W^{*}\left(p^{*}\left(m^{o}, c\right), m^{o}\right)$ for all $m^{o} \in\left[m_{3}^{o}-\varepsilon, m_{3}^{o}\right)$. Therefore, firm $\left(m_{3}^{o}, c\right)$ can raise its price slightly without a reduction in its probability of sale and increase its profit per consumer, a contradiction with $p^{*}\left(m_{3}^{o}, c\right)$ being a value maximizer for firm $\left(m_{3}^{o}, c\right)$.

Part $(i i)$. If consumer surplus does not depend on firm size through the exit probability, $W^{*}\left(p, m^{o}\right)$ reduces to a function, $W^{*}(p)$, of price only. At this point, we still allow the possibility that in equilibrium $W^{*}\left(p^{*}\right)$ depends on firm size through the optimal price $p^{*}$. By definitions (4) 
and (5), the demand functions $z^{*}\left(p, m^{o}\right)$ and $\omega^{*}\left(p, m^{o}\right)$ are also functions of price only: $z^{*}(p)$ and $\omega^{*}(p)$. Because a larger size now confers no additional surplus to any consumer, the demand functions for previous-period customers and the new customers acquired through ads must also be identical, i.e. $z^{*}(p)=\omega^{*}(p)$. Consequently, the first order condition (13) reduces to

$$
\left(m^{o}(1-\lambda)+a\right) z^{*}+\left(m^{o}(1-\lambda)+a\right) \frac{d z^{*}}{d p}\left(p-c+R^{*}\right)=0 .
$$

Dividing through by $m^{o}(1-\lambda)+a>0$ and rearranging terms, a firm's price can be written as

$$
p^{*}=\frac{\varepsilon_{z^{*}}(p)}{\varepsilon_{z^{*}}(p)-1}\left(c-R^{*}\right) .
$$

The price depends on the elasticity $\varepsilon_{z^{*}}(p)$ of the individual demand function $z^{*}(p)$, which is independent of firm size. Furthermore, $R^{*}$, which is the change in the continuation value of the firm due to a change in its size $m^{*}$ at the beginning of the next period, is also independent of current size $m^{o}$ in this case. Consequently, price is only a function of firm's marginal cost.

Proof of Proposition 3. The proof of Proposition 2(i) implies that a unique valuemaximizing $a^{*}\left(m^{o}, c\right)$ exists. Taking the total derivative of (13) and (15) with respect to $c$, solving for $\frac{\partial a^{*}}{\partial c}$ and simplifying yields

$$
\frac{\partial a^{*}}{\partial c}=-\frac{1}{\Delta}\left[\left(m^{o}(1-\lambda) \frac{\partial z^{*}}{\partial p}+a^{*} \frac{\partial \omega^{*}}{\partial p}\right)\left(\omega^{*}+\frac{\partial \omega^{*}}{\partial p}\left(p^{*}-c+R^{*}\right)\right)-\omega^{*} Y^{*}\right],
$$

where

$$
Y^{*}=2\left(m^{o}(1-\lambda) \frac{\partial z^{*}}{\partial p}+a^{*} \frac{\partial \omega^{*}}{\partial p}\right)+\left(m^{o}(1-\lambda) \frac{\partial^{2} z}{\partial p^{2}}+a^{*} \frac{\partial^{2} \omega^{*}}{\partial p^{2}}\right)\left(p^{*}-c+R^{*}\right) .
$$

To sign (34), note that $\Delta>0$, as before. Second, the first term inside the brackets in (34) is positive, following from (33) and that $\frac{\partial z^{*}}{\partial p}<0$ and $\frac{\partial \omega^{*}}{\partial p}<0$ (Proposition 1). Next, $\Delta>0$ and the properties of the Hessian of $V^{*}$ at $\left(p^{*}, a^{*}\right)$ imply

$$
Y^{*}<\frac{\left(\frac{\partial \omega^{*}}{\partial p}\left(p^{*}-c+R^{*}\right)+\omega^{*}\left(1+\frac{\partial R^{*}}{\partial p}\right)\right)^{2}}{\omega^{*} \frac{\partial R^{*}}{\partial a}-\Phi^{\prime \prime}}-\frac{1}{\Phi^{\prime \prime}} \omega^{* 2}\left(\frac{\partial R^{*}}{\partial p}\right)^{2}<0,
$$

where the sign follows because $\omega^{*} \frac{\partial R^{*}}{\partial a}-\Phi^{\prime \prime}<0$ (from $\Delta>0$ ) and $\Phi^{\prime \prime}>0$ (Assumption 1 ). As a result, the second term inside the brackets in (34) is negative. Consequently, the entire term inside the brackets in (34) is positive. Thus, (34) is negative. 
To see the monotonicity of $a^{*}$ in $m^{o}$, note that the return from marginal ad in current period is $\widetilde{\omega}_{t}^{*}\left(m^{o}, c\right)\left(p_{t}^{*}\left(m^{o}, c\right)-c_{t}\right)$ and its derivative with respect to $m^{o}$ is

$$
\frac{\partial \widetilde{\omega}_{t}^{*}}{\partial m^{o}}\left(p_{t}^{*}-c\right)+\widetilde{\omega}_{t}^{*} \frac{\partial p_{t}^{*}}{\partial m^{o}}>0
$$

where the sign follows because $\frac{\partial \widetilde{\omega}_{t}^{*}}{\partial m^{o}}>0$ and $\frac{\partial p_{t}^{*}}{\partial m^{o}}>0$ by Propositions 1 and 2 . The effect of the marginal ad on next period's variable profit (gross of advertising cost) is

$$
\beta \widetilde{\omega}_{t}^{*}\left[\left(1-X_{t+1}^{*}\right)\left(\frac{\partial m_{t+1}^{*}}{\partial m_{t}^{*}}\left(p_{t+1}^{*}-c_{t+1}\right)+m_{t+1}^{*} \frac{\partial p_{t+1}^{*}}{\partial m_{t}^{*}}\right)-\frac{\partial X_{t+1}^{*}}{\partial m_{t}^{*}} m_{t+1}^{*}\left(p_{t+1}^{*}-c_{t+1}\right)\right],
$$

and its derivative with respect to $m^{o}$ is

$$
\begin{aligned}
& \beta \frac{\partial \widetilde{\omega}_{t}^{*}}{\partial m^{o}}\left[\left(1-X_{t+1}^{*}\right)\left(\frac{\partial m_{t+1}^{*}}{\partial m_{t}^{*}}\left(p_{t+1}^{*}-c_{t+1}\right)+m_{t+1}^{*} \frac{\partial p_{t+1}^{*}}{\partial m_{t}^{*}}\right)-\frac{\partial X_{t+1}^{*}}{\partial m_{t}^{*}} m_{t+1}^{*}\left(p_{t+1}^{*}-c_{t+1}\right)\right] \\
& +\beta \widetilde{\omega}_{t}^{*} \frac{\partial m_{t}^{*}}{\partial m^{o}}\left[-\frac{\partial X_{t+1}^{*}}{\partial m_{t}^{*}}\left(\frac{\partial m_{t+1}^{*}}{\partial m_{t}^{*}}\left(p_{t+1}^{*}-c_{t+1}\right)+m_{t+1}^{*} \frac{\partial p_{t+1}^{*}}{\partial m_{t}^{*}}\right)+\left(1-X_{t+1}^{*}\right)\left(2 \frac{\partial m_{t+1}^{*}}{\partial m_{t}^{*}} \frac{\partial p_{t+1}^{*}}{\partial m_{t}^{*}}\right)\right] \\
& \quad-\beta \widetilde{\omega}_{t}^{*} \frac{\partial m_{t}^{*}}{\partial m^{o}} \frac{\partial X_{t+1}^{*}}{\partial m_{t}^{*}}\left(\frac{\partial m_{t+1}^{*}}{\partial m_{t}^{*}}\left(p_{t+1}^{*}-c_{t+1}\right)+m_{t+1}^{*} \frac{\partial p_{t+1}^{*}}{\partial m_{t}^{*}}\right) \\
& >0,
\end{aligned}
$$

where the sign follows because $\frac{\partial \widetilde{\omega}_{t}^{*}}{\partial m^{o}}>0, \frac{\partial m_{t+1}^{*}}{\partial m_{t}^{*}}>0, \frac{\partial p_{t+1}^{*}}{\partial m_{t}^{*}}>0$, and $\frac{\partial X_{t+1}^{*}}{\partial m_{t}^{*}}<0$ by Propositions 1 and 2. Similar, but tedious, calculations apply for all future periods, leading to a positive sign for each future period. Consequently, $\frac{\partial a^{*}}{\partial m^{o}}>0$.

Proof of Proposition 4. The properties of $m^{*}$ follow directly from its definition and the properties of $a^{*}$ and $z^{*}$. Since both $m^{*}$ and $p^{*}$ are strictly increasing in $m^{o}$, so is $r^{*}$. To see the monotonicity of $r^{*}$ in $c$, note that

$$
\frac{\partial r^{*}}{\partial c}=\frac{\partial a^{*}}{\partial c} \omega^{*} p^{*}+\left[\left((1-\lambda) m^{o} \frac{\partial z^{*}}{\partial p}+a^{*} \frac{\partial \omega^{*}}{\partial p}\right) p^{*}+\left((1-\lambda) m^{o} z^{*}+a^{*} \omega^{*}\right)\right] \frac{\partial p^{*}}{\partial c}
$$

Rearranging the first order condition (13), and then substituting it in (36), we obtain

$$
\begin{aligned}
\frac{\partial r^{*}}{\partial c} & =\frac{\partial a^{*}}{\partial c} \omega^{*} p^{*}+\left((1-\lambda) m^{o} \frac{\partial z^{*}}{\partial p}+a^{*} \frac{\partial \omega^{*}}{\partial p}\right)\left(c-R^{*}\right) \frac{\partial p^{*}}{\partial c} \\
& <\frac{\partial a^{*}}{\partial c} \omega^{*} p^{*}+\left((1-\lambda) m^{o} \frac{\partial z^{*}}{\partial p}+a^{*} \frac{\partial \omega^{*}}{\partial p}\right) p^{*} \frac{\partial p^{*}}{\partial c}<0
\end{aligned}
$$

where the first inequality follows because $p^{*}-c+R^{*}>0$, and the second inequality from the fact that $\frac{\partial a^{*}}{\partial c}<0, \frac{\partial z^{*}}{\partial p}<0, \frac{\partial \omega^{*}}{\partial p}<0$, and $\frac{\partial p^{*}}{\partial c}>0$. 
Theorem 1. Given the values of the parameters of the model except $\kappa$, there is some $\kappa^{\prime}>0$ such that there exists a unique stationary equilibrium with a positive advertising and positive entry and exit, i.e. $M^{*}>0$ and $x^{*}(c)>0$ for some $c \in[\underline{c}, \infty)$, as long as $\kappa<\kappa^{\prime}$.

Proof of Theorem 1. Given any equilibrium measure of firms $\mu^{*}$, the exit threshold $c^{*}\left(m^{o}\right)$ is uniquely defined for any $m^{o} \geq 0$ by Proposition 1 . Since $V^{*} \equiv 0$ for $c \geq c^{*}\left(m^{o}\right)$, we can write for any $m^{o}$

$$
\int_{c^{*}\left(m^{o}\right)}^{\infty} V^{*}\left(m^{o}, c\right) h(c) d c=0 .
$$

For positive entry in equilibrium, the free entry condition must hold with equality

$$
\int_{\underline{c}}^{\infty} V^{*}(0, c) h(c) d c=\kappa .
$$

$S=\left\{\left(m^{\prime}, c^{\prime}\right): m^{\prime}=m^{*}\left(m^{o}, c\right), c^{\prime} \leq c^{*}\left(m^{\prime}\right)\right\}$ be the set of firm of types reachable from firm type $\left(m^{o}, c\right)$, conditional on staying in the industry. Define the operator $L_{c^{*}}$ as

$$
L_{c^{*}}\left(m^{o}, c ; S\right)=\left\{\begin{array}{c}
\int_{S} h\left(c^{\prime}\right) d c^{\prime}, \text { if } c \leq c^{*}\left(m^{o}\right) \\
0, \text { otherwise }
\end{array}\right.
$$

with norm $\left\|L_{c^{*}}\right\|<1$. Then, invariance of $\mu^{*}$ in stationary equilibrium requires

$$
\mu^{*}=L_{c^{*}} \mu^{*}+M^{*} H
$$

where $L_{c^{*}} \mu^{*}(S)=\int L_{c^{*}}\left(m^{o}, c ; S\right) d \mu^{*}$. A stationary equilibrium with positive entry and exit is then given by a triplet $\left(c^{*}(\cdot), M^{*}, \mu^{*}\right)$ that satisfies equations (37)-(39) simultaneously.

Next, consider the advertising equilibrium corresponding to a measure $\mu$, an entry mass $M$, and an exit rule $c(\cdot)$. Let $E=\{\mu, M, c(\cdot)\}$. Let $\mathcal{A}$ denote the space of continuous, bounded functions defined over firm types under $E$, i.e. $a(E) \equiv a(\cdot, \cdot ; E):[\underline{m}, \bar{m}] \times[\underline{c}, \infty) \rightarrow \mathbb{R}^{+}$, where $\underline{m} \geq 0$ and $\bar{m}<\infty$ are the minimum and maximum firm sizes under $E$. Endow $\mathcal{A}$ with the sup-norm. Define $T: \mathcal{A} \rightarrow \mathcal{A}$ as the operator that matches any $a \in \mathcal{A}$ to some $T(a) \in \mathcal{A}$ that results from the firms' optimal choices of advertising given the distribution of consumer surplus $G(W)$ generated by the function $a$ under $E$. We will first show that, corresponding to any $E$, there exists a unique advertising equilibrium such that the advertising policy $a(E)$ adopted by firms under $E$ generates 
a distribution of consumer surplus across ads that renders the same advertising policy $a(E)$ optimal for $E$. We will then show the existence and uniqueness of a triplet $E^{*}=\left\{\mu^{*}, M^{*}, c^{*}(\cdot)\right\}$ that satisfies (37)-(39). The following lemmas accomplish these tasks.

Lemma 2. Given any $E, T$ has a unique fixed point $a(E)$, i.e. $T(a(E))=a(E)$.

Lemma 3. For any configuration of the model's parameters except $\kappa$, there exists some $\kappa^{\prime}>0$ such that, given any $\kappa<\kappa^{\prime}$, there is a unique $E^{*}=\left\{\mu^{*}, M^{*}, c^{*}(\cdot)\right\}$ which satisfies (37)-(39).

Proof of Lemma 2. Given $E$ and any $a \in \mathcal{A}$, consider the cumulative advertising $A\left(m^{o}, c ; E\right)$ made by firms that offer at least as much surplus as firm $\left(m^{o}, c\right)$. In other words,

$$
A\left(m^{o}, c ; E\right)=\int_{\underline{m}}^{\bar{m}} \int_{\underline{c}}^{c(x)} \Gamma(x, y, A(x, y ; E)) d \mu(x, y) .
$$

where $c(x)$ is the maximum marginal cost level corresponding to size $x$ that guarantees as much surplus as firm $\left(m^{o}, c\right)$ provides. Note that $A\left(m^{o}, c ; E\right)$ is continuous in its arguments. Using (15), the integrand $\Gamma$ is defined as

$$
\begin{aligned}
\Gamma(x, y, A(x, y ; E)) & =a(x, y ; E) \\
& =\Phi^{\prime-1}\left(\omega(p(x, y), x ; A)\left[(p(x, y ; A)-y)+\beta \int \frac{\partial V\left(m, c^{\prime} ; A\right)}{\partial m} h\left(c^{\prime}\right) d c^{\prime}\right]\right) \\
& =\Phi^{\prime-1}(\Lambda(x, y, A(x, y ; E)) .
\end{aligned}
$$

The dependence of the functions $z, p$, and $V$ on $A(x, y ; E)$ is made explicit. Equation (40) is a Volterra-Fredholm type integral equation. We will show that (40) has a unique fixed point, $A(E)$. Note that for any $A_{1}(x, y ; E)$ and $A_{2}(x, y ; E)$, an application of Mean Value Theorem implies

$$
\left\|\Gamma\left(x, y, A_{1}(x, y ; E)\right)-\Gamma\left(x, y, A_{2}(x, y ; E)\right)\right\| \leq\|D(x, y)\|\left\|A_{1}(x, y ; E)-A_{2}(x, y ; E)\right\|,
$$

where $\|\cdot\|$ denotes the sup-norm, and

$$
D(x, y)=\frac{1}{\Phi^{\prime \prime}(\Lambda(x, y, A(x, y))} \frac{\partial \Lambda(x, y, A(x, y))}{\partial A(x, y)} .
$$

$\Gamma$ is bounded and continuous in its arguments, because $\Phi^{\prime-1}$ and $\Lambda$ are both continuous. $\|D(x, y ; A)\|$ is also bounded, continuous, and integrable over $[\underline{m}, \bar{m}] \times[\underline{c}, c(x)]$. Moreover the function $A(x, y ; E)$ is bounded because $a(x, y ; E)<\infty$ for all $(x, y)$. Therefore, the conditions for the existence and uniqueness of a solution to the integral equation (40) are satisfied (See, e.g., Proposition 2 in Hacia 
(1997)). As a result, there exists a unique, continuous $A(E) \equiv A\left(m^{o}, c ; E\right)$ that satisfies (40). Consequently, the advertising function $a(E) \equiv a\left(m^{o}, c ; E\right)$ associated with $A(E)$ exists and it is unique. In other words, the operator $T(a)$ has a unique fixed point $a(E)$.

Proof of Lemma 2. Given the existence and uniqueness of an advertising equilibrium corresponding to any $E$, we now focus on the existence and uniqueness of a triplet $E$ satisfying equations (37)-(39). We build on the basic arguments in Hopenhayn (1992). Assumptions A3, A4 and A5 in Hopenhayn (1992) apply here with little modification: A3(a) is satisfied because $H$ is continuous in current period's cost shock, and $H$ is invariant to previous period's shock, implying continuity. A3(b) is replaced with an invariant i.i.d. process here, but the fact that current cost shock affects end-of-period firm size implies that firm's future value depends on the current cost shock, allowing the exit threshold to be defined as $c^{*}\left(m^{o}\right)$, as described in the text. A4 is also satisfied trivially because in any period the probability, $1-H(c)$, of observing a cost shock greater than $c$ is positive for any $c$. Finally, A5 is satisfied because the distribution of entrants' cost shocks, $H$, is continuous.

Existence: Let $\mathcal{D}$ be the set of continuous, bounded, non-decreasing functions defined as $c(\cdot)$ $: \mathbb{R}^{+} \rightarrow[\underline{c}, \infty)$. First, we show that, for any $c(\cdot) \in \mathcal{D}$, and $M>0$ an invariant measure $\mu(c(\cdot), M)$ exists, i.e. for some $\mu$

$$
\mu(c(\cdot), M)=L_{c} \mu(c(\cdot), M)+M H .
$$

Equivalently, $\mu$ satisfies

$$
\mu(c(\cdot), M)=M\left(\mathcal{I}-L_{c}\right)^{-1} H,
$$

where $I$ is the identity operator and $\left(I-L_{c}\right)^{-1}$ is the inverse operator for $I-L_{c}$. Following steps in Lemma 4 of Hopenhayn (1992), let $L_{c}^{n}$ be the composition of $L_{c} n$ times with itself and $L_{c}^{0}=I$. The assumption that $H(c)<0$ for all $c \in[\underline{c}, \infty)$ implies that the norm $\left\|L_{c}^{n}\right\|<1$, so $\left(I-L_{c}^{n}\right)^{-1}=$ $\sum_{t=0}^{\infty} L_{c}^{n t}$ following from Kolmogorov and Fomin (1970, Chapter 6, Section 23, Theorem 4, p. 231). The existence of $\left(I-L_{c}\right)^{-1}$ then follows because $\left\|L_{c}^{n}\right\|$ is non-increasing in $n$. Thus, $\mu(c(\cdot), M)$ satisfies invariance.

Next, we will say that the invariant measure $\mu(c(\cdot), M)$ is continuous on $\mathcal{D}$ if for all $c(\cdot) \in \mathcal{D}$ and for every sequence $c_{n}(\cdot) \rightarrow c(\cdot)$, we have $\mu\left(c_{n}(\cdot), M\right) \rightarrow \mu(c(\cdot), M)$. Continuity with respect to $M$ is defined similarly, but simply on $\mathbb{R}^{+}$. Using arguments similar to Lemma 5 in Hopenhayn (1992), it can be shown that the invariant measure $\mu(c(\cdot), M)$ is jointly continuous, strictly increasing in $M$, 
and non-increasing in $c(\cdot)$, i.e. for two exit schedules $c_{1}(\cdot), c_{2}(\cdot) \in \mathcal{D}$ such that $c_{2}\left(m^{o}\right) \succ c_{1}\left(m^{o}\right)$, we have $\mu\left(c_{2}(\cdot), M\right) \leq \mu\left(c_{1}(\cdot), M\right)$ in the sense that $\int_{c} u\left(m^{o}, c\right) d \mu_{2}\left(m^{o}, \cdot\right) \leq \int_{c} u\left(m^{o}, c\right) d \mu_{1}\left(m^{o}, \cdot\right)$ for any non-decreasing function $u$ and for any given $m^{o}$.

For any exit rule $c(\cdot)$, define the entry mass $M^{e}(c(\cdot))$ implicitly as

$$
V^{e}\left(\mu\left(c(\cdot), M^{e}\right)\right)=\int_{\underline{c}}^{\infty} V\left(0, c ; \mu\left(c(\cdot), M^{e}\right)\right) h(c) d c=\kappa .
$$

In other words, for the invariant measure $\mu, M^{e}(c(\cdot))$ is the mass of entrants that are needed for the expected discounted profit for entrants, $V^{e}$, to equal the cost of entry under the exit rule $c(\cdot)$. Also, define $M^{x}(c(\cdot))$ as the mass of entrants such that the for the invariant measure $\mu$, the exit rule $c(\cdot)$ is optimal, i.e. for all $m^{o} \geq 0$

$$
\int_{c\left(m^{o}\right)}^{\infty} V\left(m^{o}, c ; \mu\left(c(\cdot), M^{x}\right)\right) h(c) d c=0 .
$$

A stationary equilibrium with positive entry and exit exists if and only if there is a function $c^{*}(\cdot)$ such that $M^{e}\left(c^{*}(\cdot)\right)=M^{x}\left(c^{*}(\cdot)\right)$. This amounts to showing that the functions $M^{e}$ and $M^{x}$ intersect at least once.

It can be shown, analogous to Lemma 6 in Hopenhayn (1992), that the function $M^{x}: \mathcal{D} \rightarrow \mathbb{R}^{+}$ is well-defined, continuous and strictly increasing, i.e. for any two functions $c_{1}(\cdot), c_{2}(\cdot) \in \mathcal{D}$ such that $c_{2}(\cdot) \succ c_{1}(\cdot)$, we have $M^{x}\left(c_{2}(\cdot)\right)>M^{x}\left(c_{1}(\cdot)\right)$. In particular, let $Z\left(m^{o}, c ; c(\cdot), M\right)=$ $\int_{c\left(m^{o}\right)}^{\infty} V\left(m^{o}, c ; \mu(c(\cdot), M)\right) h(c) d c$. It can be shown that $Z$ is strictly increasing in $m^{o}$, strictly decreasing in $c$, non-decreasing in $c(\cdot)$ and strictly decreasing in $M$. Note that as $M \rightarrow \infty$, $Z\left(m^{o}, c ; c(\cdot), M\right) \rightarrow-\beta f$, because $\Pi\left(m^{o}, c\right) \rightarrow-f$. Furthermore, as $M \rightarrow 0, \mu(c(\cdot), M) \rightarrow 0$. Then, by Assumption 1(iii) for small $M>0, \Pi(0, c(0))>0$ for all $c(\cdot)$. Therefore, $Z\left(m^{o}, c ; c(\cdot), M\right)>$ 0 for $M$ small. Thus, for all $\left(m^{o}, c\right)$, there exists a unique $M$ such that $Z\left(m^{o}, c ; c(\cdot), M\right)=0$. Therefore, $M^{x}$ is the unique value such that $Z\left(m^{o}, c\left(m^{o}\right) ; \mu\left(c(\cdot), M^{x}\right)\right)=0$ for all $m^{o} \geq 0$. Continuity of $M^{x}$ follows from the continuity of $Z$, and because $Z\left(m^{o}, c\left(m^{o}\right) ; \mu(c(\cdot), M)\right)$ is strictly decreasing in $M, M^{x}$ is strictly increasing in $c(\cdot)$.

Similarly, following Lemma 7 in Hopenhayn (1992), it can be shown that $M^{e}$ is continuous and non-increasing on $\mathcal{D}$ as long as $V^{e}(0)>\kappa$. As $M \rightarrow \infty, V^{e}\left(\mu\left(c(\cdot), M^{e}\right)\right) \rightarrow 0$ and as $M \rightarrow 0$, $V^{e}(0)>\kappa$. Because $V^{e}(\mu(c(\cdot), M))$ is continuous and strictly decreasing in $M$, there exists $M^{e}$ such that $V^{e}\left(\mu\left(c(\cdot), M^{e}\right)\right)=\kappa . M^{e}$ is continuous because it is the minimizer of a continuous 
function $\left|V^{e}(\mu(c(\cdot), M))-\kappa\right| . M^{e}$ is also non-increasing because $\mu(c(\cdot), M)$ is non-increasing in $c(\cdot)$.

Now note that for any $m^{o}>0, V\left(m^{o}, c ; \mu(c(\cdot), M)\right)>V(0, c ; \mu(c(\cdot), M))$ for $c>c^{*}\left(m^{o}\right)$ because $V$ is strictly increasing in $m^{o}$. The fact that $V\left(m^{o}, c ; \mu(c(\cdot), M)\right)$ has a maximum at $\underline{c}$ then implies that $M^{x}(c(\cdot))>M^{e}(c(\cdot))$ for $c(\cdot) \equiv \underline{c}$. This implies that either there exists some function $c^{*}(\cdot)$ such that $M^{x}\left(c^{*}(\cdot)\right)<M^{e}\left(c^{*}(\cdot)\right)$, or $M^{x}(c(\cdot))>M^{e}(c(\cdot))$ for all $c(\cdot) \in \mathcal{D}$. In the former case, there exists an equilibrium where $M^{x}\left(c^{*}(\cdot)\right)=M^{e}\left(c^{*}(\cdot)\right)>0$ for some $c^{*}(\cdot) \in$ $\mathcal{D}$, and in the latter there exists a stationary equilibrium with no entry and exit, i.e. for some $\bar{c}<\infty$, the exit rule $c^{*}(\cdot) \equiv \bar{c}$, we have $M^{x}\left(c^{*}(\cdot)\right)=M^{e}\left(c^{*}(\cdot)\right)=0$. Overall, then, there exists a stationary equilibrium.

For positive entry and exit in equilibrium, entry must be relatively easy. If the entry cost satisfies $\kappa<\kappa^{*}=V^{e}\left(\mu^{*}\right)$ for some $\kappa^{*}>0$, then there exists some $c^{*}(\cdot) \in \mathcal{D}$ such that $M^{x}\left(c^{*}(\cdot)\right)<$ $M^{e}\left(c^{*}(\cdot)\right)$. Unless the advertising cost and fixed cost is very high, potential entrants have positive expected profit, i.e. $V^{e}\left(\mu^{*}\right)>0$, so that $\kappa^{*}>0$. Therefore, an equilibrium with positive entry and exit exists.

Uniqueness: Suppose that there are two exit schedules $c_{1}^{*}(\cdot)$ and $c_{2}^{*}(\cdot)$ such that the corresponding measures $\mu_{1}^{*}$ and $\mu_{2}^{*}$ constitute stationary equilibria with positive entry and exit. Assume, without loss of generality, that $c_{1}^{*}(0)>c_{2}^{*}(0)$, that is, to survive the marginal entrant needs to be more efficient in economy 2 than in economy 1 . Then, we must have $V_{2}^{*}\left(0, c_{1}^{*}(0)\right)<V_{2}^{*}\left(0, c_{2}^{*}(0)\right)=$ 0 and $V_{1}^{*}\left(0, c_{1}^{*}(0)\right)=0$. Thus, there must exist some firm type $(0, c)$ such that $V_{2}^{*}(0, c)<V_{1}^{*}(0, c)$. But free entry then implies $V^{e}\left(\mu_{1}^{*}\right)=V^{e}\left(\mu_{2}^{*}\right)=\kappa$. Therefore, firm value cannot be lower for all entrant types under $\mu_{2}^{*}$ compared to $\mu_{1}^{*}$, and must increase for some. In other words, if the values of all entrant types move in the same direction in response to a change in the measure of firms, the free entry condition is violated under $\mu_{2}^{*}$ and the two equilibria cannot coexist. We will show that this is the case. Assume, without loss of generality, that when the equilibrium measure of firms $\mu_{1}^{*}$ changes to $\mu_{2}^{*}$, the profit of the most efficient entrant decreases, i.e. $V_{2}^{*}(0, \underline{c})<V_{1}^{*}(0, \underline{c})$. If the profits of all entrants with marginal cost higher than $\underline{c}$ also decrease, then the equilibrium is unique. Take any cost level $c^{\prime} \in\left(\underline{c}, \min \left\{c_{1}^{*}(0), c_{2}^{*}(0)\right\}\right]$. Consider the set of firm types that provide a consumer at least as much surplus as firm $(0, c)$ under measure $\mu_{i}, i=1,2$

$$
B_{i}(0, c)=\left\{(x, y): W^{*}(x, y) \geq W^{*}(0, c)\right\}
$$


Since $V_{2}^{*}(0, \underline{c})<V_{1}^{*}(0, \underline{c})$, we must have $\mu_{2}\left(B_{2}(0, \underline{c})\right)>\mu_{1}\left(B_{1}(0, \underline{c})\right)$ because profit is strictly decreasing in the measure of firms that offer more consumer surplus than the firm. This implies $M_{2}^{*}>M_{1}^{*}$, i.e. entry mass must be higher for $\mu_{2}^{*}$. But since $\mu^{*}$ is strictly increasing in $M$, we have $\mu_{2}\left(B_{2}\left(0, c^{\prime}\right)\right)>\mu_{1}\left(B_{1}\left(0, c^{\prime}\right)\right)$, and therefore $V_{2}^{*}\left(0, c^{\prime}\right)<V_{1}^{*}\left(0, c^{\prime}\right)$ for all $c^{\prime} \in$ $\left(\underline{c}, \min \left\{c_{1}^{*}(0), c_{2}^{*}(0)\right\}\right]$. Thus, we have $V^{e}\left(\mu_{2}^{*}\right)<V^{e}\left(\mu_{1}^{*}\right)=\kappa$ and the free entry condition is violated under $\mu_{2}^{*}$, implying uniqueness. This completes the proof of Lemma 3 and Theorem 1.

Proof of Proposition 5. Part $(i)$ Let $F_{T}^{*}$ and $f_{T}^{*}$ denote, respectively, the cumulative distribution function and the density of firm size for firms of age $T \geq 1$. We will show that $F_{T}^{*}(m)<F_{T-1}^{*}(m)$ for all $m>0$. Let $c^{*}\left(m, m^{o}\right) \in[\underline{c}, \infty)$ be the largest cost shock that renders at least size $m$ at the end of the period, starting from a previous period firm size of $m^{o}$. Note that $c^{*}\left(m, m^{o}\right)$ is decreasing in its first argument and increasing in its second argument. To see this, note that $c^{*}\left(m, m^{o}\right)$ is implicitly defined by the law of motion (11) as

$$
m^{o}(1-\lambda) \widetilde{z}^{*}\left(m^{o}, c^{*}\left(m, m^{o}\right)\right)+a^{*}\left(m^{o}, c^{*}\left(m, m^{o}\right)\right) \widetilde{\omega}^{*}\left(m^{o}, c^{*}\left(m, m^{o}\right)\right)=m .
$$

Total differentiation with respect to $m^{o}$ and $m$ gives

$$
\begin{aligned}
& \frac{\partial c^{*}\left(m, m^{o}\right)}{\partial m^{o}}=-\frac{(1-\lambda)+\frac{\partial a^{*}}{\partial m^{o}}+m^{o}(1-\lambda) \frac{\partial \widetilde{z}^{*}}{\partial m^{o}}+a^{*} \frac{\partial \widetilde{\omega}^{*}}{\partial m^{o}}}{\frac{\partial a^{*}}{\partial c} \widetilde{z}^{*}+m^{o}(1-\lambda) \frac{\partial \widetilde{z}^{*}}{\partial c}+a^{*} \frac{\partial \widetilde{\omega}^{*}}{\partial c}}>0, \\
& \frac{\partial c^{*}\left(m, m^{o}\right)}{\partial m}=\left(\frac{\partial a^{*}}{\partial c} \widetilde{z}^{*}+m^{o}(1-\lambda) \frac{\partial \widetilde{z}^{*}}{\partial c}+a^{*} \frac{\partial \widetilde{\omega}^{*}}{\partial c}\right)^{-1}<0,
\end{aligned}
$$

where the inequalities follow from the signs of the individual terms established in earlier propositions. The conditional probability that the current period size is at most $m$ can then be written as

$$
P^{*}\left(m \mid m^{o}\right)=\left\{\begin{array}{cc}
0 & \text { if } c^{*}\left(m, m^{o}\right)<\underline{c}, \\
1-H\left(c^{*}\left(m, m^{o}\right)\right) & \text { if } c^{*}\left(m, m^{o}\right) \in\left[\underline{c}, c^{*}\left(m^{o}\right)\right) .
\end{array}\right.
$$

Therefore, for age 1

$$
F_{1}^{*}(m)=1-H\left(c^{*}(m, 0)\right)
$$

because new firms start with no customers. For age 2,

$$
F_{2}^{*}(m)=\int_{\underline{m}_{1}^{*}}^{\bar{m}_{1}^{*}}\left[1-H\left(c^{*}\left(m, m^{o}\right)\right)\right] f_{1}^{*}\left(m^{o}\right) d m^{o}=1-\int_{\underline{m}_{1}^{*}}^{\bar{m}_{1}^{*}} H\left(c^{*}\left(m, m^{o}\right)\right) f_{1}^{*}\left(m^{o}\right) d m^{o},
$$


where $\underline{m}_{1}^{*}$ and $\bar{m}_{1}^{*}$ are the minimum and maximum firm sizes at age 1 . But note that

$$
\int_{\underline{m}_{1}^{*}}^{\bar{m}_{1}^{*}} H\left(c^{*}\left(m, m^{o}\right)\right) f_{1}^{*}\left(m^{o}\right) d m^{o}>H\left(c^{*}(m, 0)\right),
$$

because $H\left(c^{*}\left(m, m^{o}\right)\right)>H\left(c^{*}(m, 0)\right)$ for all $m^{o}>0$, as $c^{*}\left(m, m^{o}\right)$ is strictly increasing in $m^{o}$. Thus, $F_{2}^{*}(m)<F_{1}^{*}(m)$ for all $m \in\left[0, \bar{m}_{2}^{*}\right]$. For any $T \geq 3$, one can write

$$
\begin{gathered}
F_{T-1}^{*}(m)=1-\int_{\underline{m}_{T-2}^{*}}^{\bar{m}_{T-2}^{*}} H\left(c^{*}\left(m, m^{o}\right)\right) f_{T-2}^{*}\left(m^{o}\right) d m^{o}, \\
F_{T}^{*}(m)=1-\int_{\underline{m}_{T-1}^{*}}^{\bar{m}_{T-1}^{*}} H\left(c^{*}\left(m, m^{o}\right)\right) f_{T-1}^{*}\left(m^{o}\right) d m^{o} .
\end{gathered}
$$

Now suppose that $F_{T-2}^{*}(m)<F_{T-1}^{*}(m)$. Then, (41) and (42) together imply $F_{T}^{*}(m)<F_{T-1}^{*}(m)$. Therefore, by induction it must hold that $F_{T}^{*}(m)<F_{T-1}^{*}(m)$ for any arbitrary $T$.

Part (ii) Follows from part $(i)$.

Part (iii) Follows from part $(i)$ and Proposition 1.

\section{B Simulation algorithm (Not for publication)}

This appendix outlines the simulation algorithm used to generate the comparative statics results. The baseline advertising technology, $\Phi(a)=\chi a^{\varphi}$, generates positive advertising for any $\varphi>1$. To see this claim, note that Assumption 1(iii) is satisfied because $\lim _{a \rightarrow 0} \Phi^{\prime}(a)=\Phi^{\prime}(0)=$ $\chi \varphi a^{\varphi-1}=0$ for $\varphi>1$. Therefore, the marginal cost of advertising at $a=0$, represented by the second term in the l.h.s. of (15), is zero. What remains to be shown is that the marginal return to advertising represented by the first term in the l.h.s. of (15) is positive, and thus exceeds the marginal cost at $a=0$. A feasible, but not necessarily optimal, action available to any firm is to charge monopoly price and sell, at least, to its captive consumers. This action yields positive revenue per ad for a firm, because, as long as advertising is not free, there is always a positive mass of consumers whose only ad is the ad they received from the firm. Formally, the revenue per ad for a type $\left(m^{o}, c\right)$ firm when it charges its monopoly price $p^{m}\left(m^{o}, c\right) \geq s$ is

$$
\omega^{*}\left(p^{m}, m^{o}\right)\left(p^{m}-c+R^{*}\right) \geq \Omega^{*}(0)\left(p^{m}-c+R^{*}\right)>\Omega^{*}(0)\left(p^{m}-c\right)>\Omega^{*}(0)(s-c),
$$

where the first inequality follows from the fact that $\omega^{*}\left(p^{m}, m^{o}\right) \geq \Omega^{*}(0)$, the second from $R^{*} \geq 0$, and the third from $p^{m} \geq s$. Because $\Omega^{*}(0)>0$, the last term, $\Omega^{*}(0)(s-c)$, is positive as long as 
$s>c$, which is satisfied for all $c<4$ because $s=4$ and $c \sim U[1,5]$. Consequently, there is positive advertising as long as the fixed cost is not too high and the industry is not empty, i.e. the entry cost is not too high. For the industry to be non-empty, there must exist some firm types which do not exit and the expected value of entry must not be lower than the entry cost. The conditions for a non-empty industry are checked as part of the simulation algorithm below.

The algorithm is based on Theorem 1 and is similar to value function iteration algorithms. The simulation setup requires a grid of firm types. We partition the support of the marginal cost distribution $U[1,5]$ into a discrete set $\left\{c_{1}, \ldots, c_{n}\right\}$, where $c_{1}=1$ and $c_{n}=5$. We also use a grid of firm size levels $\left\{m_{1}, \ldots, m_{k}\right\}$, where $m_{1}=0$ and $m_{k}=\bar{m}$, where $\bar{m}$ is taken sufficiently large to contain the upper bound on firm size. Prices and advertising levels are also defined over discrete sets $\left\{p_{1}, \ldots, p_{l}\right\}$ and $\left\{a_{1}, \ldots, a_{h}\right\}$ respectively. The algorithm has the following steps:

1. Start with initial guesses for the value function, $V\left(m^{o}, c\right)$, the surplus function, $W\left(p, m^{o}\right)$, the measure of firms, $\mu\left(m^{o}, c\right)$, and the cumulative distribution of ads, $Q\left(p, m^{o}\right)$. We look for fixed points for these functions by simultaneously iterating on them. ${ }^{50}$ We chose $V\left(m^{o}, c\right) \equiv V \geq 0$, $W\left(p, m^{o}\right) \equiv 0, W^{\varnothing}=0$, and $\Delta \mu\left(m^{o}, c\right)=b \geq 0$ such that $\sum_{m^{o}} \sum_{c} \Delta \mu\left(m^{o}, c\right)=\sum_{m^{o}} \sum_{c} b=$ 1 , implying that $b=\frac{1}{n k}$. $Q\left(p, m^{o}\right)$ is also set to be the c.d.f. of a two-dimensional discrete uniform distribution over $\left\{p_{1}, \ldots, p_{l}\right\} \times\left\{m_{1}, \ldots, m_{k}\right\}$. Given $W\left(p, m^{o}\right)$ and $Q\left(p, m^{o}\right)$ compute the individual demand functions as

$$
\begin{aligned}
z\left(p, m^{o}\right) & =\sum_{i=0}^{T} \frac{e^{-A} A^{i}}{i !} Q^{i}\left(p, m^{o}\right), \\
\omega\left(p, m^{o}\right) & =Q_{s}\left(p, m^{o}\right) \sum_{i=0}^{T} \frac{e^{-A} A^{i}}{i !} Q^{i}\left(p, m^{o}\right)
\end{aligned}
$$

where $Q_{s}\left(p, m^{o}\right)$ is the probability that among all the sales that take place, the firm type that makes a randomly selected sale is not preferred to firm type $\left(p, m^{o}\right)$. Since we do not have $Q_{s}\left(p, m^{o}\right)$ available initially, we start by assuming that $Q_{s}\left(p, m^{o}\right)=Q\left(p, m^{o}\right)$, which will be updated later in

\footnotetext{
${ }^{50}$ There are two alternative methods of iteration on these functions. One method is to construct separate loops of iteration for each function. The second method is simultaneous iteration of all or a subset of the functions under one single loop. The first method is more robust, but computationally slower. The second method is faster with potential problems of robustness. To deal with the robustness, small step sizes for updating functions may be used. We tried both methods, and given the dimensionality of the setup, we found that using the second method with small step sizes is easier for the model considered.
} 
further iterations as a computed $Q_{s}\left(p, m^{o}\right)$ becomes available. The upper limit $T$ in the summations (43) is set to a large enough number (we used $T=20$ ) and the term $\frac{e^{-A} A^{i}}{i !}$ follows from a Poisson approximation to $\Psi(i)$.

2a. Compute $\frac{\Delta z\left(p_{i}, m^{o}\right)}{\Delta p_{i}}=\frac{z\left(p_{i}, m^{o}\right)-z\left(p_{i-1}, m^{o}\right)}{p_{i}-p_{i-1}}, \frac{\Delta \omega\left(p_{i}, m^{o}\right)}{\Delta p_{i}}=\frac{\omega\left(p_{i}, m^{o}\right)-\omega\left(p_{i-1}, m^{o}\right)}{p_{i}-p_{i-1}}$, and $\frac{\Delta V\left(m_{j}^{o}, c\right)}{\Delta m_{j}^{o}}=$ $\frac{V\left(m_{j}^{o}, c\right)-V\left(m_{j-1}^{o}, c\right)}{m_{j}^{o}-m_{j-1}^{o}}$ over a grid for $p_{k n}$ and $m_{n}^{o}$. Solve the discrete-space version of the corresponding first order conditions (13) and (15), and find the optimal price and advertising levels $a_{i, j}$ and $p_{i, j}$ for each firm type $k \times n$,given $V$ and $Q$ using,

$$
p_{i j}=c_{j}-\frac{m_{i}^{o}(1-\lambda) z\left(p_{i j}, m_{i}^{o}\right)+a_{i j} \omega\left(p_{i j}, m_{i}^{o}\right)}{m_{i}^{o}(1-\lambda) \frac{\Delta z\left(p_{i j}, m_{i}^{o}\right)}{\Delta p_{i j}}+a_{i j} \frac{\Delta \omega\left(p_{i j}, m_{i}^{o}\right)}{\Delta p_{i j}}}-\beta \sum_{k} \frac{\Delta V\left(m^{*}, c_{k}^{\prime}\right)}{\Delta m^{*}} h\left(c_{k}^{\prime}\right) .
$$

where $m^{*}=m_{i}^{o}(1-\lambda) z\left(p_{i j}, m_{i}^{o}\right)+a_{i j} \omega\left(p_{i j}, m_{i}^{o}\right)$, and

$$
a_{i j}=\left[\frac{\omega\left(p_{i j}, m_{i}^{o}\right)\left[\left(p_{i j}-c_{j}\right)+\beta \sum_{k} \frac{\Delta V^{o}\left(m^{*}, c_{k}^{\prime}\right)}{\Delta m^{*}} h\left(c_{k}^{\prime}\right)\right]}{\varphi \chi}\right]^{\frac{1}{\varphi-1}} .
$$

2b. Compute period sales and profits for all firm types

$$
\begin{gathered}
m_{i j}^{*}=m_{i}^{o}(1-\lambda) z\left(p_{i j}, m_{i}^{o}\right)+a_{i j} \omega\left(p_{i j}, m_{i}^{o}\right), \\
\Pi\left(m_{i}^{o}, c_{j}\right)=m_{i j}^{*}\left(p_{i j}-c_{j}\right)-\Phi\left(a_{i j}\right)-f .
\end{gathered}
$$

Compute total number of ads

$$
A=\sum_{i} \sum_{j} a_{i j} \Delta \mu\left(m_{i}^{o}, c_{j}\right)
$$

Obtain the updated value function of firms,

$$
V^{\prime}\left(m_{i}^{o}, c_{j}\right)=\max \left\{0, \Pi\left(m_{i}^{o}, c_{j}\right)+\beta \sum_{k=1}^{n} V\left(m_{i j}^{*}, c_{k}\right) h\left(c_{k}\right)\right\}
$$

Compute the exit indicator for all firm types,

$$
X\left(p_{i j}, c_{j}\right)=\left\{\begin{array}{cc}
0, & \text { if } \Pi\left(m_{i}^{o}, c_{j}\right)+\beta \sum_{k=1}^{n} V\left(m_{i j}^{*}, c_{k}\right) h\left(c_{k}\right) \geq 0 \\
1, & \text { otherwise }
\end{array}\right.
$$

2c. Obtain the updated value functions of consumers,

$$
W^{\varnothing \prime}=\frac{1}{\left(1-\beta(1-\lambda) e^{-A}\right)} \sum_{i=1}^{T} \frac{e^{-A} A^{i}}{i !} \sum_{k} W_{k} \Delta G^{i}\left(W_{k}\right)
$$




$$
\begin{aligned}
W^{\prime}\left(p_{i j}, m_{j}^{o}\right)= & s-p_{i j} \\
& +\beta(1-\lambda)\left\{e^{-A}\left[\left(1-X\left(p_{i j}, m_{j}^{o}\right)\right) \sum_{k} W\left(p_{k j}^{\prime}, m_{i j}^{*}\right)\right] h\left(c_{k}^{\prime}\right)+X\left(p_{i j}, m_{j}^{o}\right) W^{\varnothing}\right. \\
& +\sum_{t=1}^{T} \frac{e^{-A} A^{t}}{t !}\left[\left(1-X\left(p_{i j}, m_{j}^{o}\right)\right) \sum_{k} \max \left\{W_{k}, W\left(p_{k j}^{\prime}, m_{i j}^{*}\right)\right\} \Delta G^{t}\left(W_{s}\right)\right. \\
& \left.\left.\left.+X\left(p_{i j}, m_{j}^{o}\right)\right) \sum_{k} W_{k} \Delta G^{t}\left(W_{k}\right)\right]\right\} .
\end{aligned}
$$

2d. Obtain the implied distribution of ads across firm types $Q^{\prime}\left(p_{i j}, m_{i}^{o}\right)$ using the optimal number of ads $a_{i j}$ sent by each firm type and the measure of firms $\mu\left(m_{i}, c_{j}\right)$, i.e.

$$
Q^{\prime}\left(p_{i j}, m_{i}^{o}\right)=\frac{1}{A} \sum_{(q, r) \text { s.t. } W\left(p_{q r}, m_{q}\right) \leq W\left(p_{i j}, m_{i}\right)} a_{q r} \Delta \mu\left(m_{q}^{o}, c_{r}\right) .
$$

Also, obtain the implied distribution of sales across firm types $Q_{s}^{\prime}\left(p_{i j}, m_{i}^{o}\right)$

$$
\begin{gathered}
S=\sum_{i} \sum_{j} m_{i j}^{*} \Delta \mu\left(m_{i}^{o}, c_{j}\right), \\
Q_{s}^{\prime}\left(p_{i j}, m_{i}^{o}\right)=\frac{1}{S} \sum_{(q, r) \text { s.t. } W\left(p_{q r}, m_{q}^{o}\right) \leq W\left(p_{i j}, m_{i}^{o}\right)} m_{q r}^{*} \Delta \mu\left(m_{q}^{o}, c_{r}\right) .
\end{gathered}
$$

3. Calculate the distances

$$
\begin{aligned}
d\left(Q, Q^{\prime}\right) & =\max _{i, j}\left|Q\left(p_{i j}, m_{i}^{o}\right)-Q^{\prime}\left(p_{i j}, m_{i}^{o}\right)\right|, \\
d\left(V, V^{\prime}\right) & =\max _{i, j}\left|V\left(m_{i}^{o}, c_{j}\right)-V^{\prime}\left(m_{i}^{o}, c_{j}\right)\right|, \\
d\left(W, W^{\prime}\right) & =\max _{i, j}\left|W\left(p_{i j}, m_{i}^{o}\right)-W^{\prime}\left(p_{i j}, m_{i}^{o}\right)\right| .
\end{aligned}
$$

If $d\left(Q, Q^{\prime}\right)<\varepsilon, d\left(V, V^{\prime}\right)<\eta, d\left(W, W^{\prime}\right)<\sigma$ for small $\varepsilon, \eta, \sigma>0$, then go to step 4. Otherwise, set $V \equiv \alpha V+(1-\alpha) V^{\prime}, W \equiv \alpha W+(1-\alpha) W^{\prime}$, and $Q \equiv \alpha Q+(1-\alpha) Q^{\prime}$ (with $\left.\alpha=0.1\right)$ and go back to Step 2.

4. Obtain the entry mass $M$ using the discrete version of the free entry condition,

$$
M=\sup \left\{M: \sum_{i=1}^{n} V^{\prime}\left(0, c_{i}\right) h\left(c_{i}\right)=\kappa\right\}
$$

and compute the exit rule $c\left(m^{o}\right)$ point-wise as

$$
c\left(m_{i}^{o}\right)=\max \left\{c_{j}: V^{\prime}\left(m_{i}^{o}, c_{j}\right)>0 \text { and } V^{\prime}\left(m_{i}^{o}, c_{j+1}\right) \leq 0\right\}
$$


5. Using $M$, and $c\left(m_{i}^{o}\right)$, and $\mu\left(m_{i}^{o}, c_{j}\right)$, obtain the updated measure

$$
\mu^{\prime}\left(m_{i}^{o}, c_{j}\right)=\sum_{m \leq m_{i}^{o}} \sum_{c^{\prime} \leq \min \left\{c_{j}, c^{o}\left(m^{o}\right)\right\}} \mu\left(m, c^{\prime}\right)+M \sum_{c^{\prime} \leq \min \left\{c_{j}, c^{o}(0)\right\}} h\left(c^{\prime}\right) .
$$

6. Calculate the distance

$$
d\left(\mu, \mu^{\prime}\right)=\max _{(i, j)}\left|\mu\left(m_{i}^{o}, c_{j}\right)-\mu^{\prime}\left(m_{i}^{o}, c_{j}\right)\right|
$$

If $d\left(\mu, \mu^{\prime}\right)<\xi$ for some small $\xi>0$, then stop. If $M>0$ and $c\left(m^{o}\right)>c_{1}$, then equilibrium entails positive entry and exit. Otherwise, set $\mu\left(m^{o}, c\right)=\alpha \mu\left(m^{o}, c\right)+(1-\alpha) \mu^{\prime}\left(m^{o}, c\right), V \equiv$ $\alpha V+(1-\alpha) V^{\prime}, W \equiv \alpha W+(1-\alpha) W^{\prime}, Q \equiv \alpha Q+(1-\alpha) Q^{\prime}$ (with $\alpha=0.1$ ) and go back to Step 2. For all simulations, we used $\varepsilon=10^{-4}, \xi=10^{-4}, \sigma=10^{-4}$, and $\eta=10^{-3}$.

\section{Calculation of Revenue-based TFP (Not for publi- cation)}

The logarithm of the revenue-based total factor productivity (TFP) measure is calculated for a given establishment $j$ in a 4-digit industry $i$ for a given year as follows

$\log \left(T F P_{j i}\right)=\log \left(s_{j}\right)-\alpha_{i}^{e q p} \log \left(e q p_{j}\right)-\alpha_{i}^{p l t} \log \left(p l t_{j}\right)-\alpha_{i}^{h r s} \log \left(h r s_{j}\right)-\alpha_{i}^{\text {mat }} \log \left(m a t_{j}\right)-\alpha_{i}^{e n g} \log \left(e n g_{j}\right)$

where establishment-level variables are: $s_{j}=$ deflated (real) value of shipments plus nominal inventory investments, $e q p_{j}=$ deflated value of equipment, $p l t_{j}=$ deflated value of plant, $h r s_{j}=$ total hours, mat $_{j}=$ deflated value of materials, $e n g_{j}=$ deflated value of energy; and industry-level variables are $\alpha_{i}^{e q p}=$ cost share of equipment, $\alpha_{i}^{p l t}=$ cost share of structure, $\alpha_{i}^{h r s}=$ cost share of employee hours, $\alpha_{i}^{\text {mat }}=$ cost share of materials, $\alpha_{i}^{e n g}=$ cost share of energy.

Labor inputs $\left(h r s_{j}\right)$ are measured as establishment's production-worker hours adjusted by multiplying the production-worker hours by the ratio of total payroll to payroll of production workers. Equipment $\left(e q p_{j}\right)$ and plant $\left(p l t_{j}\right)$ inputs are establishment's book values for their structure and equipment stocks deflated using sector-specific deflators from the Bureau of Economic Analysis. Materials $\left(m a t_{j}\right)$ and energy $\left(e n g_{j}\right)$ inputs are based on establishment's expenditures on materials and energy deflated using the input price indices in NBER Productivity Database. For the calculation of 4-digit industry-level cost shares, materials and energy expenditures and payments 
to labor are aggregated across establishments in the industry. Industry level cost of capital is obtained by first multiplying an establishment's real capital stock with the capital rental rates for the 2-digit industry an establishment belongs to, and then aggregating across establishments in the 4-digit industry. Each input cost is divided by the total cost at the industry level to obtain the cost share of the input. Establishment level TFP is aggregated to the firm level by weighting each establishment's TFP measure in a given industry by its share of total value of firm's shipments in that industry. For similar calculations and the calculation of quantity-based (physical) TFP, see Appendix A2 in Foster, Haltiwanger and Syverson (2008).

\section{Industry Definitions (Not for publication)}

The following information about the industries analyzed in Section 5.4 is taken from US Census Bureau's Industry Statistics Sampler. The 1987 SIC, 1997 NAICS and 2002 NAICS are comparable for all industries except for Life Insurance, as explained further below.

New Car Dealers (SIC 5511 / NAICS 441110) Establishments primarily engaged in retailing new automobiles and light trucks, such as sport utility vehicles, and passenger and cargo vans, or retailing these new vehicles in combination with activities, such as repair services, retailing used cars, and selling replacement parts and accessories.

Book Stores (SIC 5942/NAICS 451211) Establishments primarily engaged in retailing new books.

Camera and Photographic Supplies Stores (SIC 5946/NAICS 443130) Establishments primarily engaged in either retailing new cameras, photographic equipment, and photographic supplies or retailing new cameras and photographic equipment in combination with activities, such as repair services and film developing.

Prerecorded Tape, Compact Disc, and Record Stores (SIC 5735/NAICS 451220) Establishments primarily engaged in retailing new prerecorded audio and video tapes, compact discs (CDs), digital video discs (DVDs), and phonograph records.

Travel Agencies (SIC 4724/NAICS 561510) Establishments primarily engaged in acting as agents in selling travel, tour, and accommodation services to the general public and commercial clients. 
Life Insurance (SIC 6311/NAICS 524113 and 524130) Establishments primarily engaged in underwriting life insurance. These establishments are operated by enterprises that may be owned by stockholders, policyholders, or other carriers. The sales classified under SIC 3611 are made up of 95\% of the sales classified under NAICS 524113 plus nearly all of the sales classified under NAICS 524130. However, NAICS 524130 contains only $2.2 \%$ of the total establishments in SIC 6311 and have a small contribution to total sales. Therefore, we exclude NAICS 524130 in calculating the industry statistics for 1997 and 2002. 


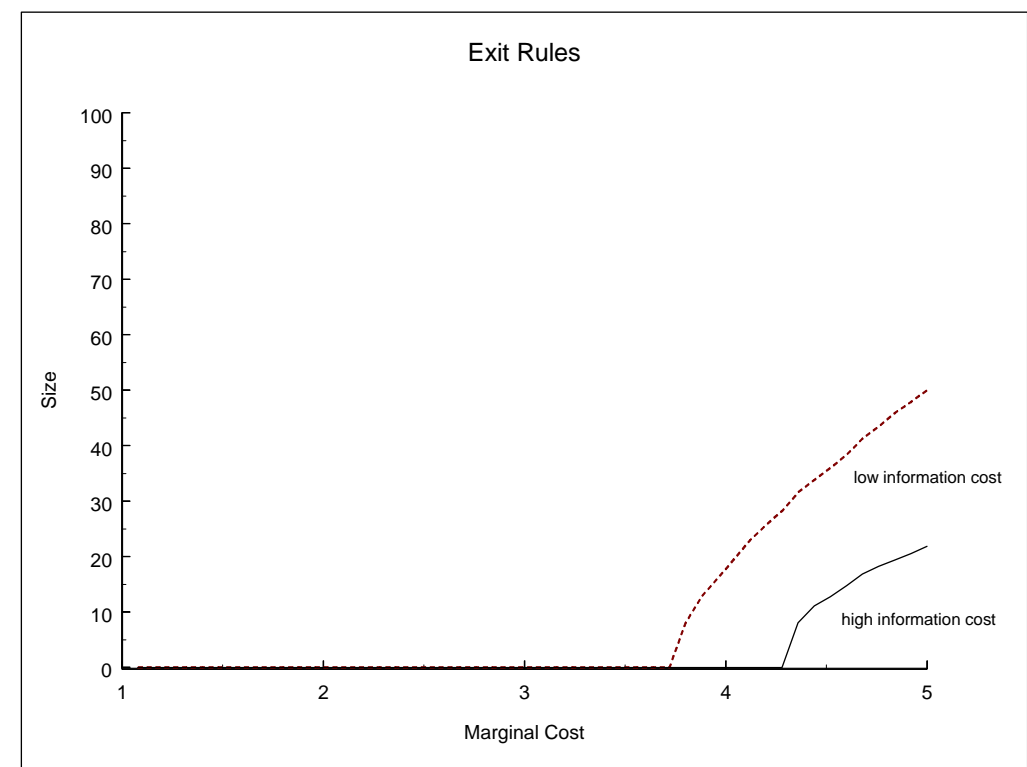

Figure 2: Scale of information cost: Exit rules

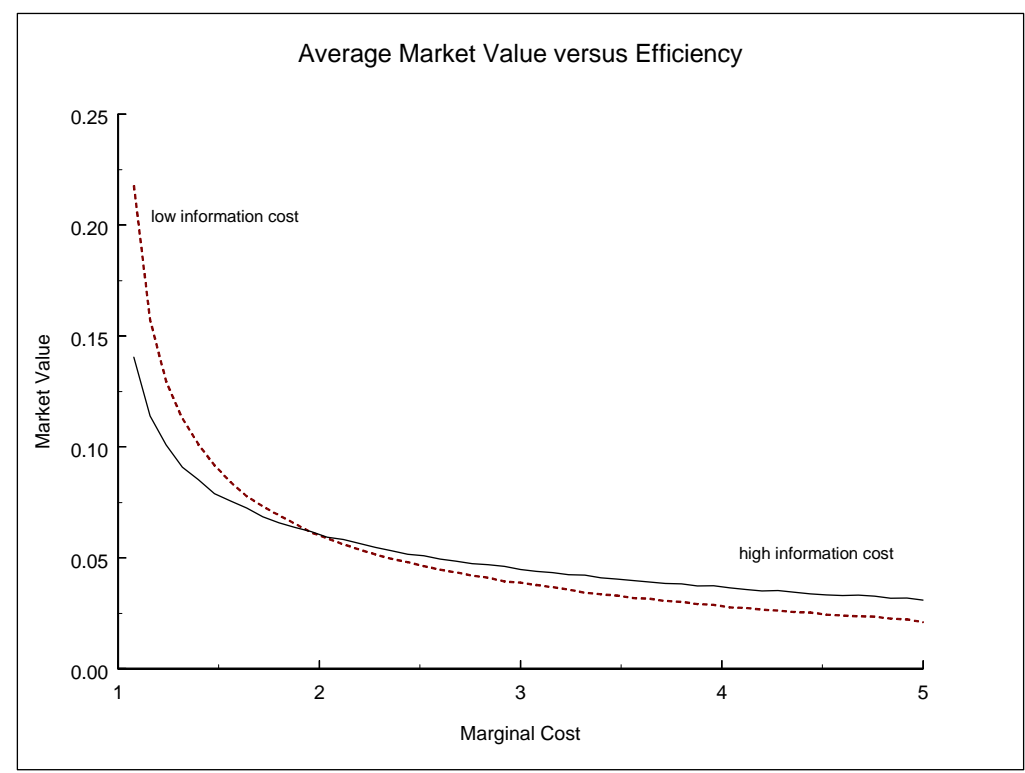

Figure 3: Scale of information cost: Firm efficiency-value relationship 


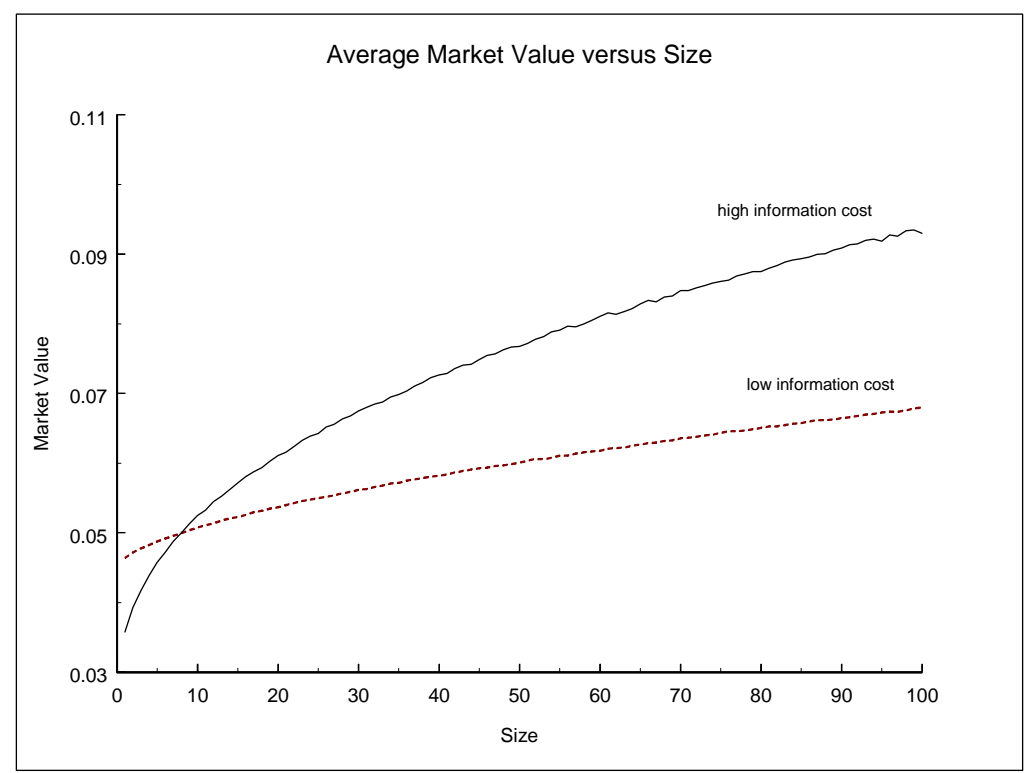

Figure 4: Scale of information cost: Firm size-value relationship ("0"=smallest)

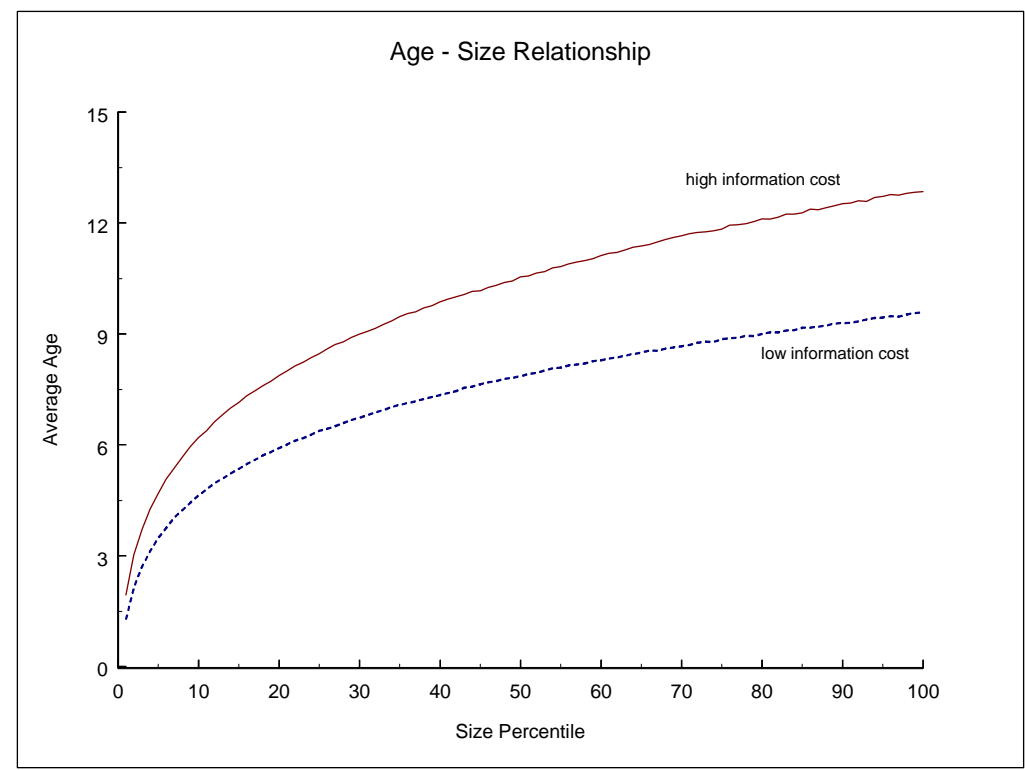

Figure 5: Scale of information cost: Firm age-size relationship ("0"=smallest) 


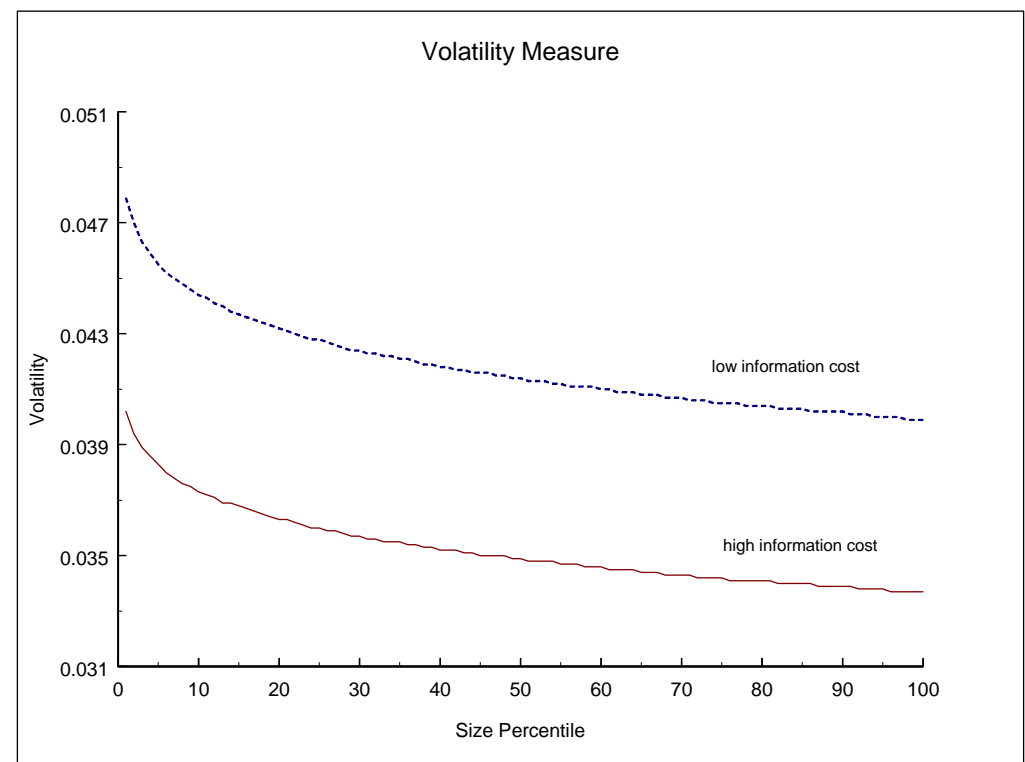

Figure 6: Scale of information cost: Firm size-volatility relationship $\left(\operatorname{Vol}\left(m^{o}\right)\right)(" 0 "=$ smallest)

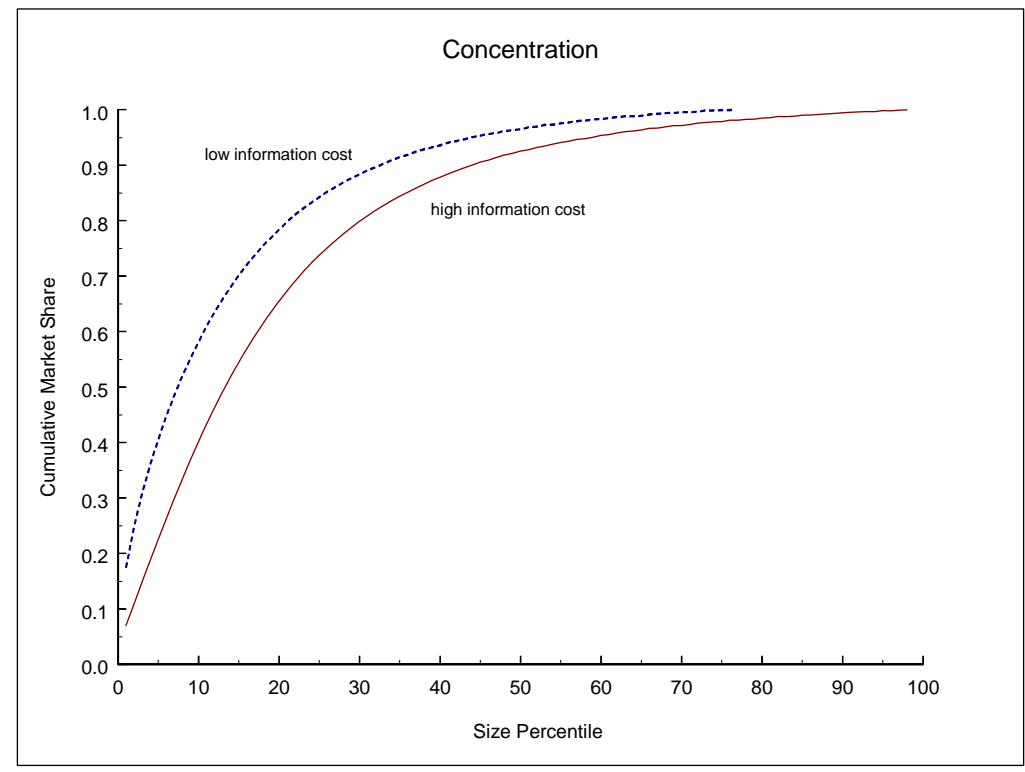

Figure 7: Scale of information cost: Distribution of consumers across firm sizes ("0"=largest) 


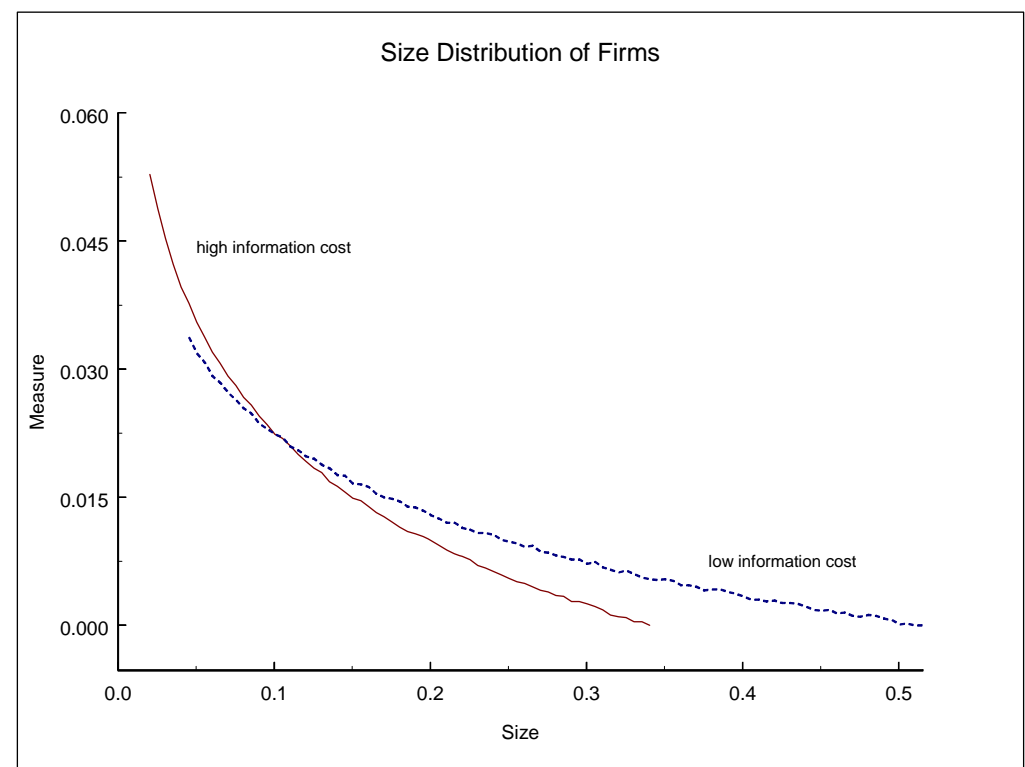

Figure 8: Scale of information cost: Density of firm size

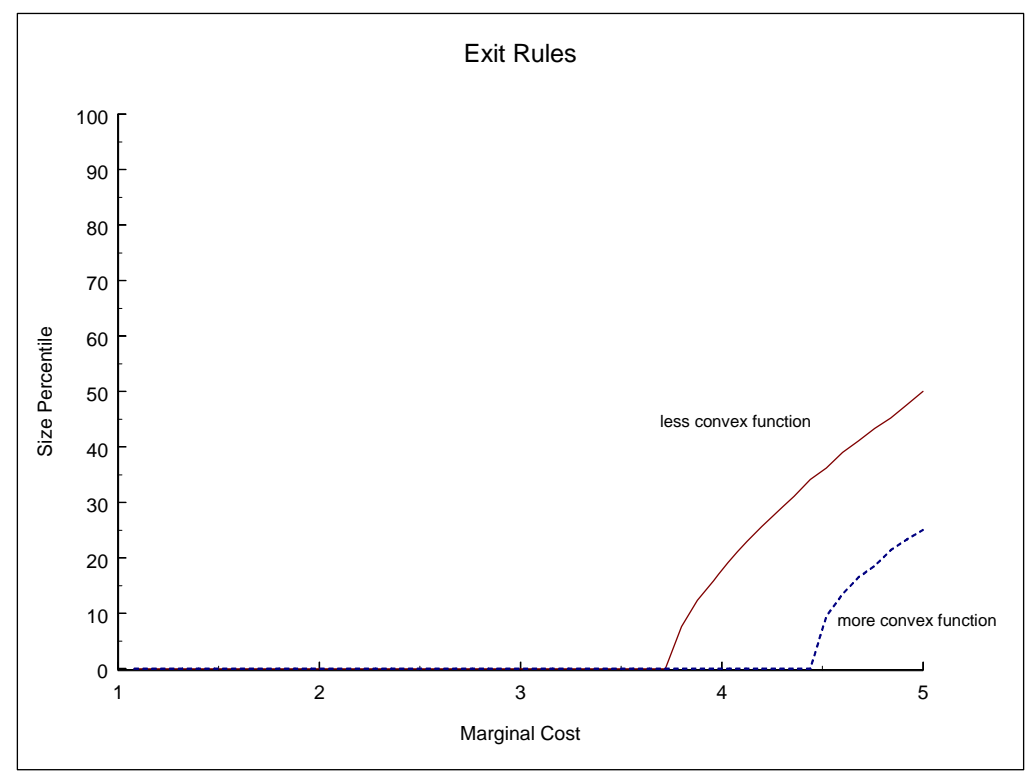

Figure 9: Convexity of information cost: Exit rules 


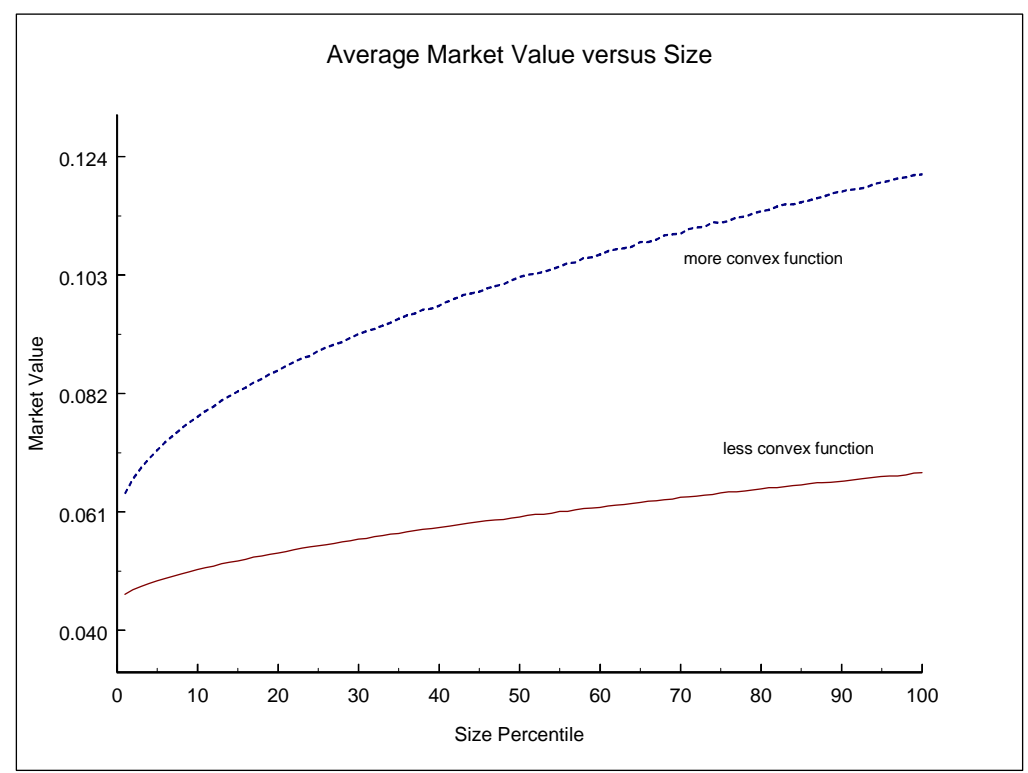

Figure 10: Convexity of information cost: Firm size-value relationship (" $0 "=$ smallest)

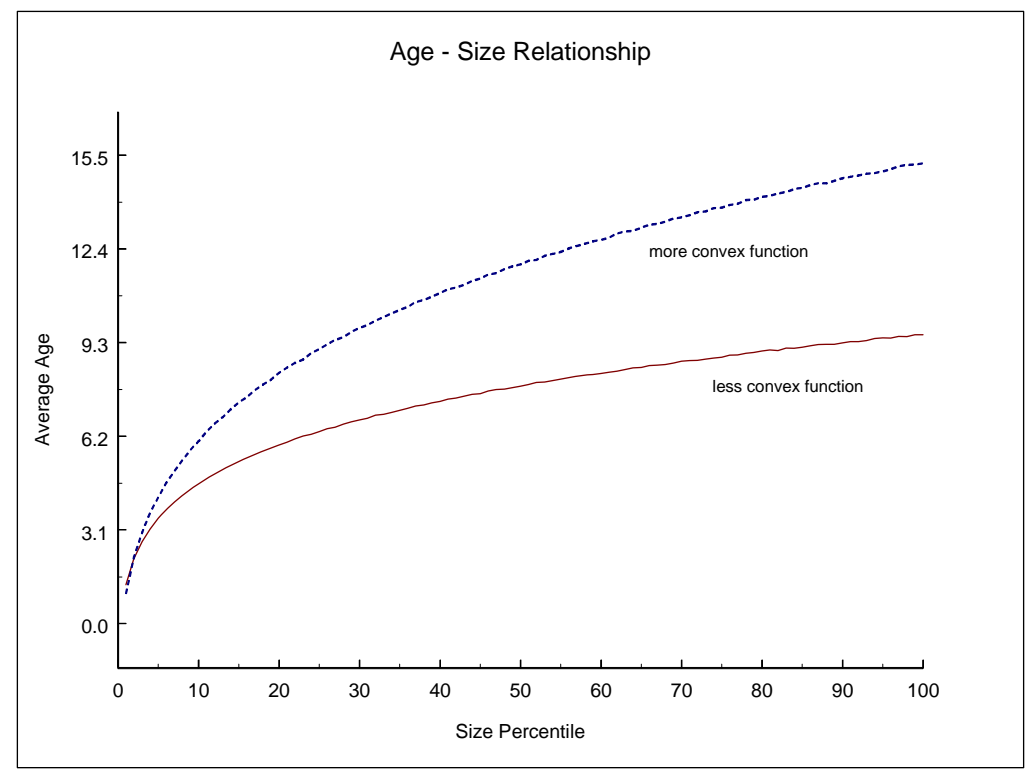

Figure 11: Convexity of information cost: Firm age-size relationship ("0"=smallest) 


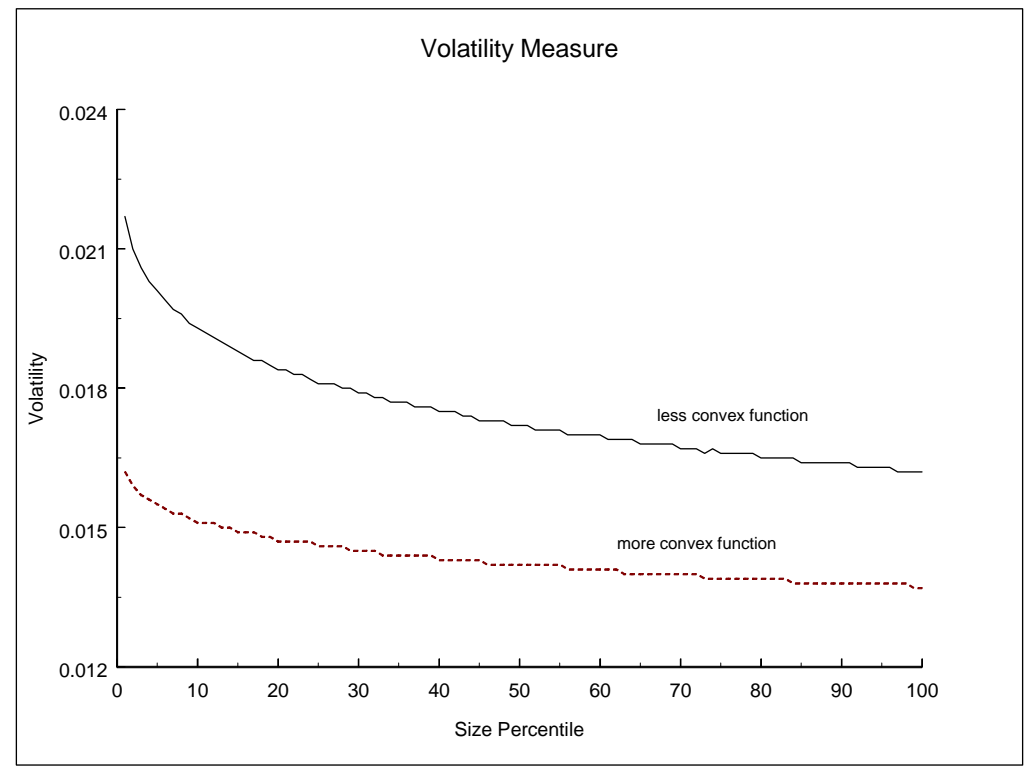

Figure 12: Convexity of information cost: Firm size-volatility relationship $\left(\operatorname{Vol}\left(\mathrm{m}^{o}\right)\right)$ ("0"=smallest)

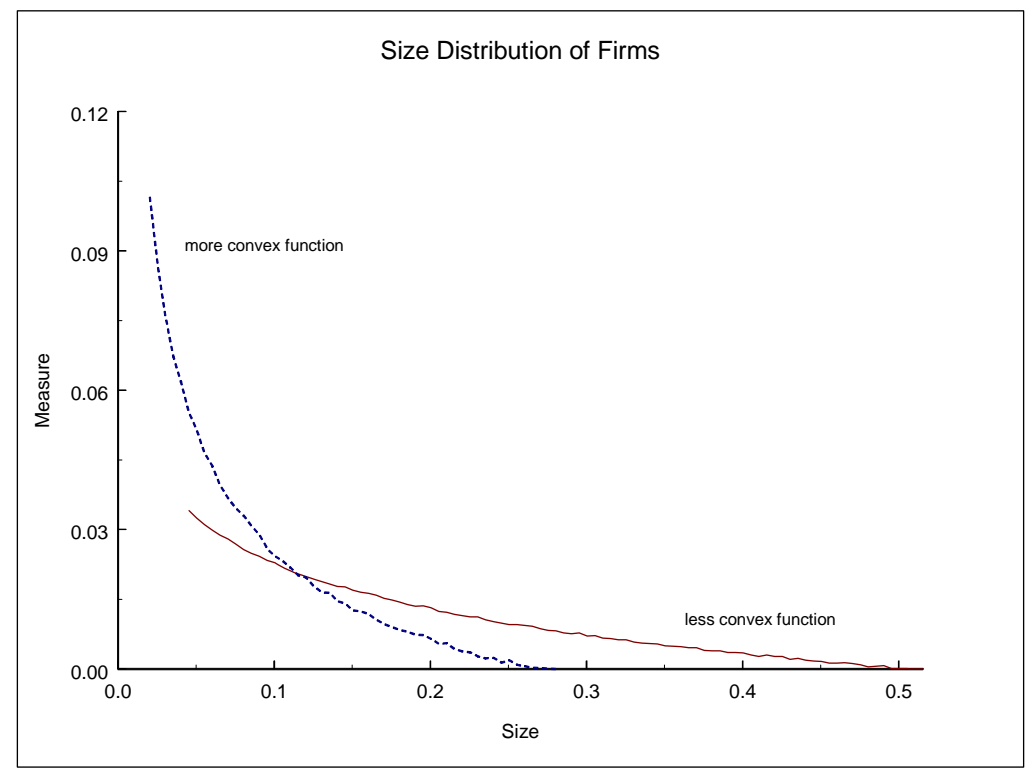

Figure 13: Convexity of information cost: Density of firm size 


\begin{tabular}{|c|c|c|c|c|c|c|c|c|c|c|}
\hline \multirow[b]{3}{*}{ Independent variables: } & \multicolumn{10}{|c|}{ Dependent Variable: 1997 Advertising Expenditures (\$K) } \\
\hline & \multicolumn{2}{|r|}{$\mathrm{I}$} & \multicolumn{2}{|c|}{ II } & \multicolumn{2}{|c|}{ III } & \multicolumn{2}{|c|}{ IV } & \multicolumn{2}{|r|}{$\mathrm{V}$} \\
\hline & OLS & Tobit & OLS & Tobit & OLS & Tobit & OLS & Tobit & OLS & Tobit \\
\hline 1992 Value of Shipments (\$K) & $\begin{array}{c}0.012^{* * *} \\
{[0.003]}\end{array}$ & $\begin{array}{c}0.013^{* * *} \\
{[0.001]}\end{array}$ & - & - & - & - & $\begin{array}{c}0.012^{\star * *} \\
{[0.003]}\end{array}$ & $\begin{array}{c}0.013^{* * *} \\
{[0.001]}\end{array}$ & - & - \\
\hline 1992 Number of Employees & - & - & $\begin{array}{c}4.066^{* * *} \\
{[0.962]}\end{array}$ & $\begin{array}{c}5.058^{* * *} \\
{[0.057]}\end{array}$ & - & - & - & - & $\begin{array}{c}4.065^{\star * *} \\
{[0.966]}\end{array}$ & $\begin{array}{c}5.031^{* * *} \\
{[0.058]}\end{array}$ \\
\hline 1997 TFP & - & - & - & - & $\begin{array}{l}0.148^{* *} \\
{[0.068]}\end{array}$ & $\begin{array}{c}1.912^{\star * *} \\
{[0.760]}\end{array}$ & $\begin{array}{l}0.130 * * \\
{[0.061]}\end{array}$ & $\begin{array}{l}1.635^{\star *} \\
{[0.653]}\end{array}$ & $\begin{array}{l}0.094^{*} \\
{[0.055]}\end{array}$ & $\begin{array}{c}1.640^{* * *} \\
{[0.580]}\end{array}$ \\
\hline Multi-unit dummy & $\begin{array}{c}209.7^{* *} \\
{[101.0]}\end{array}$ & $\begin{array}{c}17,039.0^{* * *} \\
{[136.2]}\end{array}$ & $\begin{array}{l}-116.5 \\
{[191.0]}\end{array}$ & $\begin{array}{c}17,139.4^{* * *} \\
{[142.0]}\end{array}$ & $\begin{array}{c}850.2^{* * *} \\
{[68.7]}\end{array}$ & $\begin{array}{c}21,155.3^{* * *} \\
{[171.8]}\end{array}$ & $\begin{array}{l}216.2^{*} \\
{[130.0]}\end{array}$ & $\begin{array}{c}17,271.2^{* * *} \\
{[146.4]}\end{array}$ & $\begin{array}{l}-152.1 \\
{[213.5]}\end{array}$ & $\begin{array}{c}17,320.9^{* * *} \\
{[152.2]}\end{array}$ \\
\hline Industry fixed effects ${ }^{\#}$ & $\mathrm{Y}$ & $\mathrm{Y}$ & $\mathrm{Y}$ & $\mathrm{Y}$ & Y & $\mathrm{Y}$ & $\mathrm{Y}$ & $\mathrm{Y}$ & $\mathrm{Y}$ & $\mathrm{Y}$ \\
\hline$N$ & 362,276 & 362,276 & 362,276 & 362,276 & 270,667 & 270,667 & 270,667 & 270,667 & 270,667 & 270,667 \\
\hline$R^{2} /$ Log Likelihood & 0.29 & $-294,482$ & 0.22 & $-295,134$ & 0.06 & $-272,739$ & 0.31 & $-268,844$ & 0.23 & $-269,426$ \\
\hline
\end{tabular}

Table 1. The relationship between firm advertising expenditures, size, and productivity (CM Sample) 


\begin{tabular}{|c|c|c|c|c|c|c|c|c|c|c|}
\hline \multirow[b]{3}{*}{ Independent variables: } & \multicolumn{10}{|c|}{ Dependent Variable: 1997 Advertising Expenditures (\$K) } \\
\hline & \multicolumn{2}{|r|}{$\mathrm{I}$} & \multicolumn{2}{|c|}{ "II } & \multicolumn{2}{|c|}{ (III } & \multicolumn{2}{|c|}{ IV } & \multicolumn{2}{|r|}{$\mathrm{V}$} \\
\hline & OLS & Tobit & OLS & Tobit & OLS & Tobit & OLS & Tobit & OLS & Tobit \\
\hline 1996 Value of Shipments (\$K) & $\begin{array}{c}0.009^{* * *} \\
{[0.003]}\end{array}$ & $\begin{array}{c}0.010^{* * *} \\
{[0.001]}\end{array}$ & - & & - & - & $\begin{array}{c}0.009^{* * *} \\
{[0.003]}\end{array}$ & $\begin{array}{c}0.010^{* * *} \\
{[0.001]}\end{array}$ & - & - \\
\hline 1996 Number of Employees & & & $\begin{array}{c}4.334^{* * *} \\
{[0.937]}\end{array}$ & $\begin{array}{c}4.897^{* * *} \\
{[0.069]}\end{array}$ & - & - & - & - & $\begin{array}{c}4.351^{* * *} \\
{[0.938]}\end{array}$ & $\begin{array}{c}4.912^{* * *} \\
{[0.072]}\end{array}$ \\
\hline 1997 TFP & - & - & - & - & $\begin{array}{c}0.147^{\star *} \\
{[0.065]}\end{array}$ & $\begin{array}{c}0.961^{* *} \\
{[0.466]}\end{array}$ & $\begin{array}{l}0.113^{* *} \\
{[0.045]}\end{array}$ & $\begin{array}{l}0.804^{* *} \\
{[0.402]}\end{array}$ & $\begin{array}{c}0.094^{\star *} \\
{[0.041]}\end{array}$ & $\begin{array}{c}0.801^{\star *} \\
{[0.403]}\end{array}$ \\
\hline Multi-unit dummy & $\begin{array}{c}320.2 \\
{[324.4]}\end{array}$ & $\begin{array}{c}5,762.0^{* * *} \\
{[203.7]}\end{array}$ & $\begin{array}{l}-400.0 \\
{[352.4]}\end{array}$ & $\begin{array}{c}5,049.4^{\star * *} \\
{[214.3]}\end{array}$ & $\begin{array}{c}1489.9^{* * *} \\
{[142.9]}\end{array}$ & $\begin{array}{c}8,162.8^{\star * *} \\
{[254.0]}\end{array}$ & $\begin{array}{l}321.6 \\
{[333.7]}\end{array}$ & $\begin{array}{c}5,901.9^{* * *} \\
{[219.0]}\end{array}$ & $\begin{array}{l}-431.2 \\
{[352.2]}\end{array}$ & $\begin{array}{c}5,156.9^{\star * *} \\
{[230.3]}\end{array}$ \\
\hline Industry fixed effects ${ }^{\#}$ & $\mathrm{Y}$ & $\mathrm{Y}$ & $\mathrm{Y}$ & $\mathrm{Y}$ & $\mathrm{Y}$ & $\mathrm{Y}$ & $\mathrm{Y}$ & $\mathrm{Y}$ & $\mathrm{Y}$ & $\mathrm{Y}$ \\
\hline$N$ & 38,461 & 38,461 & 38,461 & 38,461 & 34,821 & 34,821 & 34,821 & 34,821 & 34,821 & 34,821 \\
\hline$R^{2} /$ Log Likelihood & 0.33 & $-211,235$ & 0.27 & $-206,554$ & 0.10 & $-195,234$ & 0.34 & $-192,572$ & 0.27 & $-193,148$ \\
\hline
\end{tabular}

Table 2. The relationship between firm advertising expenditures, size, and productivity (ASM Sample) 


\begin{tabular}{|c|c|c|c|c|c|c|}
\hline \multirow[b]{2}{*}{ Independent variables: } & \multicolumn{6}{|c|}{ Dependent Variable: 1992 Price (\$K/unit) } \\
\hline & $\mathrm{I}$ & II & III & IV & $\mathrm{V}$ & VI \\
\hline 1987 Value of Shipments (\$K) & $\begin{array}{l}0.015^{* *} \\
{[0.007]}\end{array}$ & - & - & $\begin{array}{c}0.063^{* * *} \\
{[0.011]}\end{array}$ & - & - \\
\hline 1987 Physical Quantity & - & $\begin{array}{l}0.012^{* *} \\
{[0.005]}\end{array}$ & - & - & $\begin{array}{l}0.020^{* *} \\
{[0.008]}\end{array}$ & - \\
\hline 1987 Employment & - & - & $\begin{array}{c}0.022^{* * *} \\
{[0.008]}\end{array}$ & - & - & $\begin{array}{c}0.070^{* * *} \\
{[0.011]}\end{array}$ \\
\hline 1992 TFP (Quantity based) & $\begin{array}{l}-0.537^{* * *} \\
{[0.050]}\end{array}$ & $\begin{array}{l}-0.526^{* * *} \\
{[0.051]}\end{array}$ & $\begin{array}{l}-0.536^{* * *} \\
{[0.050]}\end{array}$ & - & - & - \\
\hline 1992 Average Variable Cost $(\$ K)$ & - & - & - & $\begin{array}{l}0.140^{* * *} \\
{[0.018]}\end{array}$ & $\begin{array}{l}0.112^{* * *} \\
{[0.018]}\end{array}$ & $\begin{array}{l}0.134^{\star * *} \\
{[0.017]}\end{array}$ \\
\hline Multi-unit dummy & $\begin{array}{l}-0.022 \\
{[0.017]}\end{array}$ & $\begin{array}{c}0.002 \\
{[0.017]}\end{array}$ & $\begin{array}{l}-0.025 \\
{[0.017]}\end{array}$ & $\begin{array}{c}-0.077^{* * *} \\
{[0.021]}\end{array}$ & $\begin{array}{c}-0.040^{* *} \\
{[0.018]}\end{array}$ & $\begin{array}{c}-0.074^{* * *} \\
{[0.020]}\end{array}$ \\
\hline Product fixed effects & Y & Y & Y & Y & Y & $\mathrm{Y}$ \\
\hline$N$ & 1,176 & 1,176 & 1,176 & 1,176 & 1,176 & 1,176 \\
\hline$R^{2}$ & 0.96 & 0.95 & 0.96 & 0.95 & 0.95 & 0.94 \\
\hline
\end{tabular}

Notes: All variables are in logarithms except for dummies. Robust standard errors in parantheses.

$\left({ }^{*}\right),\left({ }^{* *}\right)$, and $\left({ }^{* * *}\right)$ indicate significance at $10 \%, 5 \%$, and $1 \%$, respectively.

Table 3. The relationship between firm price, size, and productivity 


\begin{tabular}{|c|c|c|c|c|c|c|c|c|c|c|c|c|c|c|c|c|c|}
\hline \multirow[t]{2}{*}{ Industry } & \multicolumn{3}{|c|}{$\begin{array}{c}\text { HHI (U.S.) } \\
\text { Avg. HHI (MSAs) }^{1}\end{array}$} & \multicolumn{3}{|c|}{$\begin{array}{c}\text { CR4 (U.S.) } \\
\text { Avg. CR4 (MSAs) } \\
\end{array}$} & \multicolumn{3}{|c|}{$\begin{array}{c}\text { CR8 (U.S.) } \\
\text { Avg. CR8 (MSAs) }^{1}\end{array}$} & \multicolumn{3}{|c|}{ Skewness (U.S) } & \multicolumn{2}{|c|}{ Avg. Volatility $^{2}$ (U.S.) } & \multicolumn{3}{|c|}{ No. of Firms (U.S) } \\
\hline & 1992 & 1997 & 2002 & 1992 & 1997 & 2002 & 1992 & 1997 & 2002 & 1992 & 1997 & 2002 & $\begin{array}{c}1995- \\
2000\end{array}$ & $\begin{array}{l}2001- \\
2007\end{array}$ & 1992 & 1997 & 2002 \\
\hline $\begin{array}{l}\text { New Car } \\
\text { Dealers }\end{array}$ & $\begin{array}{c}2 \\
829 \\
{[33.9]} \\
\end{array}$ & $\begin{array}{c}2 \\
874 \\
{[36.8]} \\
\end{array}$ & $\begin{array}{c}15 \\
936 \\
{[41.0]} \\
\end{array}$ & $\begin{array}{c}1.5 \\
42.7 \\
{[1.2]} \\
\end{array}$ & $\begin{array}{r}1.5 \\
44.3 \\
{[1.3]} \\
\end{array}$ & $\begin{array}{r}5.6 \\
46.4 \\
{[1.2]} \\
\end{array}$ & $\begin{array}{l}2.2 \\
63.1 \\
{[1.6]} \\
\end{array}$ & $\begin{array}{l}2.1 \\
64.7 \\
{[1.5]} \\
\end{array}$ & $\begin{array}{c}7.5 \\
66.2 \\
{[1.4]} \\
\end{array}$ & 32.1 & 23.2 & 95.6 & $\begin{array}{c}4,958.3 \\
{[29.4]}\end{array}$ & $\begin{array}{c}5,548.6 \\
{[20.7]}\end{array}$ & 23,110 & 23,680 & 23,811 \\
\hline $\begin{array}{l}\text { Book } \\
\text { Stores }\end{array}$ & $\begin{array}{c}828 \\
\\
2,392 \\
{[149.5]} \\
\end{array}$ & $\begin{array}{l}1,151 \\
2,768 \\
{[91.1]} \\
\end{array}$ & $\begin{array}{l}1,533 \\
3,187 \\
{[93.6]} \\
\end{array}$ & $\begin{array}{l}41.3 \\
77.6 \\
{[1.0]} \\
\end{array}$ & $\begin{array}{l}54.1 \\
\\
81.8 \\
{[0.8]} \\
\end{array}$ & $\begin{array}{l}65.6 \\
\\
86.6 \\
{[0.6]} \\
\end{array}$ & $\begin{array}{l}44.8 \\
90.4 \\
{[0.7]} \\
\end{array}$ & $\begin{array}{l}59.8 \\
\\
93.2 \\
{[0.5]} \\
\end{array}$ & $\begin{array}{l}70.9 \\
95.8 \\
{[0.4]} \\
\end{array}$ & 43.3 & 58.3 & 75.5 & $\begin{array}{l}139.3 \\
{[1.5]}\end{array}$ & $\begin{array}{l}160.1 \\
{[1.7]}\end{array}$ & 7,714 & 6,716 & 3,326 \\
\hline $\begin{array}{l}\text { Camera \& } \\
\text { Photo } \\
\text { Supplies } \\
\text { Stores } \\
\end{array}$ & $\begin{array}{c}215 \\
6,016 \\
{[190.7]} \\
\end{array}$ & $\begin{array}{c}497 \\
6,040 \\
{[178.8]} \\
\end{array}$ & $\begin{array}{c}1,270 \\
6,467 \\
{[172.3]} \\
\end{array}$ & $\begin{array}{l}25.4 \\
94.3 \\
{[0.8]} \\
\end{array}$ & $\begin{array}{l}32.7 \\
\\
95.9 \\
{[0.6]} \\
\end{array}$ & $\begin{array}{l}54.3 \\
\\
97.4 \\
{[0.4]} \\
\end{array}$ & $\begin{array}{l}32.1 \\
\\
97.7 \\
{[0.5]} \\
\end{array}$ & $\begin{array}{l}38.6 \\
\\
98.5 \\
{[0.4]} \\
\end{array}$ & $\begin{array}{l}58.0 \\
\\
99.2 \\
{[0.2]} \\
\end{array}$ & 23.7 & 29.9 & 45.2 & $\begin{array}{c}202.5 \\
{[3.9]}\end{array}$ & $\begin{array}{l}276.1 \\
{[12.5]}\end{array}$ & 1,931 & 1,502 & 1,254 \\
\hline $\begin{array}{l}\text { Tape, CD } \\
\text { \& Record } \\
\text { Stores }\end{array}$ & $\begin{array}{c}559 \\
\\
3,384 \\
{[110.2]} \\
\end{array}$ & $\begin{array}{c}829 \\
\\
3,555 \\
{[112.6]} \\
\end{array}$ & $\begin{array}{c}1,000 \\
4,315 \\
{[134.3]} \\
\end{array}$ & $\begin{array}{l}40.9 \\
88.2 \\
{[0.8]} \\
\end{array}$ & $\begin{array}{l}46.8 \\
\\
88.7 \\
{[0.8]} \\
\end{array}$ & $\begin{array}{l}57.7 \\
\\
92.2 \\
{[0.7]} \\
\end{array}$ & $\begin{array}{l}57.8 \\
\\
96.2 \\
{[0.4]} \\
\end{array}$ & $\begin{array}{l}64.1 \\
\\
96.6 \\
{[0.4]} \\
\end{array}$ & $\begin{array}{l}70.2 \\
97.4 \\
{[0.3]} \\
\end{array}$ & 28.7 & 36.8 & 45.3 & $\begin{array}{l}168.3 \\
{[5.2]}\end{array}$ & $\begin{array}{l}197.8 \\
{[6.4]}\end{array}$ & 3,300 & 3,456 & 3,293 \\
\hline $\begin{array}{l}\text { Travel } \\
\text { Agencies }\end{array}$ & $\begin{array}{c}160 \\
2,102 \\
{[83.3]} \\
\end{array}$ & $\begin{array}{c}115 \\
1,639 \\
{[76.7]} \\
\end{array}$ & $\begin{array}{c}574 \\
2,515 \\
{[120.7]} \\
\end{array}$ & $\begin{array}{l}12.7 \\
63.2 \\
{[1.5]}\end{array}$ & $\begin{array}{l}16.3 \\
61.7 \\
{[1.4]} \\
\end{array}$ & $\begin{array}{l}20.9 \\
73.5 \\
{[1.3]} \\
\end{array}$ & $\begin{array}{l}18.4 \\
70.1 \\
{[1.4]} \\
\end{array}$ & $\begin{array}{l}20.8 \\
78.0 \\
{[1.4]} \\
\end{array}$ & $\begin{array}{l}29.4 \\
86.5 \\
{[1.0]}\end{array}$ & 115.0 & 105.9 & 122.1 & $\begin{array}{c}471.5 \\
{[5.1]}\end{array}$ & $\begin{array}{c}527.4 \\
{[2.1]}\end{array}$ & 21,939 & 29,332 & 21,705 \\
\hline $\begin{array}{l}\text { Life } \\
\text { Insurance }\end{array}$ & $\begin{array}{c}282 \\
3,422 \\
{[154.4]}\end{array}$ & $\begin{array}{c}238 \\
3,810 \\
{[154.7]}\end{array}$ & $\begin{array}{c}288 \\
4,836 \\
{[181.4]}\end{array}$ & $\begin{array}{l}79.7 \\
{[1.2]}\end{array}$ & $\begin{array}{l}21.0 \\
84.1 \\
{[1.1]}\end{array}$ & $\begin{array}{l}24.0 \\
89.0 \\
{[0.9]}\end{array}$ & $\begin{array}{l}35.8 \\
90.9 \\
{[0.8]}\end{array}$ & $\begin{array}{l}32.9 \\
93.3 \\
{[0.6]}\end{array}$ & $\begin{array}{l}38.8 \\
95.6 \\
{[0.5]}\end{array}$ & 18.8 & 13.2 & 12.4 & $\begin{array}{l}171.6 \\
{[2.2]}\end{array}$ & $\begin{array}{l}194.2 \\
{[5.1]}\end{array}$ & 1,035 & 1,012 & 937 \\
\hline
\end{tabular}

Notes: (1) Standard error of the average concentration measure across MSAs is in brackets. (2) Standard error of the volatility measure over years is in brackets.

The label "U.S." means the statistics are nationwide. The label "MSAs" means the statistics are calculated across MSAs only.

Table 4. The evolution of industry aggregates for selected industries 